\title{
Academic competences and labour market entry : studies among Dutch graduates
}

Citation for published version (APA):

Semeijn, J. H. (2005). Academic competences and labour market entry : studies among Dutch graduates. [Doctoral Thesis, Maastricht University]. ROA. https://doi.org/10.26481/dis.20050915js

Document status and date:

Published: 01/01/2005

DOI:

10.26481/dis.20050915js

Document Version:

Publisher's PDF, also known as Version of record

\section{Please check the document version of this publication:}

- A submitted manuscript is the version of the article upon submission and before peer-review. There can be important differences between the submitted version and the official published version of record.

People interested in the research are advised to contact the author for the final version of the publication, or visit the DOI to the publisher's website.

- The final author version and the galley proof are versions of the publication after peer review.

- The final published version features the final layout of the paper including the volume, issue and page numbers.

Link to publication

\footnotetext{
General rights rights.

- You may freely distribute the URL identifying the publication in the public portal. please follow below link for the End User Agreement:

www.umlib.nl/taverne-license

Take down policy

If you believe that this document breaches copyright please contact us at:

repository@maastrichtuniversity.nl

providing details and we will investigate your claim.
}

Copyright and moral rights for the publications made accessible in the public portal are retained by the authors and/or other copyright owners and it is a condition of accessing publications that users recognise and abide by the legal requirements associated with these

- Users may download and print one copy of any publication from the public portal for the purpose of private study or research.

- You may not further distribute the material or use it for any profit-making activity or commercial gain

If the publication is distributed under the terms of Article $25 \mathrm{fa}$ of the Dutch Copyright Act, indicated by the "Taverne" license above, 
Academic Competences and Labour Market Entry studies among Dutch graduates 
dudith Semeijn, Maastricht 2005

All rights reserved. No part of this publication may be reproduced, stored in a retrieval system, or transmitted in any form, or by any means, electronic, mechanical, photocopying, recording or otherwise, without the prior permission in writing, from author.

Published by ROA

Postbus 616

$6200 \mathrm{MD}$ Maastricht

ISBN 90-5321-410-0

Printed in the Netherlands by Unigraphic 


\title{
Academic Competences and Labour Market Entry studies among Dutch graduates
}

\author{
Proefschrift \\ ter verkrijging van de graad van doctor" \\ aan de Universiteit Maastricht, \\ op gezag van de Rector Magnificus, \\ Prof. mr. G.P.M.F. Mols, \\ volgens het besluit van het College van Decanen, \\ in het openbaar te verdedigen op \\ donderdag 15 september 2005 om 14.00 uur \\ door \\ Judith Hilde Semeijn
}




\section{Promotoren}

Prof. dr. I.A.M. Heijke

Prof. dr. C.P.M van der Vleuten

\section{Co-promotor}

Dr. R.K. W. van der Velden

\section{Beoordelingscommissie}

Prof dr. W.H. Gijselaers (voorzitter)

Dr. M. G. Heijltjes

Prof. dr. J.L. Peschar (Universiteit Groningen)

The research in this thesis has been funancially supported by the Dutch Council for Scientific Research (NWO), grant 575-36-005B, for which we are thank ful.

Dit onderzoek is mede gefinancierd door de Nederlandse Organisatie voor Wetenschappelijk Onderzoek (NWO), project 575-36-005B, waarvoor onze dank. 


\section{Acknowledgements}

First of all, I gratefully acknowledge and thank my team of supervisors, consisting of Rolf van der Velden, Hans Heijke, Cees van der Vleuten and Els Boshuizen for their support and involvement and Lex Borghans as the coordinator of the Human Capital research project my $\mathrm{PhD}$ research was a part of. I learned a lot from your diverse disciplinary backgrounds and integrating your feedback was quite a challenge. I thank the review committee, consisting of Wim Gijselaers, Mariêlle Heijltjes and Jules Peschar for their careful reading of the manuscript.

Furthermore, I owe much gratitude to the rest of my social environment. Especially help in the care for my exponential growing amount of children, in housekeeping and for practical issues, was as necessary as breathing air. Many thanks therefore go to the (grand)parents, my neighbour Corrie and our au pair Galina, especially for their help during the most demanding months of work at the end of 2004. My brother Janjaap helped me both as a fellow researcher and as an uncle to my children, keeping them occupied during food distribution and helping out in transportation problems. Somehow his field of professional interest, logistics, was always involved. Other colleagues are greatly appreciated as well: to share the room with, to travel to conferences, or to chat with, in between times of work. Christoph Meng, Jasper van Loo, and Rina Vaatstra, sometimes from distance, were some of the important motivators to keep on going. And the educational $\mathrm{PhD}$ students from Randwijck: I enjoyed our reading and discussion appointments. Besides, of course, many (other) scientific forums and interested persons hielped me in refining my research and texts, but I will be unable to thank everybody personally on this page.

Therefore, to round up with, I thank Eric Halmans for his help in illustrating, Mariëlle Beenkens for lay-outing and preparing the manuscript and Jozien Hendrikx for her finishing touch and assistance with the final printed version. And last but not least I thank Rob; without him there would never have been such a thing as my PhD thesis. While keeping an eye on its progress and planning, he restored our farmhouse, did all the cooking, worked double shifts to finance his own study, and as a general practitioner in training, kept an eye on all health issues as well. You understand I did not dare to have a lazy day. I dedicate this book to our children; Fabienne, Huib, Berend \& Sjors. As all children, they are the future for education and society, and later on for society and its edwcation again. But right now, they are just happy their mom finally finished her book.... 
3 


\section{Contents}

Acknowledgements

1 Introduction

2 Theory and operationalization 5

2.1 Theoretical background and assumptions 5

2.2 Operationalization 10

2.3 Labour market success 13

2.4 Research models 14

3 Aspects of learning style and labour market entry: an explorative study $\begin{array}{ll}\text { among economic graduates } & 21\end{array}$

$\begin{array}{lll}3.1 & \text { Introduction } & 22\end{array}$

3.2 Theoretical background 23

3.3 Data and methodology 25

$\begin{array}{lll}3.4 & \text { Results } & 28\end{array}$

3.5 Conclusion $\quad 41$

4 Economics graduates" personality characteristics and labour market entry 43

4.1 Introduction 44

4.2 Theoretical background 45

4.3 Data and Methodology 47

4.4 Results $\quad 56$

4.5 Conclusion 66

5 The role of education in selection and allocation on the labour market; an empirical study in the medical field 69

$\begin{array}{ll}5.1 \text { Introduction } & 70\end{array}$

5.2 Theoretical background 72

5.3 Data and Methodology 76

5.4 Results 80

5.5 Conclusion $\quad 94$ 
6 Competence indicators in academic education and early labour market success of graduates in health sciences

$\begin{array}{ll}6.1 \text { Introduction } & 100\end{array}$

$\begin{array}{ll}6.2 & \text { Theoretical background } \\ 6.301\end{array}$

$\begin{array}{ll}6.3 \text { Data and methodology } & 106\end{array}$

6.4 Results 109

$\begin{array}{ll}6.5 \text { Conclusion } & 121\end{array}$

7 Conclusions 125

$\begin{array}{ll}\text { Summary } & 133\end{array}$

$\begin{array}{ll}\text { Samenvatting } & 135\end{array}$

$\begin{array}{ll}\text { References } & 137\end{array}$

Appendices

Appendix A 151

$\begin{array}{ll}\text { Appendix B } & 153\end{array}$

Appendix C 155

Appendix D 159

$\begin{array}{ll}\text { Appendix E } & 161\end{array}$

$\begin{array}{ll}\text { Appendix F } & 165\end{array}$

$\begin{array}{ll}\text { Appendix } G & 167\end{array}$

$\begin{array}{ll}\text { Appendix H } & 169\end{array}$

$\begin{array}{ll}\text { Appendix 1 } & 171\end{array}$

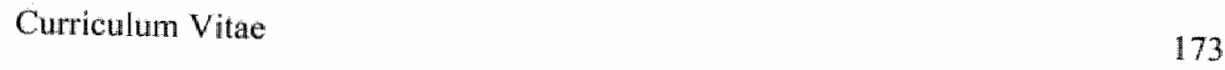

$\begin{array}{ll}\text { ROA Dissertation Series } & 175\end{array}$ 


\section{Introduction}

Today, higher education is considered a crucial factor in the economic development of modern societies. Staying competitive in the global econony requires investment in knowledge and skills of the new generation of working individuals (World Bank, 2003). In the year 2000, the European Union agreed that Europe should be the most competitive knowledge economy in the world by 2010 (Presidency's Conclusions, Lisbon European Council, 23-24 march 2000). Therefore, the participation in higher education of the population should increase. As such, having obtained a higher level of education is considered a key asset for successful integration into the labour force (Müller \& Gangl, 2003). And in turn, the entry into the labour market has important consequences for later labour market success of individuals (van der Linden \& van der Velden, 1998).

Policies regarding education and training are aimed at meeting the changing labour market needs. However, ideas about how higher educational programs should prepare students seem quite diverse. Some emphasize the importance of generic competence, i.e. skills like the ability to learn, to communicate and to work in a team (see e.g. Stasz, 1998; Vermetten, 1999). Others advocate specific competence as a priority, i.e. the profession- or field-specific knowledge and skills that are relevant for the types of jobs the educational program prepares for (see e.g. Boshuizen, Bromme \& Gruber, 2004). These wiews seem contradictory, but may be related to the different goals that education has.

Economic labour market theory assumes mainly two important roles for education: it qualifies people with relevant and productive skills or competence (the skills production function; e.g. Becker, 1964, 1983), and it screens or sorts students on general learning abilities, by which productive competence can be acquired "on the job' (the screening or sorting function; e.g. Thurow, 1975). Depending on what role is emphasized, different views may be expressed on what competence should be learned (specific work related skills or more generic skills). In addition, some educational programs prepare for a small range of jobs, such as medicine, whereas other programs prepare for a broad range of occupations, such as economics (Borghans \& de Grip, 1999). This will be reflected in a different emphasis on specific versus generic competence. Moreover, competences may have different relevance for entering the labour market versus later functioning in the career. Specific competence may be considered especially relevant as an entrance ticket to 


\section{Chapter 1}

the labor market, whereas generic competence may be considered more important for the longer term.

The problem is that what students have learnt in education has usually been measured in labour market research by proxy's such as years spent in education. study field, or in the best case by nominal or mean study results. Given the use of these proxies, what students actually learn in education still remains a black box for labour market researchers. Empirical data are needed that make the different types of competence acquired (or already present) in education more visible. Educational research on the other hand measures the learning process and the results of learning of students in education in more detail, but has rarely related these concepts to labour market outcomes. Therefore, time thas come to cross the borders.

It is at this point where the research in this thesis contributes: it explores the value of several indicators of two different types of competence (specific and generic) in predicting labour market success with samples of academic graduates (with a Masters' degree) of different educational programs. The research question that will be addressed is: What types of competences of academic graduates affect successful labour market entry? The research is conducted with graduates in economics, medicine and health sciences of Maastricht University and includes assessments of their learning experiences in education. In doing so, the current research introduces educational variables into labour market research to make an attempt to unravel the different views about what type of competence (specific or generic) is considered most important for the labour market in the first years after graduation, that is, in the transition stage.

This transition stage is important to study, because it represents a crucial moment between graduation and entry into the labour force and has important consequences for later labour market functioning of individuals. In addition, the explorative character of the studies carried out in this thesis requests a simple model for cause and effect between the measurements of competence and labour market outcomes, i.e. a short time span. A short time span between cause and effect excludes a considerable amount of other factors interfering in the relationship that will otherwise increase in number over time.

By the choice for economics, medicine and health sciences graduates, it is possible to reflect on the empirical findings for different types of educational programs that serve different domains on the academic labour market, ranging from broad domains, which implies a broad range of jobs, to narrow professional domains, which means narrow ranges of jobs. 
In short; the research will show that shdents from different educational programs appear to have different competitive types of conpetence for the labour market. For economists the roles of personality and learning style seem to have more impact than the individual differences in knowlledge and skills they have acquired during their study program. For physicians, the skills and competences learnt in education seem not to make any difference in addition to their medical degree as such. For health scientists, generic (academic) competence seems to predict success in working at an academic level, whereas specific aspects enhance the chances for work that matches the field of the study program. Independent from the competence indicators, a narrow study field. within health sciences enhances the chance to find a matching job, but decreases the chances to find a job in the first place and has a negative effect on the wages earned. The general conclusion is that the broader the educational program is, the larger the value of generic competences for graduates during labour market entry.

The structure of the thesis is as follows: in chapter 2, Theory and operationalization, first the relationship between competence development during academic education and labour market outcomes is considered, based on contemporary labour market and educational research. Then, a working definition of specific and generic competence will be formulated for our research projects. Next, the samples investigated, and the measurement of competences and labour market success will be addressed. At the end of chapter 2, more specific research models for students and graduates of the three different academic programs (economics, medicine and health sciences) are formulated to answer our research questions with the available instruments. The methods of analyses are indicated as well. The models are studied subsequently in several separate empirical analyses in the chapters 3 to 6 . The models offer the hypotheses or relations to be tested in these analyses. Each separate empirical study in chapters 3 to 6 will highlight a part of the empirical questions about the contribution of education to the development of specific and generic competence and their effects on labour market outcomes. Chapters 3 to 6 can be read separately as well, because they all are based on published, accepted, or at least submitted articles in international journals. The consequence is that there will be overlap in the text with previous sections of the thesis. The theoretical background and operationalization chapter is relevant for all four empirical studies, to explain their relationship as well as their differences and to account for the instruments used. The overlap is therefore inherent to the publication history of the individual papers and to the structure of the thesis, but may be very well profitable for the selective reader. 


\section{4 - Chapter 1}

Chapter 3 studies the effects of learning style on labour market outcomes for economics graduates, next to more traditional indicators of human capital, such as study results. Chapter 4 focuses on the importance of personality for economics graduates: Chapter 5 studies the value of several assessments of educational competence development for the short term labour market outcomes of medical doctors, and chapter 6 studies the effects of several specific and generic competences of graduates in health sciences on their entry in the labour market. In chapter 7, the results of the various studies will be discussed and related to the research question. Conclusions will be drawn and implications for further research will be given. 


\section{Theory and operationalization}

\subsection{Theoretical background and assumptions}

\section{Labour market theory}

In most empirical labour market research, the developmental process in education is not explicitly considered and direct measures of competence or competences of people are rarelly used. Traditionally, educational background has been considered in terms of level or field of education. Recently, links between education and the presence of individual capabilities have been studied more explicitly in relation to labour market returns (see e.g. Hartog, 2001). In this respect, Chiswick, Liang Lee and Miller (2003) quantify the link between schooling, and literacy and numeracy skills with labour market outcomes. In other studies, competences or knowledge and skills of graduates are measured retrospectively, by self-reports of the graduates (see e.g. Heijke \& Ramaekers, 1998; Heijke, Meng \& Ramaekers, 2003). And attempts are made to ameliorate this type of measurements (see e.g. van Loo \& Semeijn, 2004). However, assessments of competence and its development during the educational period have not been included in tabour market analysis so far.

Despite this lack of empirical studies on competence and competence development in education, mainly two different points of view on the role of education for the labour market can be distinguished. And these indirectly express a view on competence development in education. On the one hand, Human Capital theory (for an outline of this theory see e.g. Schulz, 1961) assumes that education develops competence, which is (directly) relevant for the productivity of people on the labour market. A higher productivity is reflected by better (individual) labour market outcomes, such as better jobs and higher wages.

On the other hand, Screening or Sorting theories emphasize that education selects students based on their generic competences. In some of these theories (the so-called weaker versions) it is argued that generic competence may be developed in education (Psacharopoulos, 1979; Bills, 2003), while others argue that education does not develop productive specific or generic competences, but sorts on generic competences that are already present before education, such as 'trainability". In this way, educational credentials serve as an indicator of which candidate involves the lowest training costs for an employer (see e.g. Thurow, 1975). 
Other labour market theoretical views do not explicitly consider how education affects competence dewelopment, but specify the conditions under which the rolle of education, and thereby certain types of competence, may be relevant and lead to comparative advantages for individuals on the labour market. So-called assignment models within job matching theory (for an overview see Sattinger, 1993) assume that depending on the characteristics of the job, different characteristics of the worker are rewarded (such as a particular educational background or a certain type of competence). The quality of the match, thus the "fit" between competence supply by the individual and competence demand of the job, determines the productivity in a job (see also van Eijs \& Heijke, 2000).

Assignment models assume that different higher and academic educational programs have different effects on what type of competences students develop. Educational programs will lead to different competence profiles or mixes (keeping all other variables constant). And these different competence mixes seem to have comparative advantages on different parts or domains of the academic labour market. De Wolf (2000) suggests that the academic labour market can be divided into three domains; the so-called professional labour market, the field-specific labour market and the generic labour market. These different domains may call for different competence profiles.

In the professional labour market, jobs are "professions", and emphasize the importance of profession specific competences, mainly acquired in specialized education or training programs, such as law or medicine. A profession is a job in which a speciallized type of knowledge is combined with professional skills and attitudes that meet the so-called professional standards that are set by peers (respected colleagues) and other professionals on a national or even international level. An example is the Dutch "Centraal Begeleidingsorgaan voor de intercollegiale toetsing" (CBO), a quality institution for the health care, which can be translated as 'Central Organization for Coaching of intercollegiate assessment'. Colleagues within the profession are the most important source for feedback and social control in the practice of the profession (see e.g. Slotnick, 2001). Often the members of the professional group are organized in committees to take responsibility for the development of the profession, for innovations and all types of other issues, such as the educational preparation of students for the profession (see e.g. Arnold, 2002). Often the educational degree as such is a prerequisite for entering the profession, such as in law or medicine. Therefore the comparative advantage of the medicine program, compared to the economics program, is overly clear for the professional labour market of medical doctors. The study of medicine is hereby considered a narrow study (de Wolf, 2000; Borghans \& de Grip, 1999). 
In the field-specific labour market, jobs are not professions for which only one educational program is especially desirable or requested, but several educational backgrounds are possible, such as for a manager in health care. The "professional" attitude in this domain leaves more room for diversity and other indicators than the educational background may be relewant, such as voluntary work experiences in the field. Notwithstanding this possible importance of other factors, for jobs in management in health care the economics program is more relevant than having studied medicine. But a field-specific study such as 'management of health care' (a specialisation within health sciences) may now have the highest comparative advantage. In this domain, the field-specificity of the competences of graduates will play an important role in the mix of competences that is considered most functional or desired.

In the generic academic labour market, the specific competences acquired in education are much less important for the jobs. The specific competences required for the job can be acquired on the job more easily, or are quite different from the specific competence developed in education, such as for all kinds of trainee functions (such as in IT/consultancy). Jobs in the generic domain are characterized by a large amount of on-the-job-training and strong internall labour markets (see also van Eijs \& Heijke, 2000; Breen et al., 1997). Employers are therefore assumed to select candidates on more generic capacities, referring to trainability, the motivation to learn, analytical skills and presentation skills. In this domain, educational programs without a strong emphasis on professional or field-specific knowledge and skills, such as economics, seem to have the highest comparative advantage. Beciause of its broader scope on the labour market, economics can be considered a broad study (see also de Wolf, 2000; Borghans \& de Grip, 1999).

\section{Educational theory}

In educational research the individual learning process during education is addressed more explicitly and the measurement of competence in the sense of study resuls has a long tradition. The current attention for the competence concept is a stimulus for innovative measurements of these study or learning results and a reconsideration of educational goals and objectives as such. In fact, competence oriented education is discussed in two ways: on the one hand it is concened with a tighter relationship between education and labour market demands, especially in higher vocational education, but in academic education as well. On the other hand, it is concerned with a more integrated character of what students should learn in education in terms of knowledge, skills and attitudes (van Merrienboer, van der Klink \& Hendriks, 2002). Competence is in fact what underlies separate specific and generic aspects that can be measured and distinguished (see e.g. Paulson, 2001). Research has shown that 


\section{Chapter 2}

during a study program the different assessments of learning achievements of the students attain higher correlations over time (van der Vleuten, van Luijk \& Beckers, 1989). In line with this finding, some argue that generic and specific competence cannot be easily distinguished (see e.g. Perkins \& Salomon, 1989; Glaser, 1990; van Zolingen, 1995), or even that generic competence as such does not exist without a specific context (see e.g. Mulder, 1997).

In all, it is no wonder that competence has not been measured in (academic) education systematically yet. Therefore, educational theoretical perspectives can not provide a solid rationale for our distinction in specific and generic competence, but to a certain extent, they can legitimate an operationalization of different assessments in education in terms of specific and generic competence.

For example, the expertise development view (e.g. Boshuizen, Bromme \& Gruber, 2004; Dreyfus, 2004) emphasizes the cognitive development that underlies the development of professional expertise. The establishment of a solid knowledge base is considered crucial, and is to be acquired during the academic educational phase. From this view, the development of specific competence in academic education, i.e domain or field-specific knowledge, is crucial for becoming a good professional. In this way it seems legitimate that assessments concerning the development of field-specific knowledge refer to specific competence.

Self-regulated learning theory (Boekaerts, Pintrich \& Zeidner, 2000), on the other hand, emphasizes the learning behaviour of the students itself. This leads to an emphasis on the development of learning and cogritive processing strategies of students and meta-cognitive capabilities. The changing needs from society and the labour market have turned 'learning' into an explicit necessity' during the whole (working) life-span, more than ever before. Therefore education serves not only as the provider of knowledge and skills anymore, but ass a basis for further learning as well.

Self-regulated or self-directed learning may be effectuated by so-called activating learning environments, in which the principles of self-directed learning and a so-called constructivist learning paradigm have the best opportunities to flourish (see also Simons, van der Linden \& Duffy, 2000). In the constructivist paradigm the learner is an active discoverer, who constructs his or her knowledge in interaction with the (social) environment (Savery \& Duffy, 1995). Examples of such activating learning environments in academic context are the Problem Based Learning (PBL) system as used in the curricula of Maastricht University (Schmidt \& Moust, 1998), and project learning or project based learning (see e.g. Frank, Lavy \& Elata, 2003; Thomas, 2000). In these learning environments students have to work together in groups on problems and cases that are relevant to the curriculum. This way the development of several other generic types of competence is also 
stimulated, such as the ability of working together with other people, solving problems systematically, and communicative and presentation skills (see e.g. Schmidt \& Vermeulen, 2004). And, at the same time, the so-called activating learning environments seem to stimulate the development of specific competence as well. This may be illustrated by research findings among medical students that PBL discussion leads to better learning from text (de Grave, Schmidt \& Boshuizen, 2001) and by the self-reported competence ratings of PBL graduates in medicine and health sciences, comparing themselves with graduates from other, more conventional curricula (Schmidt \& van der Molen, 2001). Therefore activating learning environments seem to lead to better learning as compared to more traditional learning environments (see e.g. Meng \& Heijke, 2004, for a retrospective analysis). In this respect, problem and project based education can be seen as vehicles or methods for competence-oriented education.

The question is, however, how students are assessed in these types of education, how learning results are assessed, and the development in what is learnt during the educational process. Current practice shows a wide variety in measurement instruments for this learning process and its outcomes. Traditional (multiple choice) knowledge tests and standardized skills tests are used (Straetmans, 1998), as well as more innovative and integrated measurements, such as portfolio's (Young, 1999), writing assignments (Hansen, 1998) and feedback methods (see e.g. Chizmar \& Ostrosky, 1998). New instruments are developed and new assessment methods proposed to make the assessment system align with the (new) learning methods used (see e.g. Atlay \& Harris, 2000; Elshout-Mohr, Oostdam \& Overmaat, 2002). However, the relationship between individual differences in the scores on the instruments from daily practice in (academic) education on the one hand, and individual labour market outcomes on the other hand, is seldom studied. This is where the empirical studies in this thesis want to offer a contribution.

\section{Specific and generic competence; compatibility between labour market and} education?

In both labour market and educational views, different definitions and operationalizations are used when considering the concepts of specific and generic competence in more detail.

From a labour market perspective, generic competence may be defined as abilities and qualities of people that are relevant for many jobs. These are for example: being able to learn and adapt, to communicate and to work together, and some personal attitudes, such as independence, or responsibility. Specific competence may be defined as the more job specific skills and knowledge; skills and knowledge that are especially relevant for one or only a few jobs. Although this 
classification may have some different comnotations from a more educational perspective, we comply with this labour market functional view. In this sense, we consider the knowledge and skills that are bound to the curricular program of education (as it prepares for a certain range of jobs) as specific, whereas the capability to adapt, to communicate, to learn and to work together, although in an educational context, can be seen as generio (as they are considered to be functional. for all jobs), as well as some more persomal attitudes of people and their learning style.

\subsection{Operationalization}

\section{Research Samples}

In the empirical studies, graduates of three different study programs of Maastricht University will be considered: economists, physicians (medical doctors) and health scientists. The study of health sciences is a multidisciplinary study amed at the field of health care; it includes different specializations within this field ranging from management of health care to biological processes underlying illness and health. These three educational programs have different scopes on the labour market, and the question is to what extent the importance of different types of competence will differ across these programs. Economists are considered to be prepared for a broad labour market domain, with an emplhasis on the generic labour market. Physicians, on the other hand, are prepared for the professional labour market, and therefor a narrow domain (de Wolf, 2000; Borghans \& de Grip, 1999). Health scientists can be considered to take a position in between, although withun the health sciences study it is also possible to specialize in fields with narrower and broader job domains (for example biological health sciences prepares for a rather narrow domain and management of health care for a rather broad job donain).

As already mentioned, Maastricht University practices the so-called Problem Based Learning system. This means that students work in groups and learn to systematically solve problems and cases that are relevant for the field of study. This may lead to a more explicit stimulation and development of both specific and generic competences, i.e. group skills and active and therefore better learning, which is also domain specific. The PBL-system may therefore create a bias with respect to the research findings compared to graduates of more traditional universities. However, the character of the educational system as such is in line with contemporary educational theoretical insights that can be considered the current state of the art in educational practice (see e.g. Dolmans, Wolfhagen, van der Vleuten \& Wijnen, 1999; Gijselaers, 1999). Other universities, nationally and internationally, use and improve the ideas of $\mathrm{PBL}$ and project-based learning, such 
as for example in Nijmegen (The Netherlands; see also van den Bosch \& Gerritsen, 1997) and at Ohio University in the United States of America (Gijselaers, 1999). This makes differences between graduates from different educational programs within such a 'modern' educational system all the more interesting.

\section{The measurement of competences and competence development}

The measurement of competences and competence development is a complicated matter. First of all, in different research areas competence and competences are perceived differently and the concept of competence and the division in specific and generic types can be formulated in several ways (for overviews see Toolsema, 2003; Stoof et al., 2002; Weinert, 2001; van Merriënboer, van der Klink \& Hendriks, 2002). For our research, the perspectives of educational research and labour market research are important. In short, the most important differences in perspectives between these two fields are the following: in labour market research the specific context (firm, industry) of the type of work or the job are crucial to distinguish specific from generic competence (see e.g. Becker, 1962; 1983, Nordhaug, 1993; Stasz, 1998). In educational research, on the other hand, the specific contents of a curricular program are the base for the classification of specific and generic competence, often in the cognitive domain of human functioning (see e.g. Mulder, 1997; Straetmans, 1998). And as the combinations of educational programs and jobs are not one on one, these perspectives do not always easily match.

Second, although theoretically competence can well refer to an integrated set of skills, capabilities and knowledge components, as for example emphasized by competence-oriented education, in practice competence can only be assessed in a specific context and by focussing on more specified components. Furthermore, when departing from a theoretically driven distinction between specific and generic competence in a field, for example by considering tield related knowiledge specific and learning ability generic, problems arise when it comes to measurement in practice as well. That is, most instruments capture elements of both types of competence, such as field related knowledge and learning ability (e.g., Perkins \& Salomon, 1989; Glaser, 1990; van Zolingen, 1995).

Third, even when instruments are available in education, the students' development in specific and generic competence is difficult to assess, since this requires longitudinal measurement properties (standardized scale across all assessments), as well as repeated measures. And these instruments are scarce (e.g., Sorensen, 1994). Neither do we find many curricula in which repeated assessments of competence (development) are taking place.

Since the concept of competence is not defined and measured consistently in research, the question is not how valid and reliable measures are as 'competence 
atssessments", but how "viable" they are (Stoof et al., 2002). Applying this perspective, the operationalization must fit the research purpose and the research context, as presented in the previous sections.

With our operationalization, we intend to offer a contribution to competence research from a more empirical point of view, instead of solving the theoretical and conceptual issues. The purpose is mainly to open the black box of education by including educational leaming results into labour market research and shed some empirical light on the debate about what types of competence are most important for the labour market. This is by no means an escape from the difficulties with respect to the operationalization of the concept, but merely offers empirical input from current daily practice in education for further analysis.

\section{Indicators of competence during the educational process}

One of the conclusions from both the labour market and educational literature on competence(s) is that specificity only exists in a defined labour market or educational domain. This complicates a translation from "generic' and "specific" requirements for work and the labour market into educational tasks and assessments for these requirements (see also Stasz, 1998). We therefore take the specificity of competence within the academic educational process as a starting point for measurements in the educational process. This specificity is thus related to the field of the educational programs to be investigated, i.e. economics, medicine and health sciences. In this way, we label available competence indicators, related to the specific knowledge and skills developed during an academic program, as "specific" competence indicators. An interesting instrument, in this respect, is the so-called Progress Test, available for two out of three of our research samples, because it measures the development of students' body of knowledge of a specific domain (longitudinal assessment). However, we do not imply that this test and other specific indicators do not capture some 'generic' capabilities as well.

On the other hand, non-specific study results, such as indications of 'group functioning" and earlier "general" indicators of educational attainments, such as "mean final exam results of secondary school' are considered as generic competence indicators. In addition to these, 'softer' competence indicators, such as 'learming style" and personality characteristics will be considered as generic competence indications as well. This multi-fold use of 'generic' concepts is often used in literature (see for example Nijhof \& Streumer; 1998).

For the measurement of competences and competence levels, different data from the graduates of the three academic programs are available. Although the instruments and data vary across the educational programs, there is also considerable 
overlap. The diversification on the one hand and the tangent planes on the other hand can help us to see the relationship between the studies.

The following instruments have been used to indicate so-called 'generic competences' in the educational process:

- Learning style inventory (information processing and motivational aspects of learning style);

- Personality inventories (on Locus of control, Self-monitoring, Type A behaviour and Sensation Seeking);

- Group Functioning-scores, that is, attained score for "functioning in educational groups' (a cumulative measure of points, awarded for 'more than average individual contributions' to the educational groups in the PBL system);

- Grade Point Averages (GPA's), that is, mean final exam results in secondary school.

In addition, the following instruments have been used to indicate "specific competences' during the educational process:

- Progress Test scores (longitudinal assessment of the development of study domain specific knowledge);

- Masters" thesis result (score for final study project);

- Skills test scores (medicine; assessment of diagnostic and treatment skills with 'fake' patients);

- Mean knowledge test scores from study courses; mean scores of the first and last year study course tests, mean scores over the last two years; and mean scores during the entire educational program, as available.

In each empirical study, the indicators used are addressed in full detail. For more information on these indicators, we therefore refer to the separate studies.

\subsection{Labour market success}

Labour market success in this thesis is restricted to short term labour market outcomes. A successful transition from education to the labour market can be measured by different indicators referring to the chances to get a job and the quality of the job. As such, it will be in line with other contemporary transition studies in 
European perspective (see e.g. Müller $\&$ Gangl, 2003). For job chances, the indicators will be:

- having a job;

- having a job within three months after graduation;

- having a tenured position (indicating job security, sometimes also considered to refer to the quality of the job).

For the quality of the job, these are:

- job level (acadenic level or less);

- the actual type of job (function or profession);

- the extent to which the job matches the education;

- wages.

These indicators are available from a large national labour market survey among Dutch academic graduates that is sent to all graduates a year and a half after graduation, on an annual basis by the Research Centre for Education and the Labour Market (ROA). For further information on this survey and the precise indicators per sample, we refer to the data and methodology sections of the separate empirical studies.

In the following section, the relations that will be tested empirically will be further elaborated. For each sample, a research model will be presented with short notes on the available instruments, and the relevant empirical study (-ies). The studies will each try to give an empirical answer to the question: What indicators of specific and generic competence of academic graduates predict successful labour market entry?

Because the data for the studies are not exactly the same and the relationships that are tested are neither, the results of the studies can not be compared one on one. However, the differences in the design of the studies also offer more diversity in information and therefore the possibility to compare the outcomes in a larger perspective.

\subsection{Research models}

\section{Research model for economists}

The study field of economics and business is preparing for a broad range of jobs. This implies that graduates in economics and business are rather flexible with respect to obtaining a job. They seem to have comparative advantages in the socalled generic academic job domain (see e.g. de Wolf, 2000). For jobs in the generic domain, specific competences of graduates will be less important; for many jobs the 
required competence is job-specific and not strictly related to the contents of one or few educational programs. We therefore expecit that generic competences of economists will prevail in making them successful on the labour market, more than their specific competences. Employers will compare candidates for a job, amongst others on the capacity and motivation to learn the required skills and knowledge for the job. Therefore we consider learning style and personality of the students as important aspects in the selection and allocation of economists.

Learning style rellates to the way students process information on the one hand and to motivational aspects on the other hand. As employers compare job candidates on their trainability, we expect certain learning styles of graduates to be predictive for better labour market outcomes. However, from a job matching perspective, a certain learning style may also predict the different types of jobs or functions that graduates are interested in, or for which they are selected by employers. lin this sense, one can imagine that a global information processing style ('grasping the main line') may be functional for managers, but dysfunctional for accountants, although both may be graduated in economics.

Personality on the other hand refers to rather stable patterns of behaviour in students. Here as well, on can imagine that some behavioural patterns lead to more labour market success than others. For example, the aptitude to ascribe experiences of success and failure to ones" own responsibility (a so-called internal Locus of Control) instead of ascribing them to luck or environmental influence, is expected to lead to more successful outcomes. Other behavioural patterns may be functional for one job, whereas they may be dysfunctional in another (matching perspective).

We will conduct two separate analyses for the economics graduates. In the first model we use data that relate to the graduates' learning style as an indicator of generic competence. In the second model we use data from personality tests as indicators of generic competence. In both models, the Masters' thesis results and mean knowledge test scores of the last two years of the doctoral program are used to indicate more specific competences. And the study field and other labour market relevant wariables, such as age and gender, are included as control variables. The research model that captures our expectation with respect to the learning style study (chapter 3) is presented in figure 2.1 .

Arrow 1 represents the main effect of learning style aspects on labour market outcomes. Arrow 2 represents effects of specific competence. By including both types of competence in the research model, their net effects are estimated, controlled for several personal characteristics (age, gender) and study length and study field (arrow 3). For more detailed information on the method of analysis and the variables used, we refer to chapter 3 . The relationship between personality and 
labour market outcomes is analysed with another sample of economics graduates, in chapter 4 . The research model for this study is presented in figure 2.2 .

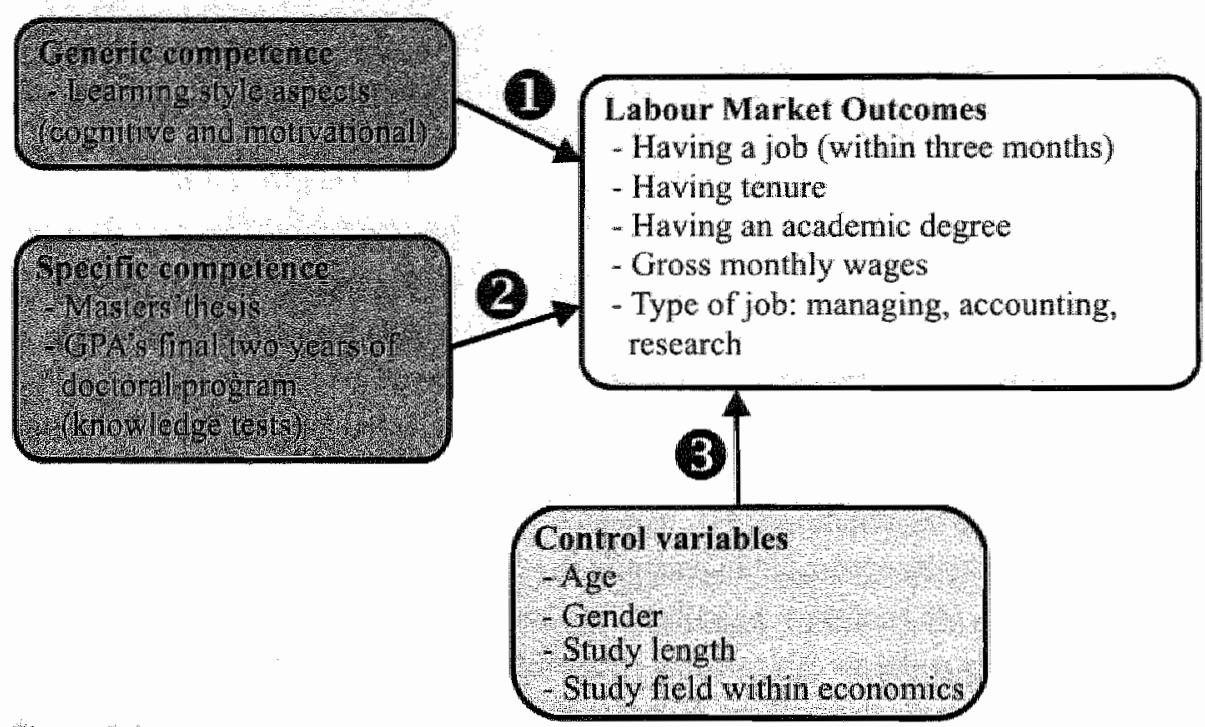

Figure 2.1

Research model for the effects of specific and generic competence on labour market outcomes for the learning style study with economics graduates.

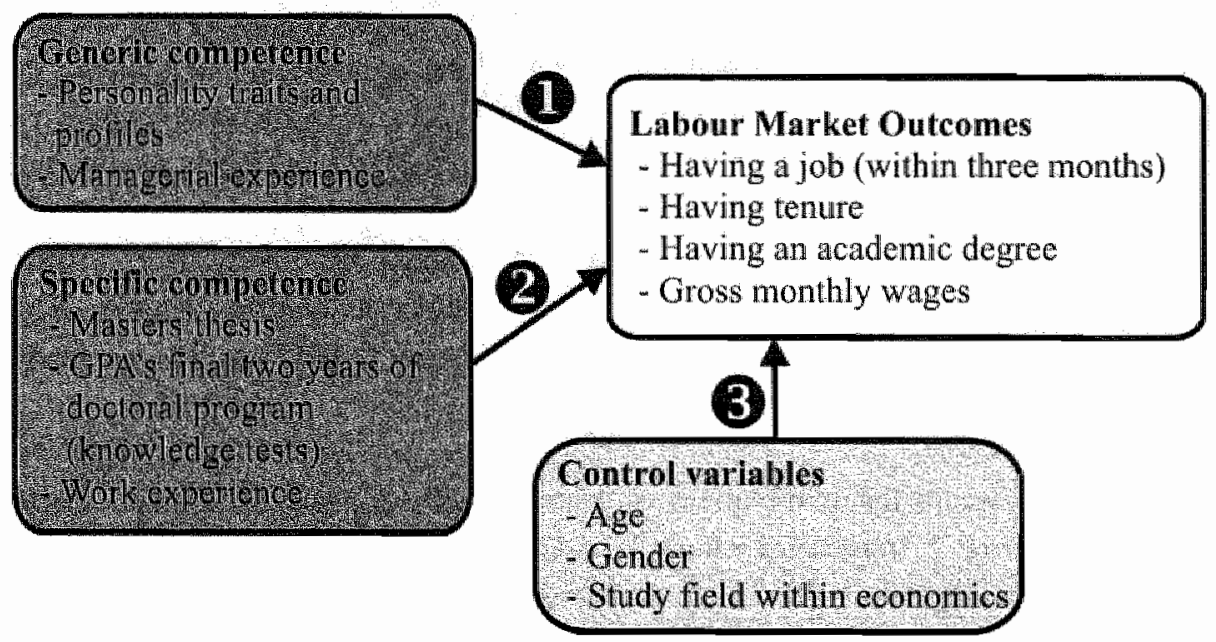

Figure 2.2

Research model for the effects of specific and generic competence on labour market outcomes for personality study with economics graduates. 
In the study in chapter 4, again we control for specific study results and other human capital variables, i.e. managerial experience as a more generic type of competence (unrelated to the study domain) and relevant work experience as a more specific type of competence (related to the study domain). In this study, labour market outcomes are analysed in terms of better chances to obtain a job and a ligher quality job. The research model that captures our expectation for the effects of personality and study results on labour market outcomes for economics graduates is presented in figure 2:2. Here, the main effect of generic competences is reflected by arrow 1 and the effect of specific competences is reflected by arrow 2. By putting both generic and specific types of competence indicators in the research model at the same time, their net effects are estimated, controlled for age, gender and study field (arrow 3 ). For more information on the available personality measures and other details of the study, we refer to chapter 4.

\section{Research model for medicall doctors}

The study of medicine may be considered a "narrow study', in the sense of preparing for: a narrow range of (professional) jobs (de Wolf, 2000; Borghans \& de Grip; 1999). In addition, the medical labour market is highly regulated with a fixed amount of students that is allowed to enter the study of medicine every year. This means that medical doctors are not necessarily prepared for being flexible on the labour market. To be attractive for employers, physicians should in the first place possess the highly specific knowledge and skills required for direct productivity This does not imply that generic competence is not important for the medicall profession. But it seems legitimate to predict that the more specific medical knowledge and skills you possess, the more attractive and more successful you are on the labour market. Medical students differ in learning abilities and acquired knowledge and skills as measured with educational instruments. And within the medical field, some positions require more traning and responsibility than other positions. Therefore we expect that the amount of specific competence acquired in medical education affects labour market outcomes.

The instruments used in the study refer to a longitudinal measurement of the accumulation of domain related knowledge (the Progress Test) and the amount of well-performed clinicall tasks at the end of the medical doctoral program (Skills Test). They seem to have relevant measurement properties for competence acquired in education. For a more detailed explanation on the competence indicators used, we refer to the methodology section in chapter 5 , and, in particular for the value of the Progress Test in measuring relevant (specific) competence for medical students, to Appendix E. 
We expect the available indicators of specific competence, i.e. the Progress Test scores and the medical Skills Test scores at the end of the doctoral study to have an effect on labour market outcomes, net of the effects of the GPA"s of secondary seltool. Because we also think that what students learn in medical education is not merely a matter of screening on their abilities, but actually refers to acquiring relevant knowledge and skills, or competence, we expect that the specific competence at the end of medical education as measured with the final Progress Test is more important than what was measured with the first Progress Test and GPA's of secondary scheol at the start of the study program.

Labour market outcomes for graduates in medicine are defined different from those of graduates in economics, because of the specific features of the medical labour market. In fact, the medical study prepares for further specialisation tracks for which different amounts of training time are needed. And wages are highly regulated within medical specialisation positions. This makes the normal wage indicator not very informative for labour market success of medical graduates. By transforming the required training period per specialisation into an investment for life-time income we obtained an alternative for the normal wage indicator. For a more detailed explanation on the labour market outcome indicators for medical doctors we refer to Appendix $\mathrm{F}$.

The research model that reflects our expectations for medicine is presented in figure 2.3.

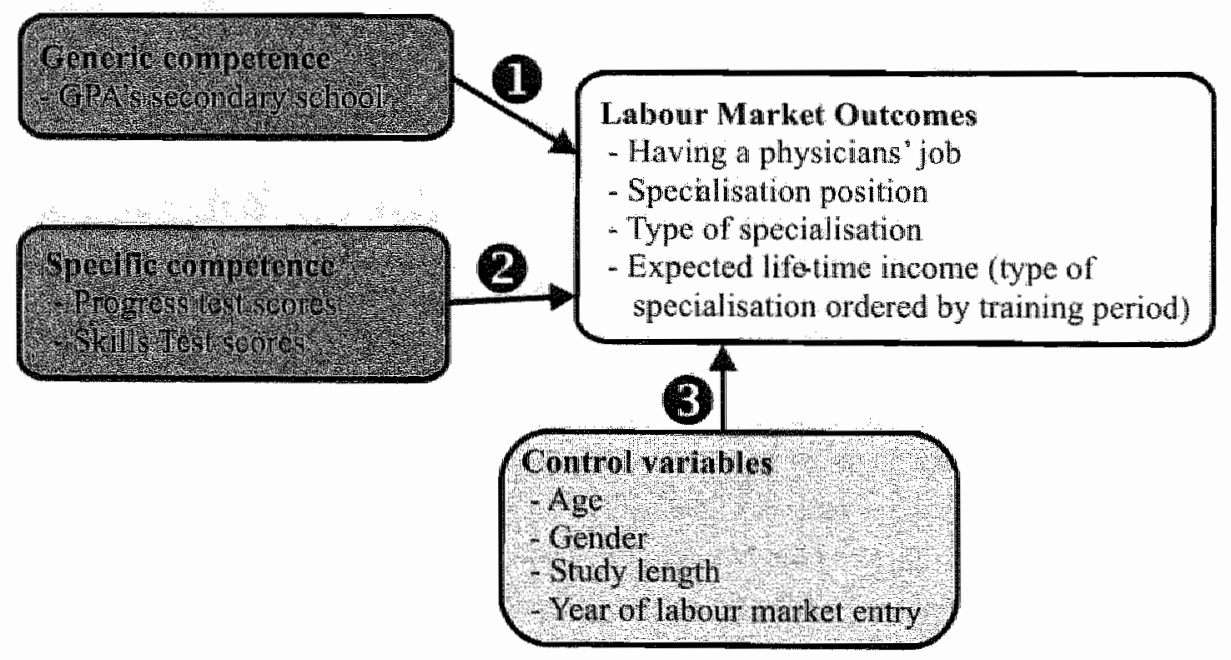

Figute 2.3

Research model for the effects of specific and generic competence on labour market outcomes for medical graduates. 
The model shows a distinction between the type of competences as presented by Progress Test scores and GPA's of secondary school. Although GPA's of secondary school can be considered a specific type of competence reflecting the study results as acquired in secondary education, we consider these scores as a more generic indicator of the students' capabilities at the start of their medical education. What medical education will add is considered more specific in the context of this study. We expect the specific competence at the end of medical education to have a main effect on labour market outcomes (arrow 2), and an effect, net of the effect of the more generic competence at the start of medical education (arrows 1). In addition, we expect the main effect of specific competence learnt in medical education to be more important (arrow 2) than the main effect of GPA's of secondary school (arrow 1). The effects of the control variables are represented by arrow 3 .

\section{Research model for health scientists}

The study of health sciences can be considered a field-specific study (e.g., de Wolf, 2000). In this sense, the study prepares for a 'broader' range of jobs than medicine, but a 'narrower' range of jobs than economics (e.g., Borghans \& de Grip, 1999). It cannot compete with the job domain of medicine, because medical jobs are exclusively for physicians. On the other hand, the health sciences study can partly compete with the job domain of economics and business, for example in the management of health care. It can also compete with other studies, for example social science studies. As long as the health care sector is the sector to compete in, the health sciences study seems to have a comparative advantage with respect to field-specific competences. Therefore, for health scientists, both specific and generic competences are important. We expect that the importance of the specific competences will prevail in making the graduates successful in their own fieldspecific labour market segment. When health sciences graduates compete in other segments as well (for example the generic labour market segment) with gracluates from different studies, we expect the generic competences to be most important. For a sample of health sciences graduates, we use several competence indicators that refer to more specific and generic aspects of educational competence. The available Group Functioning scores, for example, reflect a generic type of competence, in the sense that these scores refer to a productive and positive contribution to the learning in, and the functioning of the educational group. The available Progress Test scores reflect a specific type of competence, comparable to the Progress Test scores for medicine students: the accumulation in the domain related knowledge. The Masters" thesis is considered to reflect a specific type of competence as well, because it is highly related to the curricular domain, although it requires several types of knowledge and skills to write such a thesis. In the study in chapter 6 the Masters" 
thesis is presented as a rather integrated competence measure though, because of its different character and measurement properties from both 'group functioning' as a generic type of competence and the 'Progress Test' as a more specific competence indicator. In addition to the variables mentioned, both managerial and work experience (during education) are included as indicators for more generic and specific competence acquired outside education.

The research model that explores our expectations for health scientists is presented in figure 2.4 .

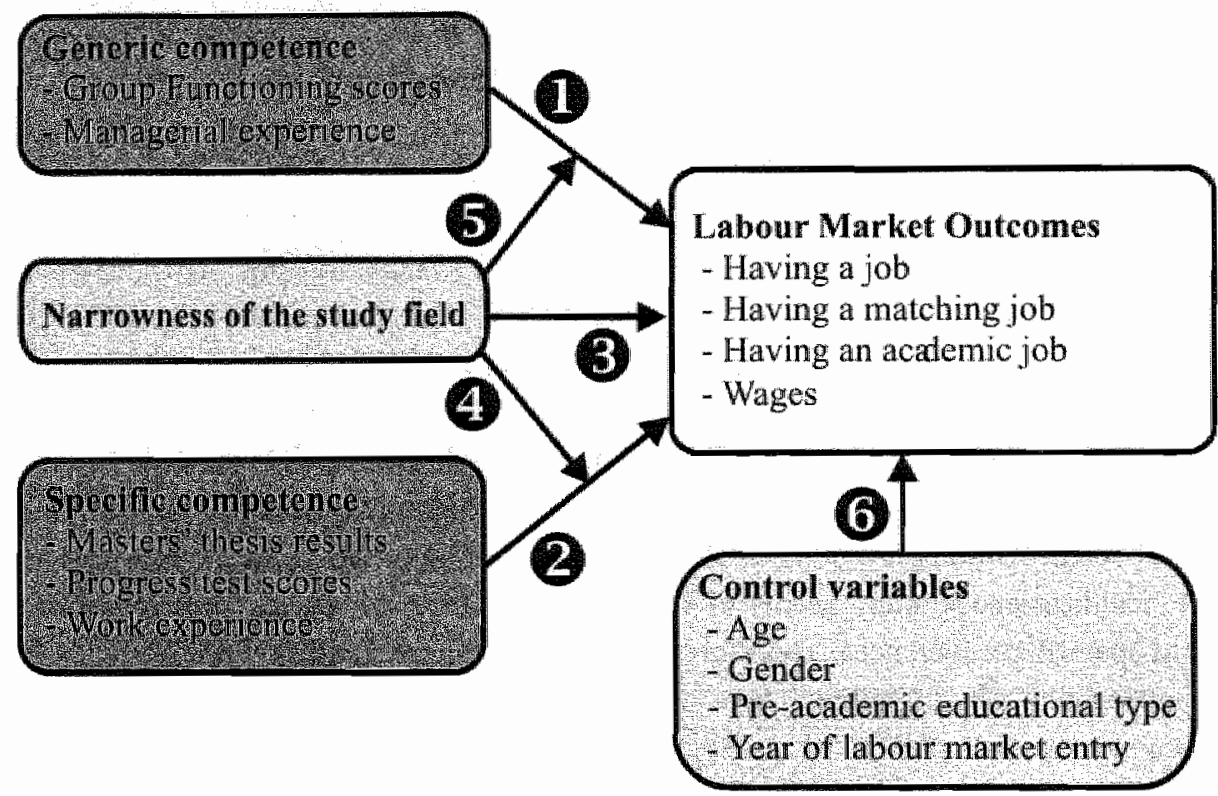

Figure 2.4

Research model for the effects of specific and generic competence on labour market outcomes for a sample of graduates in health sciences.

The effects of generic and specific competence at the end of education on labour market outcomes are represented by arrows 1 and 2 . The effect of the narrowness of the study field is represented by arrow 3 . And interaction effects of narrowness of the study field with specific and generic competence indicators are reflected by arrows 4 and 5. Several control variables are included in the study as well (arrow 6). Putting all variables in the model at the same time will reveal the net effects. The empirical findings of this study will reveal what the relative importance of specific and generic competence in education is for labour market outcomes of graduates that followed narrower and broader programs. 


\section{Aspects of learning style and labour market entry: an explorative study among economic graduates ${ }^{+}$}

\section{Sumbary}

This chapter explores the effect of learning style on labour market entry. Learning style is considered to be a relative stable educational concept representing students' learning preferences. In this respect, learning style may be seen as a type of generic competence, as opposed to more domain- or field-specific knowledge and skills referring to more specific competence. The sample consists of economics graduates. Learning style aspects were tested for their effect on job chances, quality of work and type of job (job match) at the time of the survey one and a half year after graduation. Analyses were applied within a two step model. In the first step only learning style data and control variables were included. In the second step, relevant covariates like study results were included in the analyses in addition to the learning style data. Logistic and normal lineair regression analyses point out that the motivational aspects of learning style tend to have an effect on most of the labour market indicators, whereas the cognitive information processing aspects merely affect the chance of getting an academic job. Results of multinomial logistic regression analyses reveal some effects on entering an accounting job in comparison with a managing job (job match). Altogether, the effects of learning style aspects appear to be more profound than the effects of study results with respect to labour market entry.

\footnotetext{
This chapter is an adapted version of:
}

Semeijn, J.H. \& Velden, R. van der (2002), Aspects of Learning Style and Labour Market Entry: an explorative study. In: Johannessen, T.A., Pedersen, A. \& Petersen, K. (eds), Educational fonovafion in

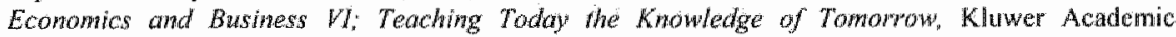
Publishers, Dordrecht/Boston/London, pp. $301-324$. 


\subsection{Introduction}

Recent demands for people at the workplace are described by modern concepts like nexibility and ability to learn. The capacity of employees to adapt to new skill requirements that result from technological developments and global market dynamics is especially stressed (URDAC, 1990; WRR, 1995; European Commission, 1996). This implies that important concepts under consideration for research into what makes people successful in labour market functioning are related to learning behaviour. In order to become and stay employable, worker's capacity for life-long learning becomes crucial.

In labour market research, educational and skill requirements are considered to be of great importance for successful labour market functioning. However, despite this importance, sociologists and economists have very much considered the educational process as a black box. At best, education has been measured in number of years of education followed, or in terms of educational outcomes by grades, but the actual content of education or learning processes has been left to the domain of educational research. Educational research in turn has neglected the actual outcomes of education in terms of the effect on successful labour market entry and functioning. This research field, however, acknowledges the importance of individual differences in learning for learning outcomes. Already since the sixties and seventies the concept of 'learning style' was used. Learning style refers to a set of individual characteristics which are relevant for individual differences i.e. preferences in the learning process (Biggs, 1993). It may be conceived as a relative stable trait of people. This stability stresses the question to what extent learning behaviour can be developed or changed. However, since growing emphasis is put on the importance of individual skills and differences for labour market functioning (Nijhof, 1997), the existing concept and measurement of "learning style" from within the educational context may be valuable for analysing differences in labour market functioning. Not only learning outcomes ma be affected by differences in learning behaviour or preferences, but labour market outcomes as well. And since learning continues after entering the labour market, the concept of learning style may be important during the further stages of working life as well, possibly related to employability.

The study in this chapter will take a first step by exploring the predictive effect of students" learning style measured during education for labour market entry. Because learning style refers to 'preferences' in behaviour, both labour market success in quantitative terms and the allocation to different types of jobs will be considered. A sample of graduates from economics is used. The research question we address is: 
"To what extent does learning style predict labour market entry features of graduates?"

\subsection{Theoreticall background}

Traditionall labour market research recognizes the importance of education for the labour market. As explained in chapter 2, there are mainly two hypotheses: in the human capital theory education is considered to enhance people's productivity directly (Becker, 1964). More education means in this view more productivity. In the screening bypothesis on the other hand, education is considered to reflect desired capacities for employers (Thurow, 1975). In this view people have no instant productive value for employers, but the real productivity will be developed on the job. Study results are widely considered to be used as screening devices by employers, to attract the employees with the best learning potential. However, the emphasis is now put on more individual characteristics in selection practice. And the question rizes what these characteristics are exactly and how to measure them.

General or generic skills, or competences, pertaining to cognitive abilities, personal characteristics and learning skills, are considered as key qualifications for people (e.g. Nijhof, 1998), but it remains unclear in most labour market research how these concepts can be measured. Presland (1994) advocates the use of the learning style concept because of its relevance for continuous development during work. We think the educational concept of learning style has something to offer in this case, although the concept itself still lacks a clear theoretical framework (Rayner \& Riding, 1997).

Roughly two views have been developed in learning style research (Biggs, 1993). These are a narrow view, which emphasizes the cognitive information processing part of learning (for example Kolb, 1976; 1984; Schmeck, Ribich \& Ramanaiah, 1977) and a broad view, which implicates several other aspects, in addition to the cognitive processing parts, like motivation and regulation preferences of individuals (for example Entwistle, Hanley \& Hounsell, 1979; Nuy, 1991; Vermunt, 1992). In the broad view, an individual's learning style consists of a particular combination of cognitive information processing, regulation aspects and motivational aspects. In general, distinctions in three or four different learning styles. are well accepted, as more or less prototypes of learning style. However, the styles are estimated using various composite measurements, depending on the instruments used. 
A distinction in three learning style types, that can be described as being reproductive, achievement oriented, and meaning oriented, is rather common though (Entwistle et al., 1979; Nuy, 1991). The meaning oriented style is considered the desirable one; people scoring high on its scales can be characterized by having a large instrinsic motivation, by being disciplined and using cogninive information processing techniques like trying to have an overview, to use concrete examples and elaborate study materials by personal experiences. All in all, the study material is handled to obtam "meaning". The reproductive style is in this way more aimed at trying to remember the material and the achievement style at trying to obtain good study results no matter what.

When considering one learning style as being desirable, the question rises to what extent the learning style can be developed or changed? From educational research findings the answer seems to be 'yes' to a certain extent; several factors affect learning style, such as teaching style (Borg \& Shapiro, 1996), kind of tasks (Tsang, 1993), and the educational system or context (Eklund-Myrskog, 1997; Nuy, 1991; Nuy \& Moust, 1990). Thus, it should be possible to manipulate students" learning behaviour with the 'right' tasks, the right teaching style and the right system. It depends on the perspective on "right" and "desirable". Research has been aimed frequently at the effects of learning style on learning outcomes (Crombach, Gaff \& Chang, 1975; Smit \& van Os, 1985; Vermunt; 1992), but the relationship is not conclusive. Probably, the factors affecting learning style do play a role in this. Gijselaers, Nuy and Mullink (1989) studied the effect of learning style on study outcomes and concluded the educational system had affected students" learning style into an "undesirable" direction.

When learning style is considered rather stable, but on the other hand, can be developed to a certain extent as well, what are the consequences for predicting labour market entry features from learning style measured during education?

In this case it seems important to analyse the predictive value of both study results and learning style at the same time to find out whether first of all there are any effects of learning style measured during education on labour market outcomes, and second whether these effects would be merely direct, or indirect, i.e. that the effects are mediated by study results.

In the case the effect is independent from study results one could argue the learning style concept has much value for labour market research. When its effects would merely be indirect, meaning study results are stronger indicators for labour market entry features, the concept would not add much value for predicting labour market entry. However, when no effects for learning style could be found, while for study results there could, we should doubt the use of this concept. 
It may be possible that learning style is not valuable in predicting a more or less successful labour market entry, but that it regulates the allocation process on the labour market in a more qualitative manner. The question that arises is whether people with different learning style characteristics end up in different jobs? One could argue that for example 'grasping just the main points' during information processing would be positive for a manager, but negative for an accountant, although both graduated in economics. This relates to the matching perspective. In the research field of personnel selection and job analysis, all kinds of individual characteristics have been studied in relation to job characteristics, for example work related values (Judge \& Bretz, 1992), cognitive ability (Lancaster, Colarelli, King \& Beehr, 1994) and personality constructs (Raymark, Schmit \& Guion, 1997). Results show that people tend to choose those jobs that match their abilities, vocational interests and personality (Shrauger \& Osberg, 1981; Lancaster et al., 1994). The personal characteristics studied all seem to have a positive effect on job functioning and satisfaction when a match is established. Cognitive ability and specific personality characteristics are considered to be more related to the job, whereas work values are more related to the organization. Despite the argument of it's relevance for the working environment (Hayes \& Allinson, 1997), the concept of learning style has not been used in this research field. However, it may be possible that the relative stable concept of learning style can tell us something about the kind of job a person chooses.

From different lines of research, learning style seems to potentially have an important effect on differences in labour market position and functioning. Therefore, in this first empirical chapter, the predictive value of different learning style aspects will be explored next to other more traditional human capital variables and study results. The research question that will be addressed is: To what extent do learning style aspects predict labour market entry features, when taking other more traditional indicators of human capital variables into account?

\subsection{Data and methodology}

\section{Subjects}

The data in this study are taken from a sample of economics graduates of the Maastricht University. In 1986 and 1987 all first year students were asked to give information about their learning behaviour (Gijselaers, 1989). Scales have been constructed to measure the different components of students' learning style, each scale consisting of 6 to 10 items. The items are Likert-type. The sum score on a scale is used to reflect the score of an individual for that scale. Most scales turned 
out to be very reliable with Alpha of 80 or more. The total range of reliablity varied from 60 for globalism to .90 for fear of failure.

\section{Labour market entry indicators}

One and a lialf year after graduation, all students received a questionnaire relating to the process of labour market entry. These surveys are carried out on a regular basis by the Research Centre for Education and the Labour Market (Dutch shortcut: ROA) and studies are reported every year with cohorts of graduates of the Maastricht University (see Ramaekers, 1993 - 1996). For this analysis, data were used from the 1991 to 1995 waves: These waves comprise most of the first-year students who were in the original 1986 and 1987 learning style survey. The resulting sample consists of 156 graduates. Six indicators of labour market entry from the labour market survey are used as dependent wariables. These indicators pertain to job chances, quality of work and type of job. The dependents are:

- being employed at the date of the survey (approximately a year and a half after graduation);

- having a job within three months after graduation;

- having a permanent job (tenure);

- having a job for which an academic degree is required;

- gross monthly wages;

- having a managing, an accounting, or a research job.

Next to the indicators of labour market success, the particular job in which graduates end up is supposed to be related to the learning style. The classification of jobs into particular types is based on theoretical views used in literature on occupational choice and classifications used in labour market research. The classification of jobs for this study will be dealt with in Appendix A.

\section{Learning style data}

The leaming style data used in this chapter relate to a number of different aspects. Table 3.1 presents an overview of the different scales that are used. The scales can be divided into aspects dealing with cognitive information processing or with motivational aspects. It is beyond the scope of this chapter to explore their developmental and theoretical background. Rather, we will take their relevance as given and explore these aspects in predicting labour market entry features. 
Table 3.4

Meaning of the scales of learning style as defined by Nuy (1991)

Scales $\quad$ Description of scale content

Cognitive information processing:

Holism

Student reacts easily to new study subjects by intuitive knowledge and broad associations; ability to grasp the main point in short time

Globalism

Studying is limited to the most important points, working up to a rough view of the matter, skipping (possibly relewant) details

Extendedness

Broad versus narrow scope in exploring study content; locating answers to study questions within a wider context; taking into account different perspectives to describe the subject

Elaboration

Relating study content to preknowledge and own experience; looking for examples and applications.

Construction Active and critical incorporation of concepts and theories into a coherent and interconnected body of knowledge

Memorilizing Learning by hart; concentrating on literal recall

Atomism

Concentration on specific and isolated elements in the subject matter, which prevents reaching an overview

Motiwational aspects:

Intrinsic motivation

Interest in study content; challenged by questions and problems

Extrinsic motivation

instrumental function of studying

Achievement motivation

Need to excel; high standards of achievement

Fear of failure

Avoidance of stress and uncertainty

\section{Covariates}

For the purpose of this study, relevant covariates were considered for their effect on labour market entry as well. By using administrative data for all students, the following covariates (i.e. control variables and more specific study results or competence indicators) have been taken on board."

- male (dummy);

- age;

- study length;

- study field Business Administration, core subjects accounting \& finance (dummy);

- study field Business Administration, core subjects organization \& marketing (dummy);

- study field International Management, core subjects accounting \& finance (dummy); 
- study ireld International Management, core subjects organization \& marketing (dumamy);

- mean study results during the last two years of the graduate study program;

- masters" thesis result; grade for the individual final study project.

\section{Method of analysis}

Logistic and normal linear regression analyses will be applied with respect to the labour market indicators pertaining to job chances and quality of work for the motivational aspects and the following cognitive information processing aspects: Atomism, Elaboration, Memorizing and Construction. Multinomial logistic regression analyses will be applied to the type of job graduates obtain with respect to the following cognitive information processing aspects: Holism, Globalism and Extendedness. The reason for including just these three cognitive information processing aspects is the following: when considering the meaning of the scales as described in table 3.1 , we interpreted these scales intuitively to be possibly positive for some jobs, but at the same time possibly megative for other jobs. However, the nature of this study is explorative and we therefore do not pretend to have some fundamented reason behind this choice. On the other hand, including al॥ variables into the multinomial logistic regression analyses would not be informative, because of the large number of variables and the modest number of cases. In our opinion, for the other cognitive information processing scales, the different effects for different jobs would be less clear from their content meaning.

Analyses will be applied in a two-step model; in the first step the learning style aspects and covariates age, gender and study length are analysed for their effect on labour market entry. In the second step, the more traditional labour markett research variables are introduced into the model: study field and study results. In this way, the gross effect of learning style will be measured by the first-step model and the nett effect in relation to study related independents by the second-step-model.

\subsection{Results}

\section{Ganeral descriptive statistics}

First of all, descriptive results and plots were analysed to screen for outliers and normality.

For learning style aspects, no outhers are present and most interval variables show a near normal distribution. Table 3.2.a presents the descriptives of all variables in the analyses, and the Pearson correlations of all variables with the dependents. For detailed information on Table 3.2.a we refer to Appendix B. 


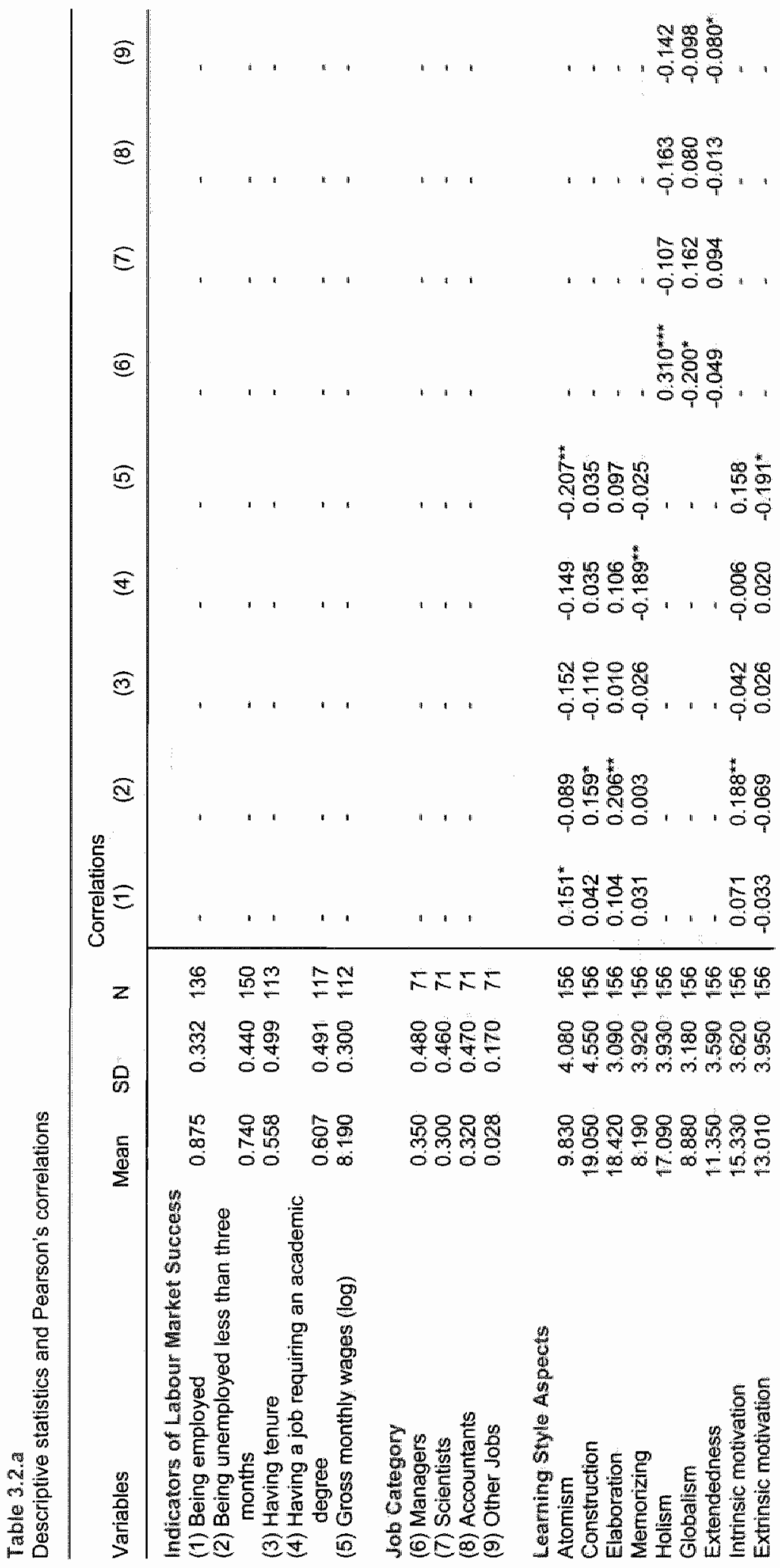




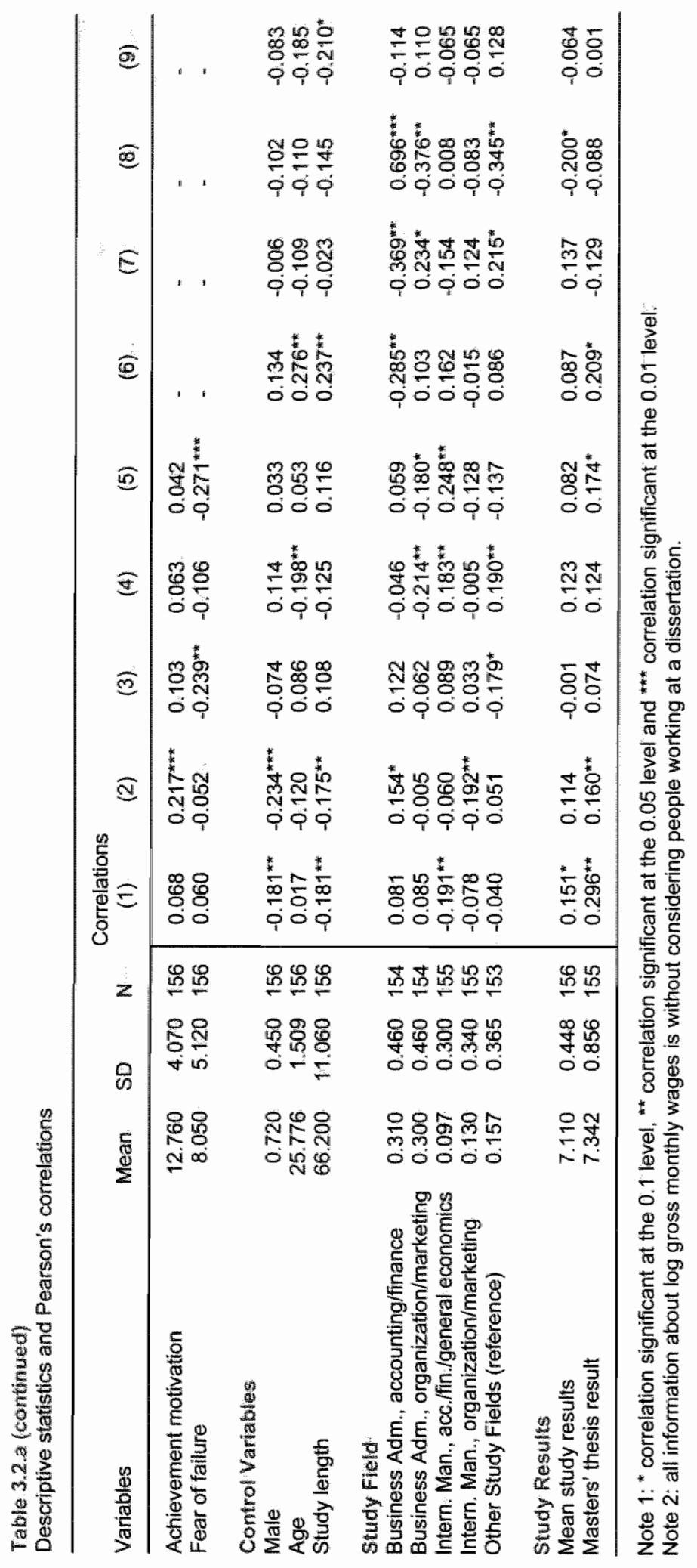


Table 3.2.b presents the Pearson correlations between learning style aspects and study results.

Table 3.2.tb

Pearson's correlations between learning style aspects and covariates

Variables Mean study results Correlations Final thesis result

Learning style aspects

Atomism

Construction

$-0.053$

0.084

Elaboration

0.010

0.013

Memorizing

0.027

0.085

Holism

$-0.174^{* *}$

0.006

Globalism

0.060

0.119

Extendedness

$-0.091$

$-0.081$

Intrinsic motivation

$-0.020$

$-0.150^{*}$

Extrinsic motivation

$-0.014$

$-0.005$

Achievement motivation

Fear of failure

$-0.197^{* *}$

$-0.053$

0.075

0.003

$-0.005$

0.050

* significant at $0.10, * *$ significant at 0.05 and *** significant at 0.01 .

As can be seen from Table 3.2.b, the correlations between the learning style aspects on the one hand and study results on the other hand are rather limited. The only significant results point to negative effects of Extrinsic Motivation and Memorizing on mean study results. With normal linear regression analyses, the effects of learning style aspects on study results has been tested; the negative effect of Extrinsic Motivation can be confirmed for mean study results. No other scales sort any effect. For the tinal thesis variable, various scales have diverse effects, which are not easy to interpret. The only scale that seems to have an effect from the bivariate correlation, Extendedness, does not have any effect on final thesis result in the regression model.

So far, the learning style scales seem not to have a clear relationship with study results, which makes the possibility that learning style affects labour market entry through affecting study results less convincing.

\section{Regression results for labour market entry chances}

Table 3.3 presents the results of the logistic regression analysis on the first dependent variable, related to job chances: being employed at the date of the survey. 
Table 3.3

Regression estimates of the effects of learning style on having a job

\begin{tabular}{|c|c|c|c|c|}
\hline & \multicolumn{2}{|l|}{ first-step model } & \multicolumn{2}{|c|}{ second-step model } \\
\hline & $\mathrm{B}$ (estimate) & s.e. & B & s.e \\
\hline Constant & -2.438 & 6.698 & $-43.804^{*+4 k}$ & 15883 \\
\hline \multicolumn{5}{|l|}{ Learning Style Aspects } \\
\hline Atomism & $0.222^{-t}$ & 0.105 & $0.358^{* *}$ & 0.156 \\
\hline Coinstruction & -0.034 & 0.092 & -0.059 & 0.125 \\
\hline Elaborism & 0.147 & 0.134 & -0.028 & 0.241 \\
\hline Memorizing & -0.116 & 0.087 & -0.159 & 0.119 \\
\hline Intrinsic Motivation & -0.062 & 0.128 & 0.132 & 0.167 \\
\hline Extrinsic Motivation & -0.109 & 0.094 & -0.137 & 0.151 \\
\hline Achievement Motivation & 0.062 & 0.087 & 0.044 & 0.136 \\
\hline Fear of Fallure & -0.048 & 0.069 & -0.134 & 0.101 \\
\hline \multicolumn{5}{|l|}{ Control Variables } \\
\hline Male & $-1.884^{*}$ & 1.103 & $-2.884 *$ & 1.494 \\
\hline Age & 0.447 & 0.310 & $1.208^{*}$ & 0.525 \\
\hline Study Length & $-0.096^{* *}$ & 0.038 & $-0.151^{\text {in* }}$ & 0.068 \\
\hline \multicolumn{5}{|l|}{ Study Flold } \\
\hline Business Adm, acc./fin. & - & - & $2.851^{*}$ & 1.458 \\
\hline Business Adm. org /mark. & - & - & 1.572 & 1.350 \\
\hline Internat. Man., acc./fin./gen.econ. & - & - & -11.639 & 1.421 \\
\hline Internat. Man., org fimark. & $=$ & - & 0.075 & 1.223 \\
\hline \multicolumn{5}{|l|}{ Study Results } \\
\hline Mean Study Results & - & - & $2.069^{\mathrm{m}}$ & 1.122 \\
\hline Masters" Thesis Result & - & - & $1.771^{* \ldots+\infty}$ & 0.644 \\
\hline \multicolumn{5}{|l|}{ Model Statistics } \\
\hline Number of cases (n) & & 136 & & 133 \\
\hline Model chi-square & & 19.573 & & 43.625 \\
\hline dif & & 11 & & 17 \\
\hline$p$ & & 0.052 & & 0.000 \\
\hline$R_{L}^{2}$ & & 0.191 & & 0.806 \\
\hline
\end{tabular}

* significant at 0.10, *** significant at 0.05 and "*** significant at 0.01 .

It appears that both models (first- and second-step model) differ significantly from the base model, in which only a constant is included. The learning style aspect Atomism has both in the first and the second-step model a significant positive effect on the odds of being employed a year and a half after graduation. To be precise, a one unit increase in the score on the Atomism scale is related to a multiplicative change in the odds of being employed of 1.25 and 1.43 respectively, which means changes up to $40 \%$. The finding of Atomism being positive related to being employed, is not intuitively clear. Taking the meaning of this cognitive aspect into 
account (table 3.1) the effect may be caused by search behaviour in which every vacant job is possibly interesting, ending up in many applications for vacant jobs and (therefore) a larger chance for success. For all other learning style aspects, no effects are found. Study results appear to have strong positive effects on the chance of having a job. And for the control variables, the larger the study length, the more detrimental it is for the chances of having a job, a year and a half after graduation. Men seem to have more difficulties in finding a job than women, and age appears to have a positive effect, although only in the second model. Finally, studying Business Administration, subjects accounting and finance, has a positive effect on the odds of having a job.

Table 3.4 presents the results of the logistic regression on having a job within three months, the next variable related to job chances.

Both the first- and second-step model appear to differ significantly from the base model. With respect to the learning style aspects, Achievement Motivation appears to have a positive effect on having a job within three months. For the other learning style aspects, no profound effects are found. Fear of failure however, seems to indicate a negative effect on finding a job within three months, which is consistent with the apparent meaning of the scale content. No effects of study results were found on this labour market indicator. Being a male seems to be detrimental though, just as study length. The effect of the latter variable disappears in the second model. Study field International Management, subjects organization and marketing, shows a negative effect.

Table 3.5 presents the results with respect to the last indicator of labour market chances: having tenure. The results are obtained with logistic regression analyses again.

Both the first- and the second-step model differ significantly from the base model. The most striking result is the negative effect of Construction with regard to its meaning. This effect could be explained by the fact that most of the academic research jobs are on a temporary basis. The negative effect of Fear of Failure is more in line with our expectations, taking the content meaning of the scale into account. Achievement Motivation shows a positive effect on this labour market indicator. And being a male seems to be detrimental again. Study field variables in the second model do lead to large differences in the odds of having tenure. Studying Business Administration, subjects accounting and/or finance, or studying International Management with the same subjects, leads to a much higher chance of having 


\section{4 - Chapuer 3}

tenure, than the other study programs. Study results, finally, do not show any effect on this labour market indicator.

Tabis 3.4

Regression estimates of the effects of learning style on having a job within three months

\begin{tabular}{|c|c|c|c|c|}
\hline & \multicolumn{2}{|c|}{ first-step model } & \multicolumn{2}{|c|}{ second-step model } \\
\hline & $B$ & s.e. & B & s.e \\
\hline Constant & 6.929 & 4.233 & -0.091 & 7.305 \\
\hline \multicolumn{5}{|l|}{ Learning Style Aspects } \\
\hline Atomism & -0.052 & 0.067 & -0.045 & 0.073 \\
\hline Construction & -0.039 & 0.071 & -0.030 & 0.077 \\
\hline Elaborism & 0.081 & 0.099 & 0.004 & 0.1113 \\
\hline Memorizing & -0.005 & 0.058 & -0.020 & 0.065 \\
\hline Intrinsic Motivation & 0.078 & 0.090 & 0.143 & 0.097 \\
\hline Extrinsic Motivation & 0.005 & 0.064 & 0.055 & 0.075 \\
\hline Achlevement Mativation & $0.118^{*}$ & 0.062 & $0.151^{* * *}$ & 0.073 \\
\hline Fear of Faillure & -0.081 & 0.052 & $-0.118^{* * i}$ & 0.059 \\
\hline \multicolumn{5}{|l|}{ Control Vartables } \\
\hline Male & $-1.645^{* *}$ & 0.627 & $-2.113^{\star * *}$ & 0.695 \\
\hline Age & -0.167 & 0.160 & -0.149 & 0.182 \\
\hline Study Length & $-0.036^{*}$ & 0.021 & -0.021 & 0.023 \\
\hline \multicolumn{5}{|l|}{ Study Field } \\
\hline Business Adm., acc./fin. & - & - & 0.552 & 0.822 \\
\hline Business Adm., org./mark. & - & - & -0.869 & 0.756 \\
\hline Internat. Man., acc./fin./gen.econ. & - & - & -1.422 & 0.920 \\
\hline Internat. Man., org./mark. & - & - & $-1.576^{*}$ & 0.869 \\
\hline \multicolumn{5}{|l|}{ study Results } \\
\hline Mean Study Results & - & - & 0.550 & 0.600 \\
\hline Masters' Thesis Resuli & - & - & 0.287 & 0.276 \\
\hline \multicolumn{5}{|l|}{ Modal Statisties } \\
\hline Number of cases $(n)$ & & 150 & & 147 \\
\hline Model chi-square & & 28.194 & & 39.737 \\
\hline dff & & 11 & & 17 \\
\hline p & & 0.003 & & 0.001 \\
\hline $\mathbb{R}^{2} L$ & & 0.164 & & 0.237 \\
\hline
\end{tabular}

" significant at $0.10, * *$ significant at 0.05 and $* *$ significant at 0.01 . 


\section{Regression results for labour market qually}

The next two variables tested in this study pertain to the quality of work. Table 3.6 presents the results of the effects on having an academic job, the first of these two variables.

Table 3.5

Regression estimates of the effects of learning style on having tenure

\begin{tabular}{|c|c|c|c|c|}
\hline & first-s & p model & secor & -step model \\
\hline & $B$ & s.e. & $B$ & s.e \\
\hline Constant & -1.005 & 4.213 & -12.267 & 7.564 \\
\hline Learning Style Aspects & & & & \\
\hline Atomism & -0.059 & 0.070 & -0.053 & 0.076 \\
\hline Construction & $-0.199^{* \star}$ & 0.087 & $-0.155^{*}$ & 0.091 \\
\hline Elaborism & 0.084 & 0.094 & 0.005 & 0.102 \\
\hline Memorizing & 0.014 & 0.059 & -0.004 & 0.065 \\
\hline Intrinsic Motivation & 0.050 & 0.094 & 0.116 & 0.101 \\
\hline Extrinsic Motivation & 0.022 & 0.070 & 0.054 & 0.079 \\
\hline Achievement Mativation & $0.1 .43^{*}$ & 0.065 & 0.089 & 0.070 \\
\hline Fear of Failure & $-0.119^{* *}$ & 0.052 & $-0.147^{* * *}$ & 0.058 \\
\hline Control Variables & & & & \\
\hline Male & -0.448 & 0.492 & $-0.95 \|^{*}$ & 0.571 \\
\hline Age & 0.042 & 0.163 & 0.138 & 0.183 \\
\hline Study Length & 0.019 & 0,022 & 0.034 & 0.025 \\
\hline Study Fileld & & & & \\
\hline Business Adm., acc./fin. & - & - & $1.842^{* * *}$ & 0.812 \\
\hline Business Adm., org./mark. & - & - & 0.413 & 0.773 \\
\hline Internat Man., acc. ffin./gen econ. & - & - & $2.008^{* * *}$ & 1.044 \\
\hline Internat. Man., org./mark. & - & - & 0.963 & 0.888 \\
\hline Study Results & & & & \\
\hline Mean Study Results & $\infty$ & - & 0.659 & 0.593 \\
\hline Masters" Thesis Result & - & - & 0.357 & 0.290 \\
\hline Model Statistics & & & & \\
\hline Number of cases (n) & & 113 & & 112 \\
\hline Model chi-square & & 19.170 & & 29.452 \\
\hline$d f$ & & 11 & & 17 \\
\hline $\mathrm{p}$ & & 0.058 & & 0.031 \\
\hline$R_{L}^{2}$ & & 0.124 & & 0.237 \\
\hline
\end{tabular}

* significant at $0.10, "$ significant at 0.05 and *** significant at 0.01 .

Both models only differ significantly at the 0.1 significance level from the base model. Memorizing appears to have a negative effect on having an academic job. In the second-step model, Elaborism shows a positive effect. A negative effect of age is present $\ddot{n}$ both models. This effect of age seems rather surprising, but is possibly 
caused by graduates who finished a study at higher vocational education before entering university. These graduates are in general older and more often inclined to look for a job at higher vocational level. Study fields within the Business Administration course seem to have detrimental effects on this labour market indicator. Study results, finally, appear to thave no effects on the odds of having an academic job.

Table 3.6

Regression estimates of the effects of learning style on having an academic job

\begin{tabular}{|c|c|c|c|c|}
\hline & \multicolumn{2}{|c|}{ first-step model } & \multicolumn{2}{|c|}{ second-step model } \\
\hline & B & se. & B & s.e \\
\hline Constant & $10.421^{k \text { kt }}$ & 4.080 & 11.852 & 7.522 \\
\hline \multicolumn{5}{|l|}{ Learning Style Aspects } \\
\hline Atomism & -0.010 & 0.066 & -0.021 & 0.071 \\
\hline Construction & -0.078 & 0.079 & -0.137 & 0.087 \\
\hline Elaborism & 0.139 & 0.091 & $0.182^{*}$ & 0.099 \\
\hline Memorizing & $-0.125^{\star \star}$ & 0.060 & -0.096 & 0.067 \\
\hline Intrinsic Motivation & 0.028 & 0.093 & 0.004 & 0.099 \\
\hline Extrinsic Motivation & 0.019 & 0.069 & 0.013 & 0.074 \\
\hline Achievement Motivation & 0.050 & 0.062 & 0.068 & 0.069 \\
\hline Fear of Fallure & -0.047 & 0.052 & -0.040 & 0.054 \\
\hline \multicolumn{5}{|l|}{ Controll Variables } \\
\hline Male & 0.685 & 0.489 & 0.559 & 0.541 \\
\hline Age & $-0.436^{* * *}$ & 0.157 & $-0.409^{* * *}$ & 0.172 \\
\hline Study Length & -0.001 & 0.022 & 0.010 & 0.025 \\
\hline \multicolumn{5}{|l|}{ Study Field } \\
\hline Business Adm., acc./fin. & - & - & $-1.469^{*}$ & 0.850 \\
\hline Business Adm. org./mark. & - & - & $-1.727^{* * *}$ & 0.845 \\
\hline Internat. Man. acc./fin./gen.econ. & - & - & 0.253 & 1.314 \\
\hline Internat. Man. org./mark. & - & - & -1.243 & 0.939 \\
\hline \multicolumn{5}{|l|}{ Study Resultis } \\
\hline Mean Study Results & - & - & -0.402 & 0.597 \\
\hline Masters" Thesis Result & - & - & 0.227 & 0.276 \\
\hline \multicolumn{5}{|l|}{ Model statistlos } \\
\hline Number of cases (n) & & 117 & & 115 \\
\hline Model chi-square & & 18.327 & & 27.302 \\
\hline df & & 11 & & 17 \\
\hline $\mathrm{p}$ & & 0.074 & & 0.054 \\
\hline $\mathrm{R}^{2} \mathrm{~L}$ & & 0.117 & & 0.214 \\
\hline
\end{tabular}

\footnotetext{
"significant at $0.10,{ }^{* *}$ significant at 0.05 and ${ }^{* * *}$ significant at 0.01 .
} 
The second variable related to the quality of work is (the log of gross monthly wages, which will be tested in the next analysis. Graduates who are in a Ph. D. programm were left out of this analysis, because their wages are fixed at a wery low level, more comparable with a student loan than with regular wages. Table 3.7 presents the results.

Table 3.7

Regression estimates of the effects of learning style on gross monthly wages (log)

\begin{tabular}{|c|c|c|c|c|}
\hline & \multicolumn{2}{|c|}{ first-step modell } & \multicolumn{2}{|c|}{ second-step model } \\
\hline & $\mathrm{B}$ & s.e. & & 8.0 \\
\hline Constant & $8.445^{* * * * *}$ & 0.049 & $7.624^{* * *}$ & 0.740 \\
\hline \multicolumn{5}{|l|}{ Learning Style Aspects } \\
\hline Atomism & -0.002 & 0.008 & -0.006 & 0.008 \\
\hline Construction & $-0.018^{*}$ & 0.009 & $-0.019^{* i k}$ & 0.009 \\
\hline Ellaborism & 0.001 & 0.011 & 0.001 & 0.011 \\
\hline Memorizing & 0.001 & 0.006 & 0.005 & 0.007 \\
\hline Intrinsic Molivation & $0.023^{\text {s.x }}$ & 0.010 & $0.022^{\star \star x}$ & 0.010 \\
\hline Extrinsic Motivation & -0.009 & 0.008 & -0.008 & 0.008 \\
\hline Achievement Motivation & 0.005 & 0.007 & 0.005 & 0.007 \\
\hline Fear of Failure & $-0.014^{* * k}$ & 0.006 & $-0.012^{*}$ & 0.006 \\
\hline \multicolumn{5}{|l|}{ Control Variabies. } \\
\hline Male & 0.029 & 0.054 & -0.009 & 0.056 \\
\hline Age & -0.001 & 0.017 & 0.010 & 0.018 \\
\hline Study Length & -0.001 & 0.002 & 0.001 & 0.002 \\
\hline \multicolumn{5}{|l|}{ Study Field } \\
\hline Business Adm., acc./fin. & - & - & 0.025 & 0.085 \\
\hline Business Adm., org./mark. & - & - & -0.106 & 0.083 \\
\hline Internat. Mlan., acc/fin./gen econ. & - & - & 0.175 & 0.105 \\
\hline Internat. Mlan., org./mark. & - & - & -0.071 & 0.096 \\
\hline \multicolumn{5}{|l|}{ Study Results } \\
\hline Mean Study Results & - & - & 0.024 & 0.059 \\
\hline Masters' Thesis Result & - & $\therefore$ & 0.041 & 0.033 \\
\hline \multicolumn{5}{|l|}{ Model Statistics } \\
\hline Number of cases (n) & & 105 & & 103 \\
\hline Adj. $R^{2}$ & & 0.065 & & 0.139 \\
\hline $\mathrm{F}$ & & 1.662 & & 1.973 \\
\hline p & & 0.095 & & 0.022 \\
\hline
\end{tabular}

"significant at 0.10, " significant at 0.05 and *** significant at 0.01 .

Only the second-step model differs significantly from the base model at the 0.05 level. Intrinsic Motivation shows a stable positive effect on wages. Fear of failure 
shows a negative effect on wages in both models. Construction shows a negative effect on wages as well, for which no clear argumentation can be given. No effects of study results and control variables are found.

\section{Regression results for obtaining different jobs}

To test the effect of the remaining three cognitive learning style aspects on labour market position, a different perspective is used. To see whether high scores on these different aspects would lead to (preference for) a different type of job, multinomial logistic regression is applied, again following the two step method of all other analyses, with exception of the inclusion of the variable study field. Study field is considered to be related to the type of job people obtain, because of relevance of the content. It is considered to be an important selection device for employers. In this way a match between study field and type of job is obvious. Table 3.8.a shows the relation between study field and type of job.

Table 3.8.a

Crosstabulation of study field wih job category

Job category

Study field

managing job accounting job research job

totall

Business Adm. ,acc./finance

Business Adm., org./ marketing

Int. Man., acc/fin./gen.econ.

Int. Man., org./marketing

totall

3
7
5
3
18

17

0

3

2

18

22

1
8
1
4
14

21

15

9

9

54

As can be seen from Table 3.8.a, accountants and other employees from the accountant job category are recruited almost exclusively from the study field accounting and finance. Researchers are in general recruited from the study fields. organisation and marketing. Only in the case of management jobs recruitment takes. place from all possible study fields. Considering the high correlation between study field and type of job we expect that any effect of learning style on the type of job will be mediated through the choice of a specific study field. As we are interested merely in the gross effect of learning style on type of job, we decided to leave the study field variable out of the analyses altogether. Table 3.8.b presents the results of the analysis. 
Table 3.8.6

Estimates of the effects of learning style on having an accounting job and a research job compared to having a managing job

first-step model second-step model
accounting research accounting research

estinate s.e. estimate s.e. estimate s.e. estimate s.e.

$\begin{array}{lcccccccc}\text { Constant } & -9.957 & 6.724 & 0.217 & 6.446 & -12.050 & 10.193 & 14.725 & 9.835 \\ & & & & & & & & \\ \text { Learning Style Aspects } & & & & & & & \\ \text { Holism } & 0.186^{*} & 0.102 & 0.001 & 0.101 & 0.167 & 0.104 & 0.032 & 0.107 \\ \text { Globalism } & -0.216^{* *} & 0.105 & -0.065 & 0.100 & -0.210^{*} & 0.107 & -0.063 & 0.105 \\ \text { Extendedness } & -0.152 & 0.102 & -0.079 & 0.100 & -0.184^{*} & 0.105 & -0.108 & 0.106 \\ & & & & & & & & \\ \text { Control Variables } & & & & & & & & \\ \text { Male } & -0.122 & 0.392 & 0.139 & 0.340 & -0.139 & 0.398 & 0.087 & 0.359 \\ \text { Age } & 0.384 & 0.275 & 0.130 & 0.273 & 0.380 & 0.276 & 0.025 & 0.277 \\ \text { Study Length } & 0.008 & 0.036 & -0.029 & 0.035 & 0.012 & 0.038 & -0.059 & 0.041\end{array}$

Study Results

Mean Study

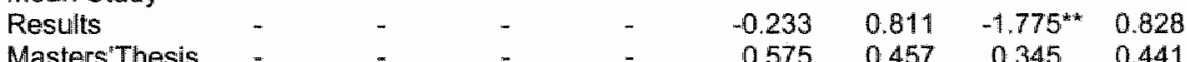

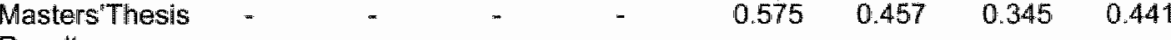

Result

Model statistics

Number of

cases $(n)$

$-2 \log$

Liketihood

" significant at $0.10, * *$ significant at 0.05 and *** significant at 0.01 .

As can be seen from Table $3.8 . \mathrm{b}$, in both models effects of learning style aspects are present. In the analysis managing jobs are the reference category. The analysis tests the effects of the independents on the chance to obtain a job from the accounting job category or the research job category, in comparison with the managing job category (for more information about the job categories see appendix A). The effect of Holism in the first model points to a positive effect of a high score on the Holism scale on entering an accounting job. No effect appears for entering a research job (in comparison with a manager"s job). The effect of Holism is only significant at the 0.1 level and disappears in the second model, however. Globalism shows a negative effect on entering an accounting job in both models. This would mean that scoring high on the Globalism scale would decrease the chances for entering an accounting 
job, in comparison with a manager"s job, which is consistent with our expectation based on the content meaning of the scale; being accurate and precise is extremely important in accountant jobs. Globalism would not be convenient in such jobs. For managing jobs, however, Globalism is (sometimes) inevitable and therefore nuch more useful. Extendedness shows a negative effect on entering an accounting job in comparison with a manager's job in the second model at the 0.1 level. Again, no effect for entering a research job is found. With respect to the covariates, no effects are found. Higher mean study results, however, seem to be detrimental for entering a research job in the second astep model. This seems rather surprising. Apparently, people with better study results do enter more managing and accounting jobs than research jobs.

To summarize the most important results of this chapter, Table 3.9 presents the significant outcomes for the learning style and study results variables.

Talble 3.9

Results of the analyses

Dependents

Independents

Being Being un- Hawing Having an Gross accoun- research employed employed tenure academic monthly ting job job $<3$ mths job wages category category

Learning Style Aspects

Atomism

Construction

Elaboration

Memorizing

Holism

Globalism

Extendedness

Intrinsic motivation

Extrinsic motivation

Achievement motivation

Fear of failure

$\begin{array}{lllll}x+ & x & x & x & x \\ x & x & x- & x & x- \\ x & x & x & x+ & x \\ x & x & x & x- & x\end{array}$

Study Results

Mean study results

Masters' thesis result

$\begin{array}{lllll}x & x & x & x & x+ \\ x & x & x & x & x \\ x & x+ & x+y & x & x \\ x & x- & x- & x & x-\end{array}$

$\begin{array}{ll}x+ & x \\ x- & x \\ x- & x\end{array}$

$x=$ the independent variable is included in the analysis.

* = effect of the independent variable is positive.

$=$ effect of the independent variable is negative. 
As can be seen from Table 3.9, learning style aspects affect both labour market entry success and type of job. Study results in fact only affect the indicator of having a job in general and obtaining a research job in this study. The effect of study results on having a job seems independent from the effect of the learning style aspect Atomism; the effect of Atomism does not disappear when the study related varialbles are introduced into the model. However, for the other dependents no profound effects of study results are found at all. The only learning style aspect that appeared to correlate with study results was Memorizing. However, for obtaining an academic job, Memorizing shows a stable negative effect, while study results do not show any effect at all.

Based on the content meaning of the scales, the effects of the motivational aspects of learning stylle seem rather straightforward, whille the effects of the cognitive information processing aspects are far more difficult to explain. In the following and last section, the results of this explorative study will be considered for some conclusive remarks.

\subsection{Conclusion}

In this explorative study the effects of learning style aspects on labour market entry success and type of job have been explored. The following conclusions can be drawn.

Aspects of cognitive information processing appear to affect both labour market chances and quality. Getting an academic job is the one indicator affected by only cognitive learning style aspects; a negative effect of Memorizing and a positive effect of Elaboration appeared. Since Memorizing correlates with study results within our sample, the effect of this aspect seems all the more important. Introducing the study results variables into the model did not diminish the effect of Memorizing, nor revealed an effect of study results variables themselves. The effects of information processing aspects for the other indicators of labour market success were more difficult to interpret. Motivation seems important for both job chances and quality of work. We found positive effects of Intrinsic and Achievement Motivation and negative effects of Fear of Failure, all reasonable to explain. Extrinsic Motivation shows no effect, which in fact means that it has no detrimental effect for labour market entry success.

With respect to the relation between learning style and type of job, the results were not conclusive. Globalism appears to have a negative effect on entering an accounting job in comparison with a managing job, for which we could give some 
reasonable explanation. We also found a positive effect of Holism and a negative effect of Extendedness on entering an accountant job, in comparison with a managing job. Both effects are not intuitively clear.

Study results only show an effect on the chance of being employed at the time of the survey. For the other indicators of labour market entry success no significant effects were found. This striking outcome seems to suggest that the effects of learning style aspects are more important for explaining labour market entry success than the more traditional indicators of human capital, like study results.

However, careful choice of the instrument to measure learning style is warranted. Recent findings indicate relevant aspects of learning style as metacognition or self-regulating activities. These aspects seem to be very important in learning outcomes (Schouwenburg; 1996; Simons, 1997). Possibly, they will be important in labour market functioning as well. These aspects were not ineorporated in the assessment of learning style used in this study.

Further, aspects of the learning style concept can be considered fundamental individual characteristics themselves, like personality traits and differences in brain functioning. The value added by using the learning style concept should therefore be clearly distinguished from these other concepts and possible measurements in further research.

Related to other shortcomings of this study we like to mention that only economics graduates have been taken into account. And the effects of the indicators of knowledge, skills and learning style have only been measured shortly after graduation.

Despite the limitations of the study, we think the results are promising. The findings indicate the importance of a generic type of competence, i.e. individual differences in cognitive information processing and motivational aspects for labour market research. This effect seems more important than the effect of the study results, for which we found only an effect on one of the indicators of labour market success. We think that linking the educational concept of learning style with labour market research reveals promising possibilities in extending both research fields. This is extremely important for both fields, now arriving at the point of integration, forced by the recent developments in the working environment. 


\title{
4 Economics graduates' personality characteristics and labour market entry ${ }^{+}$
}

\begin{abstract}
Summary
In this chapter, we explore the value of personality characteristics in explaining success in labour market entry with a sample of graduates in economics. Specifically, the study addresses the following two-fold research question: does personality explain labour market outcomes, and how much weight does this 'generic' factor have compared to traditional human capital and individual preference variables such as study results, study field and demographic characteristics? Personality is measured both by separate indicators for traits as well as by so-called 'profiles', based on combinations of these indicators. The results show that both measurement methods reveal significant personality effects, which are independent from the effects of traditional human capital variables, such as grade point averages (GPA's) in the academic program, and work experience. A key finding is that both types of factors have their own and independent effect on labour market outcomes.
\end{abstract}

This chapter thas been adapted from:

Semeijn, J.H., Boone, C., Velden, R. van der \& Witteloostuijn, A. van (2005), Graduates" personality characteristics and labour market entry; an empirical study among Dutch economics graduates, Economics of Education Review, 24 (1), pp. 67.83. 


\subsection{Introduction}

Due to rapid technological developments and the expanding international orientation of many organizations, labour market demands have changed. Working environments require people to be more flexible in order to keep up with the continuous changes and developments inside and outside the organization. This is reflected in personnel selection practices, where more and more emphasis is put on so-called 'soft' factors and 'generic" competencies such as communication skills and personality features (Spencer \& Spencer, 1993). Work settings are less structured and productivity is more dependent on individuals" contributions through, e.g., interpersonal communication and teamwork. This dependency requires different skills and competences from people, which are not automatically acquired in the traditional educational context (Boyatzis, Cowen, Kolb and associates, 1995). These new key qualifications are also called generic competences (Nijhof, 1998). Examples of these generic requirements and the importance of personality features for job selection can be found in many job advertisements in magazines and papers. Catchy lines like "a solid personality required", "independence and flexibility are requirements" and "we are looking for an ambitious, enthusiastic personality" are part of the job ads, time and again.

Notwithstanding these observations, the importance of these new generic requirements for the labour market have only recently been recognized as such, and have not yet (fully) been integrated into the research models and explanations for labour market performance. In so far as personality received attention in the context of work-related issues, most studies have been conducted in the field of organizational research. In this latter research domain, mainly the relationship between employee personality and job performance has been studied. The purpose of this chapter is to analyse the importance of personality features for early labour market performance, next to and on top of more specific kinds of competences, characterized by normal human capital variables such as the grade point averages (GPA's) in the academic program followed, relevant work experience and study field. So, this study will address the following two-fold research question: to what extent does personality predict labour market outcomes of graduates in economics, and how much weight does this effect have compared to traditional human capital variables such as study results and study field? Additionally, we discuss the possible theoretical explanations for the effects of graduates' personality on labour market outcomes. 


\subsection{Theoretical background}

In the nineties of the last century, number of large meta-analytic neviews into the value of personality measures revealed acceptable and promising results in explaining and predicting work-related outcomes (e.g., Barrick \& Mount, 1991; Tet, Jackson \& Rothstein, 1991). These findings, in fact, reflect the growing importance of personality measures for job selection at that time, which triggered a renewed interest in using personality constructs for research in the context of work. Nicholson (1996) mainly discusses the relevance of personality research for organizational settings in terms of person-environment fit (matching), personal change and employee development. Although issues of personality linve gained serious attention in organizational research, the effects of personality features on (early) labour market outcomes for those who enter the labour market for the first time have been poorly addressed. There are a few studies into the effects of personality (i.e., psychological human capital) on wages (e.g., Filer, 1981; Goldsmith, Veum \& Darity, 1997; Duncan \& Dunifon, 1998; Murnane, Willett, Braatz \& Duhaldeborde, 2001). However, other labour market outcomes have barely been considered at all, as yet. Since the importance of personality characteristics in personnel selection practices is evident, this type of research could fill an important gap in both the organizational (work) and labour market literatures.

Without any prior theoretical restrictions, given the lack of earlier work, we decided to merely explore the various possible relationships between personality features and labour market outcomes. For this purpose, an explorative conceptual research model is formulated that captures the possible effects of personality characteristics on early individual labour market success. This model is sumnarized in Figure 4.1. For the sake of simplicity, standard control variables such as age and gender are left out in the research model (but not in the empirical analyses).

Filer (1981) already presented a comparable framework in the context of a test for the effects of "affective" human capital, next to traditional variables, on wages. The "human capital variables" construct in our scheme refers to traditional learning. and educational outcome measures. On the one hand, as suggested by Figure 4.1, personality features can have a direct effect on labour market outcomes, which is illustrated by Arrow 1. In this way, personality characteristics have their own undependent effect on labour market success (or failure, for that matter), for example, because employers use personality impressions and personality tests as direct screening devices in the selection of new employees (Spencer \& Spencer, 1993; Smith \& George, 1994). On the other hand, personality features could have an indirect effect on labor market outcomes. This indirect effect may come through two different routes. 


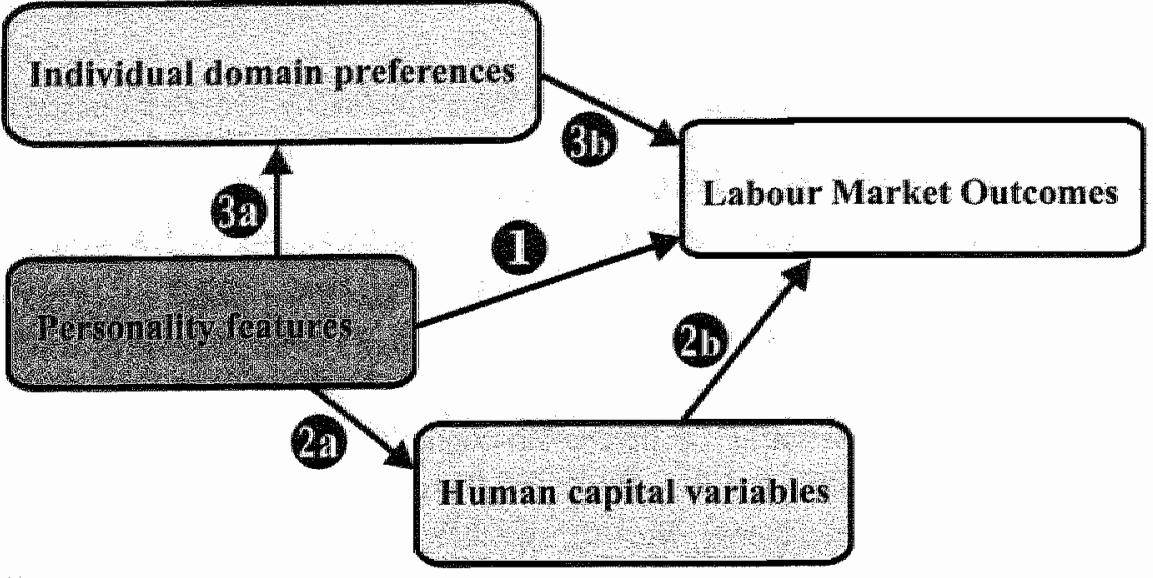

Figure 4.1

Conceptual relationship between personality and labour market outcomes.

First, personality characteristics are known to affect learning outcomes (Borg \& Shapiro, 1996; Timmers, 1997). In turn, educational achievements are considered to influence labor market outcomes, as extensively argued in traditional labour market research. This indirect relationship is illustrated by Arrow 2a-b. Human capital theory (Becker, 1964) indeed argues that the level and type of education are the main sources of productivity of people in the labour market. With respect to the impact of the human capital variables, another possible route for indirect personality effects is suggested by the screening theory in labour market research. This theory suggests that employees are selected on the basis of the level and type of education followed. That is, for employers, education is an ex ante indicator of the ex post 'trainability' of the potential employees, as well as of other 'desired innate capabilities that enhances the capacity to become productive' (Thurow, 1975). After all, real productivity is to be ex post acquired on the job. In this context, the selection on the basis of educational outcomes might reflect the selection on 'innate capabilities" that may well refer to personality characteristics.

Second, personality features can have an indirect impact on labour market outcomes via associated differences in individual preferences as far as study fields, job characteristics and organization types are concerned. This route, indicated by Arrow $3 a-b$, is therefore not dealing with employer selection behaviour, but rather with the choices made by potential employees. More specifically, Schneider (1987) argues that people are attracted to certain jobs (and organizations, for that matter) that fit their personality traits. When we follow this line of thought, the attraction can start with the choice of a certain field of study (or specialization track therein), to continue with attraction to certain jobs and/or organizations. That is, personality 
features are associated with spectific mdividwal domain preferences in terms of, specifically, study fields, job characteristics and organization types.

Based on these theoretical considerations, we will test the following hypothesis:

Personality features have an effect on labour maxket outcomes, net of traditional human capital wariables (e.g., study results) and individual domain preferences (e.g., study fields).

As said, given the lack of earlier work, we refrain from formulating specific hypotheses about the labour market effects of specific personality features. Rather, we let the data speak, which implies that the current study must be regarded as an explorative steppingstone for more in-depth future work.

\subsection{Data and Methodology}

Personality measurement

Various definitions of personality float around in the literature (Pervin, 1990). They differ as to their underlying theoretical assumptions, as well as in terms of their usefulness in empirical work. We propose a working definition that reflects the use of the personality constructs in this study: personality is defined as a rather stable trait, or set of traits, of people that directs their behaviour in different situations. A recent study concludes that personality displays modest continuity from childhood to adulthood, with the consistency in personality increasing with age (Caspi \& Roberts, 2001). Personality measures that are frequently used in empirical studies into the relationship between personality features and work characteristics are the so-called Big Five personality constructs (Tett, Jackson \& Rothstein, 1991). Factor-analytic research has revealed that these constructs (agreeableness, conscientiousness, emotional stability, extraversion and openness to experience) cover the broad domain of personality to a large extent (Barrick \& Mount, 1991; Robbins, 1996). However, other scholars argue that different, more specific personality constructs are useful as well, or even more useful, for work-related research because hypotheses with respect to work-related outcomes can be specified in greater detail when using specific personality constructs (Robertson, 1994). A number of specific personality constructs have gained substantial credibility in the area of work-related studies, prominent examples being "locus of control" (Boone, De Brabander \& van Witteloostuijn, 1996), "type A behaviour" (Tett et al, 1991), "sensation seeking" (van den Berg, 1992), and "self-monitoring" (Kilduff \& Krackhardt, 1994). These constructs are often mentioned in handbooks and textbooks of organizational behaviour (e.g., Robbins, 1996), having a solid research history. They are associated 
with acceptable values of validity and reliability in work-related research. The above four specific personality constructs will be used in this study, too.

Locus of control refers to the individual's generalized belief in internal versus external control of reinforcements. The concept was first introduced by Rotter (1966) in his social leaming theory. He distinguishes people who believe that events are uncontrollable and that achievements are merely based on luck or the influence of other people or institutions (externals) vis-à-vis people who believe that they can influence their environment and that achievements do depend to a large extent on their own efforts (internals). Research conducted with this concept in relation to job functioning has concentrated on several different features, such as job satisfaction, absenteeism, job involvement and tumover (Spector, 1982; Blau, 1987). Generally speaking, internals seem to perform better in their jobs. However, differences between different kinds of jobs should be taken into account: internals seem to do well in complex tasks and in jobs which require initiative and independence, whereas externals seem to be better performers in structured, routine tasks and in jobs which require compliance (Robbins, 1996). With respect to a prominent issue in labour economics, internality appears to have an indirect and positive effect (via self-esteem) on wages (Goldsmith et al., 1997).

Type A behaviour pertains to a behavioural pattern characterized by being in a hurry and trying to achieve more in less time. People with type A behaviour are associated with impatience, hostility, a high level of competitiveness and a consitant feeling of time urgency. In fact, this behavioural pattern has been recognized to stimulate coronary heart disease prone behaviour. Type A behaviour measures are therefore used to screen people in the context of health research (Friedman \& Rosenman, 1974; Appels, 1985). More recent research has questioned the relationship between type A behaviour and heart disease (Gleick, 1999). This research does not refute the type $A$ personality, just the relationship with heart disease. Research conducted with this concept related to job functioning has revealed that type A's are fast workers, who emphasize quantity over quality and who tend to make poor decisions because they make them too fast. In managerial positions, these characteristics are rarely desirable to reach the top positions (Friedman \& Rosenman, 1974). However, great salespersons are often associated with type $A$ behaviour. So, the continuous urge for achieving more in less time seems useful in particular labour market segments. Situational and organizational preferences of type A's are found to be associated with high performance standards, and the need to display effort (Burke \& Deszca; 1982; Feather \& Volkmer, 1988).

Self-monitoring involves the ability of peoplle to adapt their self-presentation to the requirements of the environment or situation. It is therefore related to a person's sensibility for what is considered appropriate or desirable expressive 
behaviour in different situations. It involves the ability to control and alter this behaviour (Snyder, 1974). People scoring high on this trait can alter their expressive behaviour according to the social requirements, despite feeling quite differently inside. People scoring low on this trait do behave more according to their own inner state of mind so that their expressive behaviour is more in line with their own feelings and thoughts, without bothering much about what would be appropriate in a social sense. High self-monitoring could be very useful in jobs which are associated with different roles (e.g., managerial jobs) or which require public appearance (e.g., sales jobs). At a general level, it seems that self-monitoring can enhance an individual's chances to obtain career suecess in organizations (Kilduff \& Krackhardt, 1994). Research with respect to the effect of self-monitoring on managerial career success reveals that high self-monitors achieve more crosscompany promotions than low scorers, and obtain more internal promotions when they stay with the same employer (Kilduff \& Day, 1994). Furthermore, high selfmonitors appear to be more active in searching for information about potential employers than low self-monitors (Snyder \& Copeland, 1989).

Sensation seeking relates to the motivation to experience sensation (Zuckerman, 1979a; 1991; Feij \& van Zuilen, 1984). People scoring high on this trait are characterized by a continuous need to experience new and varied, arousal triggering, events. They therefore like unpredictable and risky situations, whereas people scoring low on this trait prefer more predictable and stable environments. High scorers have a high level of arousal tolerance, whilst low scorers are associated with low arousal tolerance. This difference seems to have a biological basis (Zuckerman, 1979a). Research with respect to this personality characteristic and job functioning has focused on job preference and job fit, but also on job performance and work satisfaction. Additionally, the relationship with the job search process has been studied empirically (van den Berg, 1992). That is, sensation seeking has been related to the ease and speed of finding a job, indicating that high sensation seekers find a full-time job faster than low sensation seekers do (Cellini \& Lorenz, 1983). There are also signs that high sensation seeking is associated with success in higher management jobs (Franken, 1988).

This staccato review of earlier work reveals that the above four personality constructs have all been studied in different empirical settings and for answering different work-related research questions (Robbins, 1996). Research has produced linear relationships between these personality constructs and indicators of overall work performance, as well as with a series of more specific work-related outcomes. In practice, however, the importance of the personality of individuals is based on at particular combination of personality characteristics, summarized in so-called profiles. In this profile context, the effects of the underlying traits may not be linear. 
The literature observes a need to deepen our understanding of the combined effect of different personality characteristics, and the shape of the relationship between personality factors and aspects of work behaviour, to make further progress in unravelling the value of personality for work (Robertson, 1994; Nicholson, 1996). Until now, much research seems to merely analyse the effects of separate personality traits in the working context, even when using the Big Five personality instruments (e.g., Barrick \& Mount, 1993; De Fruyt \& Mervielde, 1999; Boudreau, Boswell \& Judge, 2001). Therefore, in the analyses within this study, the above four personality traits will be used both separately and combined into so-called personality profiles (as produced by cluster analysis).

\section{Subjects and sample data}

This study was conducted with a sample of economics graduates. For 137 persons, we gathered measures of all four separate personality characteristics before their graduation in the period 1993-1995 in the context of skills and training courses that were then part of the studly program (Boone, De Brabander \& van Witteloostuijn, 1999). To enlarge the sample, additional personality data have been collected after graduation for 200 graduates as well. In total, complete personality data are available for 308 graduates. For 42 persons, personality measures are available twice or even three times. This group has been used to conduct test-retest reliability analyses with respect to the personality constructs used here. For the purpose of this study, the personality data gathered during the study program are most valuable. For predicting labour market success during the entry phase, the personality data should be collected in advance to be sure that the direction of any association goes from personality features to labor market performance, rather than the other way around. Luckily, the results of the test-retest correlation analyses within our sample confirm the well-established assumption that personality characteristics are rather stable over time and over situations (e.g., Hogan, Hogan \& Roberts, 1996). Therefore, to increase the sample size, we decided to supplement the sample of pre-graduation personality data with additional information gathered after graduation whenever pregraduation personality measures were not available. As a second check, analyses with the four separate personality scales have been conducted for labour market outcomes while controlling for the effect of old and new cases by introducing dummy variables indicating old and new cases for all variables in the analysis. As no significant differences were found in the estimated effects of personality profiles or traits for old vis-à-vis new cases, only the results of the analyses with the complemented sample will be reported here. 


\section{Measures}

Locus of control has been measured with a Dutch translation of the Rotter locus of control scale (Rotter, 1966). Whereas the original scale contains 29 forced-choice items, the translated version has 37 items. The difference pertains to the amount of filler-items, which are included to obscure the purpose of the test. In the Dutch translation, there are 8 filler items more (producing a total of 14 filler items). We obtained a total locus of control score by counting the external alternatives chosen from the 23 forced-choice locus of control items (0-23). Thus, high scores imply an external orientation. An example of an item from the scale is the following: "The things that happen to me are the consequence of my own behaviour" (internal alternative) versus "Sometimes I feel I have too little control over the direction in which my life develops"(external alternative). The reliability (Cronbach's alpha) and validity (test-retest correlation) of the Dutch translated version have been demonstrated with acceptable values in several studies (Boone, De Brabander, Gerits \& Willemé, 1990; Boone, 1992; De Brabander, Boone \& Gerits, 1992). In our sample, the reliability of the scale (Cronbach's alpha) is $0.74(\mathrm{n}=325)$, which is rather satisfying. The test-retest conelation in our sub-sample is $0.61(n=42)$, which is acceptable, considering the large test-retest time span of about two to three years. Normally, retesting takes place in about two weeks to one month (Nicholson, 1996; Goldsmith et al., 1997). Test-retest correlations reported by Rotter amount to 0.72 for elementary psychology students $(n=60)$ within a one-month period, and to 0.55 $(\mathrm{n}=\mathbb{1 1 7})$ in a two-month period (Rotter, 1966).

Type A behaviour has been measured by a Dutch adaptation of the original Jenkins Activity Survey (JAS) (Appels, 1985). The adapted version contains 24 forced-choice items with some response categories being indicative of type A behavior, and others not. The indicative responses are valued with score 1 and the others with score 0 , implying a total score range that runs from 0 to 24 . An example of a survey item is the following: "Are you in a hurry when you have to go somewhere, even when you have enough time?" The Dutch JAS reveals salisfactory levels of reliability (Cronbach's alpha) and validity (Appels, 1985). In our sample, the reliability (Cronbach's alpha) is $0.76(\mathrm{n}=329)$, and the test-retest correlation in our sub-sample is $0.65(\mathrm{n}=42)$.

Self-monitoring has been measured with a Dutch translation of the 18-item self-monitoring scale (Snyder \& Gangestad, 1986). Respondents are asked to consider the 18 statements as true or false (forced choice), in their opinion. In fact, there are no true or false answers. The total score can be obtained by counting the number of high self-monitoring answers (in the 0 - 18 range). An example of a selfmonitoring item is: "I find it hard to copy the behaviour of others". "The level of validity has been demonstrated to be sufficiently high (Snyder \& Gangestad, 1986). 
The reliability of the instrument in our sample (Cronbach's alpha) is $0.65(\mathrm{n}=332)$. Test-retest correlation within our sub-sample is rather low $(0.57$, with $\mathrm{n}=42)$, though. Taking into account the small number of cases in the sub-sample and the large interval time, we decided nevertheless to consider this to be acceptable.

Sensation secking has been measured with the so-called Excitement Need List (Spanningsbehoeftelijst": SBL), developed by Feij and Van Zuilen (1984). This is a Dutch translation of the American Sensation Seeking Scale (Zuckerman, 1979b). The SBL consists of 51 sensation seeking items and 16 filler items, for which tespondents have to indicate on a five-point scale to what extent they (dis)agree with the statements. An example of a statement is: "Camping in a lonely area under primitive circumstances seems a great experience to me". The composite total sensation seeking score is obtained by summing the scores for the individual items (in the $0-51$ range). The reliability (Cronbach's alpha) and validity levels of the scale have been demonstrated to be satisfactory (Feij \& van Zuilen, 1984). In our sample, the reliabillty level is very satisfactory, too, with a Cronbach's alpha of $0.84(\mathrm{n}=$ 323). Test-retest correlation within our sub-sample is a high $0.82(\mathrm{n}=41)$.

In combination with the available labour narket data the sample size decreases from 308 to 171 graduates. To check for possible biases in the personality scores of people for whom labour market data are available compared to those for whom no datta are avallable, significance of differences in personality scores are estimated for the four constructs with analyses of variances. Only a significant higher score for sensation seeking is found for the group for whom labour market data are available. We must keep this finding in mind in the discussion of the results. In this context, recall that earlier research related (higher) sensation seeking (positively) to the ease and speed of finding a job.

In ordei to neasure the effect of personality profiles on labour market outcomes, the available scores on the specific personality constructs in our study sample have been submitted to four $\mathbf{K}$-means cluster analyses with two to five clusters. The four or five-cluster solution reveals the best results with respect to explained variance in the scores on the four separate personality scales. In Table 4.1, these explained variance percentages are presented.

However, because of the small amount of cases remaining in the clusters in the fivecluster solution when conducting labour market analyses, we decided to opt for the four-cluster" solution in the further analyses. Table 4.2 shows the descriptives of the four-cluster solution. 
Table 4.1

Results of cluster analyses with 2-5 clusters for the personality constructs used

Explained variance (\%) in personality scores for several cluster solutions

\begin{tabular}{lcccc}
\cline { 2 - 5 } & $\begin{array}{c}\text { Two-cluster } \\
\text { solution }\end{array}$ & $\begin{array}{c}\text { Three-cluster } \\
\text { solution }\end{array}$ & $\begin{array}{c}\text { Four-cluster } \\
\text { solution }\end{array}$ & $\begin{array}{c}\text { Five-cluster } \\
\text { solution }\end{array}$ \\
\hline $\begin{array}{l}\text { Type A behaviour } \\
\text { Locus of control }\end{array}$ & 45.1 & 60.5 & 60.8 & 73 \\
Sensation seeking & 32.5 & 52.3 & 59.6 & 58.7 \\
Self-monitoring & 10.1 & 9.2 & 13.7 & 13.7 \\
N of clusters: & 7.5 & 9.5 & 30.1 & 34.1 \\
& $1=139$ & $1=102$ & $1=63$ & $1=100$ \\
& $2=169$ & $2=92$ & $2=80$ & $2=62$ \\
& & $3=114$ & $3=81$ & $4=65$ \\
& & & $4=84$ & $5=43$ \\
N off total sample: & 308 & 308 & 308 & 308 \\
& & & & \\
\hline
\end{tabular}

Table 4.2

Descriptives for personality traits in each cluster

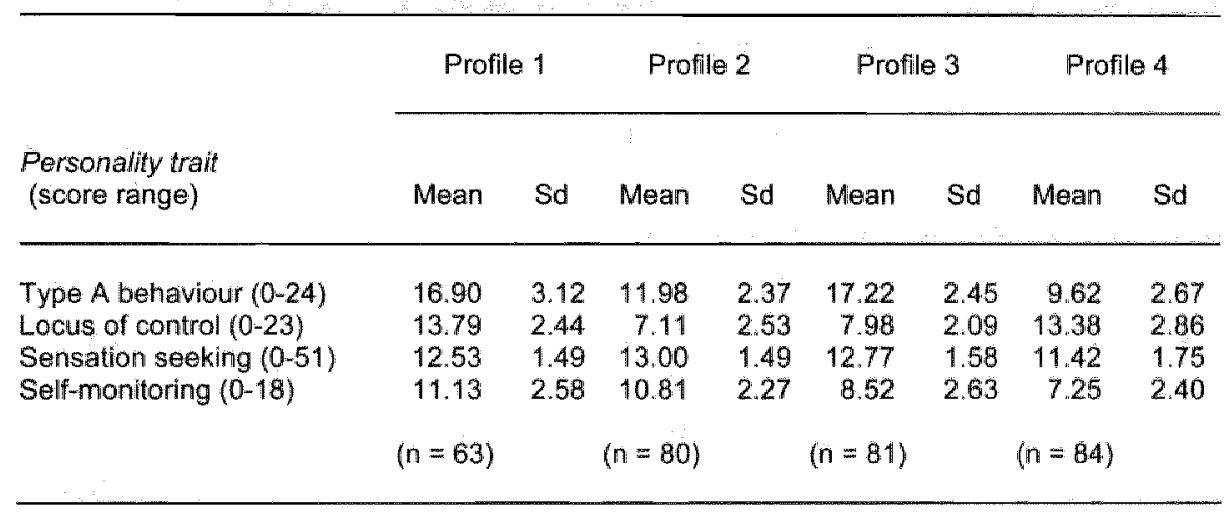

Based on the content meaning of the separate personality measures, the cluster (profile) scores can be interpreted as follows:

1. Profile $I$ involves ambitious, external individuals, who do not particularly favour sensation seeking and who like to adapt their behaviour according to the perceived (social) requirements of the environment.

2. Profile 2 relates to less ambitious, internal individuals, who have comparable scores on sensation seeking and self-monitoring as profile 1 individuals. 
3. Profile 3 is associated with ambitious, internal individuals, who score comparable on sensation seeking as the profile 1 and 2 individuals, but who are less adaptive to the perceived (social) requirements of the environment.

4. Profile 4 pertains to unambitious, external indrviduals, who score the lowest on sensation seeking (for that matter) and who are the least adaptive to the perceived (social) requirements of the environment.

As a check, the cluster analysis has been conducted for the reduced personality sample group $(n=171)$, too. Comparable results appear for the content meaning of the then resulting clusters. The percentage of cases per cluster remains comparable as well.

In our view, these profiles seem to make sense, as they describe and represent imaginable existing individuals. This provides face validity for our profile measure (Robertson, 1994). For profile 1, we might think of a rather nervous, hard-working individual who is trying and willing to keep the boss satisfied, possibly related to a preference for extrinsic rewards. In part, this profile seems to fit 'young starters' (for example, in research, sales or management), although after a while the profile may raise some 'career' trouble. Environmental changes may confuse the profile individual, who then starts to face problems in finding intrinsic rewards and in developing independency and self-confidence. For profile 2 , we might think of a far more (self-)satisfied person or colleague, not eager to excel in terms of performance, although liable in existing structures and long-term commitments, but with a rather service-minded attitude. The stereotype bookkeeper seems to share characteristics with this profile. For profile 3, we might refer to the 'typical' successful individual: self-confident, without too much sensitivity for environmental cues and requirements, being more self-directed. Together with ambition, success must be within reach, which is good for those in top positions (in mamagement, sales or any other leader job). Profile 4, finally, represents mal-adapted persons, feeling not in control in their situation, probably quite anxious, and prone to tailures and negative experiences. This profile seems therefore to be the least related to career and job successes.

The effects of the personality traits and personality profiles on labour market outcomes will be assessed, in separate analyses, in terms of objective labour market entry success measures. For defining a 'successful' labour market entry, Van der Velden and Wieling (1994) argue that both chances for work and quality of the job should be considered. Several indicators could be used to reflect these success measures, such as finding a job soon after graduation, having tenure, occupying an academic job (a job for which a Master"s degree is required), and earning high 
wages. We obtained labour market entry data from a survey sent to all Maastricht economics graduates a year and a half after graduation. In this survey, all kinds of information with respect to the search process, the labour market position and other activities are asked. This survey measurement is carried out on a regular basis by the Maastrich University's Research Centre for Education and the Labour Market (Dutch acronym: ROA). Studies are published each year on the subsequent graduation cohorts of the University Maastricht (Ramaekers, 1996 and 1997; Ramaekers \& Welters, 1998). For the purpose of our study, the 1994-1996 waves are used. These waves contain most of the economics graduates for whom personality data are available.

To test for the effects of personality features (i.e., profiles and traits) on labour market outcomes, the following four dependent variables are taken on board as measures of labour market entry performance: (a) finding a job within three months after graduation; (b) having a tenure position; (c) occupying a job for which an academic degree is required; and (d) gross monthly wages. Next to our independent variables, the personality measures introduced above, relevant covariates are considered for their effect on labour market entry performance. The following ten covariates are included: (1) gender (dummy, with male coded 1); (2) age (years); (3) GPA's of the last two years of the study program (ten-point scale); (4) masters" thesis result (ten-point scale); (5) managerial experience during education (dummy); (6) (relevant) work experience during education (dummy); (7) study field (marketing and organization, accounting and finance, or otherwise, indicated by dummies); (8) working in the profit sector (dummy); (9) working in a small or medium-sized company (dummy); and (10) having a leadership position (dummy). In terms of figure 4.1, covariates (3) to (6) relate to human capital variables (Arrow 2a-b), and (7) to (10) involve the individual domain preferences (Arrow 3a-b). Control variables (1) and (2) are standard in labour market research.

Logistic regression and normal linear regression analyses are conducted twice: once with the personality profiles and once with the personality traits. The analyses involve a three-step hierarchical estimation. In the first step, only the personality features and demographic covariates (i.e., age and gender) are included (Model 1). In the second step, the preferential study field variable is introduced into the model (Model 2); and in the third step, the traditional human capital variables - study results, managerial experience and work experience - are taken on board (Model 3). In so doing, the second and third-step models analyse the direct effect of personality features, whilst controlling for human capital variables and individual domain preferences. In the wage regressions, a fourth-step model is tested so as to control for the job and organizational preferences of students (Model 4), which is of course not meaningful in the context of the other labour market outcomes. 


\subsection{Results}

First of all, deseriptives and plots for all variables were analysed for outliers and normality. All interval variables show a near normal distribution. Descriptive data and Pearson's correlations are presented in Tables C. 1 and C.2 in Appendix C.

A large majority of the sample found a job within three months after graduation (79\%). Of all graduates in our sample, $63 \%$ has a tenured position at the date of the survey, whereas $49 \%$ occupies an 'academic' job. The gross monthly wages are 3,835 Dutch guilders (now about 1743 euro), on average. There are more males than females in this study (males $57 \%$ ), and the average age is about 26 years at the time of the Labour market survey. Of all graduates, $48.5 \%$ have passed through the marketing and/or organization specialization, whereas $28.7 \%$ have specialized in accounting and/or finance. The remaining $22.8 \%$ have graduated in different specialization tracks. For the purpose of our study, it is statistically not interesting to split this group further into several smaller sub-groups. Study fields in this reference category are, for example, "general' (i.e., non-business) economics or quantitative economies. During their study, $45 \%$ of the students have gained relevant working experience, and $59 \%$ have accumulated ditto managerial experience. of all graduates, $91 \%$ work in the profit sector, and $77 \%$ in a large firm. Already a $21 \%$ of the graduates are promoted into a leadership position, a year and a half after graduation. Note that this percentage is based on self-reports. Finally, with respect to the correlations between covariates, at first sight, multicollinearity is not an issue.

Tables $4.3 . a$ and $4.3 . \mathrm{b}$ report the results of the logistic regression analyses with respect to the effects of personality profiles and separate traits on the first labour market indicator the odds of having a job within three months after graduation.

All models differ significantly from the base model in which only the constant is included. The large parameter value of the constant refers to the high probability of having a job within three months anyway. The third personality profile has a large (direct) effect on having a job within three months, compared to the fourth personality profile which represents the reference category, after controlling for the influence of individual domain preferences and human capital variables. With respect to these control variables, the study fields show large positive effects. In Table 4.3 .6 , witli the separate personality traits, only Models 2 and 3 differ significantly from the base model. The effect of personality traits is significant for the locus of control scale: externality produces negative effects, again after controlling for the impact of individual domain preferences and human capital 
variables. Overall, the personality profile effect is more profound than the influence of the separate personality characteristics.

Table 43.3

Logistic regression of the effects of personality profiles on having a job within three months

\begin{tabular}{|c|c|c|c|c|c|c|}
\hline & \multicolumn{2}{|c|}{ Model 1} & \multicolumn{2}{|c|}{ Model 2} & \multicolumn{2}{|c|}{ Model 3} \\
\hline & $\mathrm{B}$ & s.e & $\mathrm{B}$ & $s . \theta$ & B & s.e \\
\hline Constant & $9.631^{\text {*tat }}$ & 4.021 & $9.293^{* *}$ & 4.330 & 1.609 & 5.645 \\
\hline \multicolumn{7}{|l|}{ Personally proflles } \\
\hline Profile 1 & -0.120 & 0.553 & -0.168 & 0.581 & -0.052 & 0.606 \\
\hline Profile 2 & -0.227 & 0.508 & 0.221 & 0.546 & 0.310 & 0.575 \\
\hline Profile 3 & 0.934 & 0.605 & $1.337^{\star \star}$ & 0.656 & $1.483^{\text {m** }}$ & 0.696 \\
\hline \multicolumn{7}{|l|}{ Covariates. } \\
\hline Age & $-0.314^{* * *}$ & 0.157 & $-0.343^{* *}$ & 0.170 & $-0.302^{*}$ & 0.181 \\
\hline Gender (male) & -0.454 & 0.438 & -0.536 & 0.454 & -0.519 & 0.475 \\
\hline \multicolumn{7}{|l|}{ Marketing and } \\
\hline organization & & & $1,013^{* * *}$ & 0.463 & $1.096^{\text {nin }}$ & 0.480 \\
\hline Accounting and finance & & & $2.178^{* * * \pi}$ & 0.677 & $2.32 .5^{\text {m****at }}$ & 0.693 \\
\hline Grade Point Average & & & & & 0.594 & 0.443 \\
\hline Masters' thesis result & & & & & 0.379 & 0.311 \\
\hline Work experience & & & & & -0.228 & 0.464 \\
\hline Managerial experience & & & & & -0.219 & 0.444 \\
\hline \multicolumn{7}{|l|}{ Model statistics } \\
\hline Number of cases (n) & & 168 & & 168 & & 168 \\
\hline Modiel chi-square & & 11.916 & & 24.542 & & 29.410 \\
\hline-2 Log likelihood & & 162.663 & & 150.037 & & 145.169 \\
\hline Df & & 5 & & 7 & & 11 \\
\hline$P$ & & 0.036 & & 0.001 & & 0.002 \\
\hline
\end{tabular}

Note 1: "significant at 0.10 "* significant at 0.05 and *** significant at 0.01 (two-sided). Note 2: personality profile 4 represents the reference category. 
Table 4.3.6

Logistic regression of the effects of personality traits on having a job within three months

\begin{tabular}{|c|c|c|c|c|c|c|}
\hline & \multicolumn{2}{|c|}{ Model 1} & \multicolumn{2}{|c|}{ Model 2} & \multicolumn{2}{|c|}{ Model 3} \\
\hline & $\mathrm{B}$ & s.e. & B & s.e & B & s.e \\
\hline Constant & $10.078^{\text {*x }}$ & 3.975 & $8.759^{* *}$ & 4.324 & 1.811 & 5.750 \\
\hline \multicolumn{7}{|l|}{ Personallin traits } \\
\hline Type A behaviour & 0.216 & 0.216 & 0.189 & 0.223 & 0.226 & 0.232 \\
\hline Locus of control & .0 .242 & 0.215 & $-0.432^{\star}$ & 0.229 & $-0.415^{*}$ & 0.236 \\
\hline Sensiation seeking & 0.005 & 0.239 & 0.019 & 0.248 & -0.010 & 0.258 \\
\hline Self-monitoring & -0.061 & 0.200 & -0.034 & 0.199 & -0.012 & 0.207 \\
\hline \multicolumn{7}{|l|}{ Covariates } \\
\hline Age & $-0.327^{*}$ & 0.154 & $-0.307^{*}$ & 0.168 & -0.275 & 0.183 \\
\hline Gender (male) & -0.422 & 0.446 & -0.582 & 0.467 & $\approx 0.549$ & 0.483 \\
\hline \multicolumn{7}{|l|}{ Marketing and } \\
\hline Accounting and finance & & & $2.206^{* * *}$ & $\begin{array}{l}0.450 \\
0.669\end{array}$ & $2.295^{\text {זx+kx }}$ & 0.680 \\
\hline Grade Point Average & & & & & 0.565 & 0.460 \\
\hline Masters' thesis result & & & & & 0.346 & 0.312 \\
\hline Work experience & & & & & -0.185 & 0.463 \\
\hline Managerial experience & & & & & -0.276 & 0.443 \\
\hline \multicolumn{7}{|l|}{ Model statistics } \\
\hline Number of cases (n) & & 168 & & 168 & & 168 \\
\hline Madel chi-square & & 9.925 & & 23.210 & & 27.461 \\
\hline-2 Log likelihood & & 164.654 & & 151.369 & & 147.118 \\
\hline Df & & 6 & & 8 & & 12 \\
\hline $\mathrm{P}$ & & 0.128 & & 0.003 & & 0.007 \\
\hline
\end{tabular}

Note: "significant at 0.10 , significant at 0.05 and ** significant at 0.01 (two-sided).

In the next analysis, the chance of having tenure is explored. Tables 4.4.a and 4.4.b present the results.

Now, none of the models differs significantly from the base model in which only a constant is included. However, in Table 4.4.a, the third personality profile shows a positive effect on the odds of having tenure, even after controlling for the role of human capital variables and individual domain preferences. Additionally, we observe a moderately significant positive effect of GPA's. In table 4.4.b, a stable positive effect of type A behaviour appears and a negative effect of locus of control externality. Overall, for this labour market indicator, the separate personality traits are more informative than the personality profiles.

The next indicator for success of labour market entry is occupying a job for which an academic degree is required. Tables 4.5 .a and 4.5 .b report the results of these analyses. 
Again, none of the models differs significantly from the base model. For this labour market indicator, a profound positive effect of the third personality profile is found again. In Model 3, after introducing the traditional human capital variables, a positive effect is observed for the final thesis result. In the analyses with separate personality traits, no effects for personality are found. However, this time more human capital variables appear relevant: the final thesis result and managerial experience reveal positive effects. Apparently, personality does onlly have an effect on the odds of getting an academic job when it is seen in terms of integrated characteristics, not in terms of separate traits.

\section{Table 4.4.a}

Logistic regression of the effects of personality profiles on having tenure

\begin{tabular}{|c|c|c|c|c|c|c|}
\hline & \multicolumn{2}{|c|}{ Model 1} & \multicolumn{2}{|c|}{ Model 2} & \multicolumn{2}{|c|}{ Model 3} \\
\hline & $B$ & s.e. & $\mathrm{B}$ & $s . \theta$ & B & s.e \\
\hline Constant & 3.080 & 3.503 & 1.969 & 3.589 & -1.879 & 4.942 \\
\hline $\begin{array}{l}\text { Personality profiles } \\
\text { Profile } 1 \\
\text { Profile } 2 \\
\text { Profile } 3\end{array}$ & $\begin{array}{c}-0.233 \\
0.405 \\
0.958\end{array}$ & $\begin{array}{l}0.480 \\
0.470 \\
0.491\end{array}$ & $\begin{array}{c}-0.197 \\
0.658 \\
1.133^{\text {t** }}\end{array}$ & $\begin{array}{l}0.487 \\
0.496 \\
0.509\end{array}$ & $\begin{array}{c}-0.169 \\
0.560 \\
1.064^{\text {*ik }}\end{array}$ & $\begin{array}{l}0.507 \\
0.517 \\
0.533\end{array}$ \\
\hline $\begin{array}{l}\text { Cowariates } \\
\text { Age } \\
\text { Gender (male) } \\
\text { Marketing and } \\
\text { organization } \\
\text { Accounting and } \\
\text { finance } \\
\text { Grade Point Average } \\
\text { Masters' thesis result } \\
\text { Work experience } \\
\text { Managerial experience }\end{array}$ & $\begin{array}{r}-0.109 \\
0.000\end{array}$ & $\begin{array}{l}0.138 \\
0.366\end{array}$ & $\begin{array}{r}-0.085 \\
-0.072 \\
0.281 \\
0.915^{\star}\end{array}$ & $\begin{array}{l}0.140 \\
0.372 \\
0.443 \\
0.519\end{array}$ & $\begin{array}{r}-0.095 \\
0.025 \\
0.189 \\
\\
0.853 \\
0.674^{\star} \\
-0.061 \\
0.248 \\
-0.056\end{array}$ & $\begin{array}{l}0.151 \\
0.386 \\
0.453 \\
\\
0.531 \\
0.398 \\
0.264 \\
0.376 \\
0.369\end{array}$ \\
\hline $\begin{array}{l}\text { Model statistics } \\
\text { Mumber of cases (n) } \\
\text { Model chi-square } \\
-2 \text { Log likelihood } \\
\text { Df } \\
\text { P }\end{array}$ & & $\begin{array}{l}157 \\
7.152 \\
199.664 \\
5 \\
0.210\end{array}$ & & $\begin{array}{l}157 \\
10.757 \\
196.059 \\
7 \\
0.150\end{array}$ & & $\begin{array}{l}157 \\
11.915 \\
191.901 \\
11 \\
0.186\end{array}$ \\
\hline
\end{tabular}

Note 1: "significant at $0.10,{ }^{* *}$ significant at 0.05 (two-sided).

Note 2: personality profile 4 represents the reference category. 
Tabla $4,4, b$

Logistic regressilon of the effects of personally traits on having tenure

\begin{tabular}{|c|c|c|c|c|c|c|}
\hline & \multicolumn{2}{|c|}{ Madel 1} & \multicolumn{2}{|c|}{ Model 2} & \multicolumn{2}{|c|}{ Model 3} \\
\hline & $B$ & s.e. & $\mathbb{B}$ & s.e & $\mathrm{B}$ & s.e \\
\hline Constant & 2.832 & 3.500 & 1.582 & 3.633 & -2.336 & 5.023 \\
\hline $\begin{array}{l}\text { Personallty traits } \\
\text { Type A behavioui } \\
\text { Locus of control } \\
\text { Sensation seeking } \\
\text { Self-monitoring }\end{array}$ & $\begin{array}{l}0.460^{*} \\
-0.341^{*} \\
-0.208 \\
-0.038\end{array}$ & $\begin{array}{l}0.197 \\
0.197 \\
0.206 \\
0.182\end{array}$ & $\begin{array}{l}0.467^{*} \\
-0.443^{*} \\
-0.205 \\
-0.013\end{array}$ & $\begin{array}{l}0.200 \\
0.209 \\
0.207 \\
0.181\end{array}$ & $\begin{array}{l}0.507^{* *} \\
-0.379^{*} \\
-0.213 \\
-0.037\end{array}$ & $\begin{array}{l}0.206 \\
0.214 \\
0.220 \\
0.185\end{array}$ \\
\hline $\begin{array}{l}\text { Covariates } \\
\text { Age } \\
\text { Gender (male) } \\
\text { Marketing and } \\
\text { organization } \\
\text { Accounting and finance } \\
\text { Grade Point Average } \\
\text { Masters' thesis result } \\
\text { Work experience } \\
\text { Managerial experience }\end{array}$ & $\begin{array}{r}-0.094 \\
0.123\end{array}$ & $\begin{array}{l}0.137 \\
0.376\end{array}$ & $\begin{array}{r}-0.056 \\
0.007 \\
0.219 \\
0.868^{*}\end{array}$ & $\begin{array}{l}0.141 \\
0.385 \\
0.440 \\
0.521\end{array}$ & $\begin{array}{l}-0.077 \\
0.136 \\
0.120 \\
0.792 \\
0.788^{* *} \\
-0.138 \\
0.277 \\
0.058\end{array}$ & $\begin{array}{l}0.153 \\
0.396 \\
0.454 \\
\\
0.534 \\
0.397 \\
0.270 \\
0.374 \\
0.374\end{array}$ \\
\hline $\begin{array}{l}\text { Model statistics } \\
\text { Number of cases ( } n \text { ) } \\
\text { Model chi-square } \\
-2 \text { Log likelihood } \\
\text { Df } \\
\text { P }\end{array}$ & $\begin{array}{c}157 \\
8.370 \\
198.446 \\
6 \\
0.212\end{array}$ & & $\begin{array}{l}157 \\
11.730 \\
195.086 \\
8 \\
0.164\end{array}$ & & $\begin{array}{l}157 \\
17.086 \\
189.730 \\
12 \\
0.146\end{array}$ & \\
\hline
\end{tabular}

Note: * significant at $0.10,{ }^{* *}$ significant at 0.05 (two-sided). 
Table 4.5.

Logistic regression of the effects of personality profiles on having an academic job

\begin{tabular}{|c|c|c|c|c|c|c|}
\hline & \multicolumn{2}{|c|}{ Model 1} & \multicolumn{2}{|c|}{ Model 2} & \multicolumn{2}{|c|}{ Model 3} \\
\hline & $\mathrm{B}$ & s.e. & $\mathrm{B}$ & sie & $B$ & $8 . e$ \\
\hline Constant & 4.500 & 3.512 & 4.260 & 3.611 & -2.427 & 4.859 \\
\hline \multicolumn{7}{|l|}{ Personality proflies } \\
\hline Profile 1 & 0.342 & 0.491 & 0.330 & 0.492 & 0.148 & 0.520 \\
\hline Profile 2 & 0.547 & 0.474 & 0.605 & 0.491 & 0.510 & 0.513 \\
\hline Profile 3 & $1.112^{\text {k* }}$ & 0.468 & $1.138^{* i}$ & 0.475 & $1.006^{*}$ & 0.504 \\
\hline \multicolumn{7}{|l|}{ Covariates } \\
\hline Age & -0.207 & 0.139 & -0.208 & 0.141 & -0.125 & 0.148 \\
\hline Gender (male) & 0.358 & 0.355 & 0.356 & 0.357 & 0.237 & 0.375 \\
\hline Marketing and organization & & & 0.339 & 0.435 & 0.423 & 0.455 \\
\hline Accounting and finance & & & 0.281 & 0.498 & 0.451 & 0.519 \\
\hline Grade Point Average & & & & & 0.072 & 0.376 \\
\hline Masters" thesis result & & & & & $0.532^{k+t}$ & 0.265 \\
\hline Work experience & & & & & -0.250 & 0.366 \\
\hline Managerial experience & & & & & 0.577 & 0.361 \\
\hline \multicolumn{7}{|l|}{ Model statistics } \\
\hline Number of cases (n) & & 156 & & 156 & & 156 \\
\hline Model chi-square & & 8.025 & & 8.644 & & 17.021 \\
\hline-2 Log likelihood & & 207.595 & & 206.976 & & 198.599 \\
\hline Df & & 5 & & 7 & & 11 \\
\hline$P$ & & 0.155 & & 0.279 & & 0.107 \\
\hline
\end{tabular}

Note 1: ** significant at 0.05 (two-sided).

Note 2: personality profile 4 represents the reference category. 
Table 4.5.b

Logistic regression of the effects of personality traits on having an academic job

\begin{tabular}{|c|c|c|c|c|c|c|}
\hline & \multicolumn{2}{|c|}{ Mondel 1} & \multicolumn{2}{|c|}{ Madel 2} & \multicolumn{2}{|c|}{ Model 3} \\
\hline & $B$ & s.e. & $B$ & s.e & B & $s . e$ \\
\hline Constant & 4.805 & 3.462 & 4.610 & 3.578 & -2.214 & 4.835 \\
\hline $\begin{array}{l}\text { Personality tratts } \\
\text { Type A behaviour } \\
\text { Locus of control } \\
\text { Sensation seeking } \\
\text { Self-monitoring }\end{array}$ & $\begin{array}{r}0.160 \\
-0.168 \\
0.199 \\
-0.066\end{array}$ & $\begin{array}{l}0.186 \\
0.190 \\
0.199 \\
0.176\end{array}$ & $\begin{array}{r}0.155 \\
-0.189 \\
0.198 \\
-0.067\end{array}$ & $\begin{array}{l}0.186 \\
0.196 \\
0.201 \\
0.177\end{array}$ & $\begin{array}{r}0.126 \\
-0.220 \\
0.065 \\
-0.061\end{array}$ & $\begin{array}{l}0.193 \\
0.204 \\
0.212 \\
0.182\end{array}$ \\
\hline $\begin{array}{l}\text { Covariates } \\
\text { Age } \\
\text { Gender (male) } \\
\text { Marketing and } \\
\text { organization } \\
\text { Accounting and } \\
\text { finance } \\
\text { Grade Point Average } \\
\text { Masters' thesis result } \\
\text { Work experience } \\
\text { Managerial } \\
\text { experience }\end{array}$ & $\begin{array}{r}-0.195 \\
0.192\end{array}$ & $\begin{array}{l}0.136 \\
0.364\end{array}$ & $\begin{array}{r}-0.196 \\
0.189 \\
0.318 \\
0.232\end{array}$ & $\begin{array}{l}0.140 \\
0.367 \\
0.432 \\
0.491\end{array}$ & $\begin{array}{c}-0.113 \\
0.134 \\
0.408 \\
0.405 \\
0.100 \\
0.494^{*} \\
-0.189 \\
0.632^{*}\end{array}$ & $\begin{array}{l}0.147 \\
0.382 \\
\\
0.453 \\
0.514 \\
0.375 \\
0.267 \\
0.359 \\
0.362\end{array}$ \\
\hline $\begin{array}{l}\text { Model statistics } \\
\text { Number of cases ( } n \text { ) } \\
\text { Modell chi-square } \\
-2 \text { Log likelihood } \\
\text { Df } \\
\text { P }\end{array}$ & & $\begin{array}{c}156 \\
5.895 \\
209.725 \\
6 \\
0.435\end{array}$ & & $\begin{array}{c}156 \\
6.440 \\
209.180 \\
8 \\
0.598\end{array}$ & & $\begin{array}{c}156 \\
14.384 \\
201.236 \\
12 \\
0.277\end{array}$ \\
\hline
\end{tabular}

Note: "Significant at 0.10 (two-sided).

In the final analyses, the effects of personality profiles and traits on gross monthly wages are considered. Tables $4.6 \mathrm{a}$ and $4.6 \mathrm{~b}$ present the results. Note that the single graduate who is working on a PhD thesis, is left out because of the regulated low wages for PhD students in the Netherlands.

All Models $\$ to 4 differ significantly from the base model. For the personality profilles, stable positive effects are found for both the first and third profile. For the second profile, the effect fades away after introducing our human capital variables in Model 3. Table $4.6 \mathrm{~b}$ reveals that mainly type A behaviour is associated with a stable positive effect. The significant effect of the locus of control trait disappears when traditional human capital variables are introduced. The effect of GPA's possibly accounts for this. In Model 4, additionally, academic job level and firm size affect 
wages. Here, type A behaviour remains important. A high score for type A behaviour is, in fact, what the first and third personality profile have in common.

Table 4.6.

Regression of the effects of personality profiles on gross monthly wages

\begin{tabular}{|c|c|c|c|c|c|c|c|c|}
\hline & \multicolumn{2}{|c|}{ Model 1} & \multicolumn{2}{|c|}{ Model 2} & \multicolumn{2}{|c|}{ Model 3} & \multicolumn{2}{|c|}{ Model 4} \\
\hline & B & s.e. & B & s.e & $\mathrm{B}$ & se. & $B$ & s.e. \\
\hline Constant & $7.939^{\text {wat }}$ & 0.362 & $7.970^{* * *}$ & 0.368 & $7.279^{\text {(x) }}$ & 0.509 & $7.122^{\text {wax }}$ & 0.473 \\
\hline \multicolumn{9}{|l|}{$\begin{array}{l}\text { Porsonality } \\
\text { proflles }\end{array}$} \\
\hline Profille 1 & $0.097^{*}$ & 0.052 & $0.103^{*}$ & 0.052 & $0.104^{*}$ & 0.053 & $0.1099^{\text {intw }}$ & 0.050 \\
\hline Profille 2 & $0.093^{*}$ & 0.050 & $0.090^{*}$ & 0.052 & 0.075 & 0.052 & 0.050 & 0.050 \\
\hline Profille 3 & $0.155^{\text {id } \hbar}$ & 0.049 & $0.154^{* *}$ & 0.049 & $0.134^{2 * * x}$ & 0.050 & $0.087^{*}$ & 0.048 \\
\hline \multicolumn{9}{|l|}{ Covariates } \\
\hline Age & 0.009 & 0.014 & 0.010 & 0.014 & 0.016 & 0.015 & $0.025^{*}$ & 0.014 \\
\hline Gender (male) & -0.013 & 0.037 & -0.015 & 0.037 & -0.016 & 0.038 & -0.039 & 0.036 \\
\hline $\begin{array}{l}\text { Marketing and } \\
\text { organization } \\
\text { Accounting and }\end{array}$ & & & $-0.087^{\star}$ & 0.046 & $-0.098^{\text {*i* }}$ & 0.046 & $-0.102^{* * k}$ & 0.044 \\
\hline $\begin{array}{l}\text { finance } \\
\text { Grade Point }\end{array}$ & & & -0.050 & 0.050 & -0.053 & 0.052 & -0.073 & 0.050 \\
\hline Average & & & & & $0.071^{*}$ & 0.039 & $0.067^{\star}$ & 0.037 \\
\hline resulit & & & & & 0.008 & 0.027 & -0.013 & 0.025 \\
\hline Work experience & & & & & 0.003 & 0.037 & -0.005 & 0.035 \\
\hline Managerial & & & & & & & & \\
\hline experience & & & & & 0.040 & 0.037 & 0.022 & 0.035 \\
\hline Profit sector job & & & & & & & $0.101^{*}$ & 0.060 \\
\hline $\begin{array}{l}\text { Small/medium- } \\
\text { sized firm job } \\
\text { Academir level }\end{array}$ & & & & & & & $-0.105^{* *}$ & 0.043 \\
\hline $\begin{array}{l}\text { Academic level } \\
\text { required }\end{array}$ & & & & & & & $0.1153^{* \text { *wi* }}$ & 0.034 \\
\hline Leadership position & & & & & & & 0.034 & 0.042 \\
\hline Model statistics & & & & & & & & \\
\hline $\begin{array}{l}\text { Num } \\
\text { (n) }\end{array}$ & & 149 & & 149 & & 149 & & 147 \\
\hline Adjusted R-square & & 0.040 & & 0.052 & & 0.065 & & 0.202 \\
\hline$F$ & & 2.246 & & 2.153 & & 1.928 & & 3.466 \\
\hline $\mathrm{P}$ & & 0.053 & & 0.042 & & 0.041 & & 0.000 \\
\hline
\end{tabular}

Note 1: One case, representing an individual who is working on a dissertation, is excluded from the analyses

Note 2: "significant at 0.10 , ${ }^{* *}$ significant at 0.05 and $* * *$ significant at 0.01 (two-sided).

Note 3 : personality profile 4 represents the reference category. 


\section{Chapter 4}

Table 4.6.6

Regression of the effects of personality traits on gross monthly wages

\begin{tabular}{|c|c|c|c|c|c|c|c|c|}
\hline & \multicolumn{2}{|c|}{ Model 1} & \multicolumn{2}{|c|}{ Model 2} & \multicolumn{2}{|c|}{ Madel 3} & \multicolumn{2}{|c|}{ Model 4} \\
\hline & $\mathrm{B}$ & s.e. & $\mathrm{B}$ & s.e & $\mathrm{B}$ & s.e. & $\mathrm{B}$ & s.e. \\
\hline Constant & $8.053^{\text {intinit }}$ & 0.350 & $8.084^{* * *}$ & 0.358 & $7.450^{\cdots}$ & 0.487 & $7.335^{* \ldots}$ & 0.461 \\
\hline Personally trats & & & & & & & & \\
\hline Type A behaviour & $0.068^{14}$ & 0.020 & $0.068^{* * *}$ & 0.019 & $0.067^{* * * *}$ & 0.020 & $0.056^{\text {****** }}$ & 0.019 \\
\hline Locus of control & $-0.041^{m}$ & 0.020 & $-0.039^{*}$ & 0.021 & -0.033 & 0.021 & -0.019 & 0.020 \\
\hline Sensation seeking & 0.004 & 0.022 & 0.003 & 0.022 & -0.000 & 0.022 & 0.001 & 0.021 \\
\hline Self-monitoring & -0.005 & 0.018 & -0.003 & 0.018 & -0.004 & 0.018 & 0.002 & 0.017 \\
\hline Covariates & & & & & & & & \\
\hline Age & 0.008 & 0.014 & 0.009 & 0.014 & 0.013 & 0.014 & 0.021 & 0.014 \\
\hline Gender (male) & -0.023 & 0.038 & -0.025 & 0.038 & -0.022 & 0.038 & -0.044 & 0.037 \\
\hline $\begin{array}{l}\text { Marketing and } \\
\text { arganization } \\
\text { Accounting and }\end{array}$ & & & $-0.081^{*}$ & 0.044 & $-0.092^{* * t}$ & 0.045 & $-0.098^{* *}$ & 0.043 \\
\hline $\begin{array}{l}\text { finance } \\
\text { Grade Point }\end{array}$ & & & -0.045 & 0.050 & -0.049 & 0.050 & -0.067 & 0.048 \\
\hline $\begin{array}{l}\text { Average } \\
\text { Masters' thesis }\end{array}$ & & & & & $0.070^{*}$ & 0.038 & $0.063^{*}$ & 0.036 \\
\hline result & & & & & 0.003 & 0.026 & -0.015 & 0.025 \\
\hline $\begin{array}{l}\text { Work experience } \\
\text { Managerial }\end{array}$ & & & & & 0.005 & 0.036 & -0.001 & 0.034 \\
\hline $\begin{array}{l}\text { experience } \\
\text { Profit sector job }\end{array}$ & & & & & 0.042 & 0.036 & $\begin{array}{l}0.022 \\
0.083\end{array}$ & $\begin{array}{l}0.035 \\
0.059\end{array}$ \\
\hline $\begin{array}{l}\text { Smallmedium- } \\
\text { sized firm job } \\
\text { Acadernic level }\end{array}$ & & & & & & & $-0.090^{* *}$ & 0.042 \\
\hline required & & & & & & & $0.146^{* \text { *t+ }}$ & 0.033 \\
\hline Leadership position & & & & & & & 0.012 & 0.042 \\
\hline
\end{tabular}

Model statistics

Number of caises

$\begin{array}{lcccr}\text { (n) } & 149 & 149 & 149 & 147 \\ \text { Adjusted R-square } & 0.095 & 0.104 & 0.118 & 0.232 \\ \text { F } & 3.584 & 3.150 & 2.648 & 3.764 \\ \text { P } & 0.002 & 0.003 & 0.003 & 0.000\end{array}$

Note 1: One case, representing an individual who is working at a dissertation, is excluded from the analyses.

Note 2: " significant at 0.10 ** significant at 0.05 and *** significant at 0.01 (two-sided). 
Our findings are summarized in table 4.7 .

The effects of personality, measured through combined profiles or separate traits, are clearly relevant for the explanation of labour narket entry outcomes in our sample of Dutch graduates in economics. ${ }^{2}$ An important overall finding is that the effects of personality are stable, even after controlling for traditional human capital variables. Effects of traditional human capital variables are present as well, for each labour market indicator, which suggests that including both types of data is associated with value added.

Table 4.7

Summary of significant results

\begin{tabular}{|c|c|c|c|c|c|c|c|c|c|c|c|c|c|}
\hline & \multicolumn{13}{|c|}{ Labour market outcomes } \\
\hline & \multicolumn{3}{|c|}{$\begin{array}{l}\text { Being un- } \\
\text { employed } \\
<3 \text { months }\end{array}$} & \multicolumn{3}{|c|}{$\begin{array}{l}\text { Having } \\
\text { tenure }\end{array}$} & \multicolumn{3}{|c|}{$\begin{array}{c}\text { Occupying an } \\
\text { Academ } \\
\text { job }\end{array}$} & \multicolumn{4}{|c|}{$\begin{array}{l}\text { Gross } \\
\text { monthy } \\
\text { wages }\end{array}$} \\
\hline $\begin{array}{l}\text { Predictors } \\
\text { Personallity } \\
\text { Profile } 1 \\
\text { Profile } 2 \\
\text { Profile } 3 \\
\text { Type A behaviour } \\
\text { Locus of control } \\
\text { Sensation seeking } \\
\text { Self-monitoring } \\
\text { Covariates } \\
\text { Study field } \\
\text { Grade Point Average } \\
\text { Masters' thesis result } \\
\text { Managerial experience } \\
\text { Profit sector job } \\
\text { Small/medium-sized firm job } \\
\text { Academic level required }\end{array}$ & 1 & $\begin{array}{c}\text { Model } \\
2 \\
+\end{array}$ & $\begin{array}{l}3 \\
+ \\
+\end{array}$ & + & $\begin{array}{c}\text { Model } \\
2 \\
+ \\
+ \\
+\end{array}$ & $\begin{array}{l}+ \\
+ \\
-\end{array}$ & + & $\begin{array}{c}\text { Model } \\
\quad 2 \\
+\end{array}$ & 3 & $\begin{array}{l}1 \\
+ \\
+ \\
+\end{array}$ & $\begin{array}{l}1 \\
2 \\
+ \\
+ \\
+\end{array}$ & $\begin{array}{r}\text { del } \\
3 \\
+ \\
+ \\
+ \\
+ \\
+ \\
-\end{array}$ & $\begin{array}{r}4 \\
+ \\
+ \\
+\end{array}$ \\
\hline
\end{tabular}

* = effect of the independent variable is positive.

- = effect of the indiependent variable is negative.

With respect to the use of combined personality profiles vis-à-vis separate personality traits the results indicate that different mixtures of characteristics produce different effects on different labour market outcomes. Not surprisingly, graduates with profile 4 (the unambitious, rather rigid, external person) are clearly the least successful ${ }_{s}$ considering the positive effects of all other profiles compared to 


\section{Chapter 4}

this reference category for at least one of the labour market outcome indicators. Labour market entrants with profile 3 , who represent the ambitious, internal and flexible persons who are willing to take reasonable risks, are clearly the most successful in all labour market outcomes. This, again, is not surprising as this profile corresponds to the ideal-typical personality type that many employers would prefer, ceteris paribus. People with profile 1 also obtain higher entry wages, which is probably due to the ambitious nature of these graduates.

Graduates with profile 2 also obtain higher wages, although the effect of their personality seems merely indirect, possibly through the effect of better GPA's, or a preference for working in a large firm. When using separate personality traits, rather consistent results appear. On the one hand, type A behaviour and an internal locus of control do indeed pay off. On the other hand, sensation seeking and self-monitoring fail to produce any separate effect. For the academic jobs, though, none of the separate traits seem of interest to employers, whille the third personality profile, that combines characteristics of all four traits, is considerably valued. Apparently, for some labour market features, the conception of personality in terms of a combination of characteristics is more important than a conception in terms of separate traits. For the separate traits, the sensation seeking and self-monitoring concepts (contrary to the locus of control and type A behaviour features), though relewant for work-related issues after labour market entry, are not considered to be effective screening signals in the employee selection process of fresh university graduates in economics.

\subsection{Conclusion}

In this chapter, the value added of personality characteristics has been explored in the context of explaining four labour market outcomes. A successful transition from education to work is important, because labour market entry affect careers later in life (van der Linden \& van der Velden, 1998). The results reported above underline the importance of personality characteristics for several labour market outcomes. This relatively new finding for labour market research is in line with current job selection practices, where personality characteristics already fight for prominence in job ads and assessment procedures. An important overall finding is the rather direct and solid effect of personality on all labour market outcomes. Our hypothesis, that personality has an effect on labour market outcomes in addition to traditional human capital variables (such as study results) and individual domain preferences (such as study field) can therefore be confirmed. 
Finally, related to the shortcomings of the present study, we want to point to three examples of interesting avenues for further research. First, although we find a significant effect of personality features on labour market outcomes, the variables taken on board here appear not to be overly adequate to "explain" the mechanisms underlying this relationship. That is, whether this effect is caused by the selection behaviour of employers or by the unobserved choice and performance behaviour of graduates, or by both, remains an interesting area for further research. Similarly, we focus on short-term labour market outcomes only. It would be interesting to find out whether these effects can still be traced when analysing longer-term labour market performance, many years after entry. If personality features are indeed significantly" related to labour market outcomes, one should be able to find long-run consequences, too.

Second, the findings for graduates in economics cannot simply be generalized to other graduation populations. The economics curriculum is considered to reflect a rather 'generic' program, similar to management or law studies, but opposed to more specific types of professional (academic) education. After all, there is no specific profession at which the economics study is tailored, as it merely prepares the graduates for a range of different functions in many different organizations for which different specific types of knowledge and skills may be important. These specific knowledge and skills cannot all be acquired within the educational program, and thus many are still to be learnt after entering into a job. This may explain the importance of personality characteristics for economics graduates, next to the specific human capital they already have acquired, since it is important for employers to assess the personality features and long-run potential of candidate employees, especially in this case where learning-on-the-job is so important. For more specific profession-targeting studies, such as medicine, the effects of personality characteristics might be much smaller, or may be quite different. In such professional education programs, the acquired knowledge and skills are highly standardized for each and every student. It is necessary to unravel the impact of these educational differences to develop a clear view on the effects of personality features on labour market outcomes for graduates of different types of study (specialization).

Third, and related to the second suggestion above, is the observation that we need far more theory development on the linkages between and among the personality profilles and traits on the one hand and different labour market outcomes on the other hand. In the present study, forced by the lack of earlier labour market research in this area, we choose traits that have proven relevance in managerial and organizational contexts. However, in different jobs or organizations - that is, in different segments of the labour market -, other profiles and traits might be more 


\section{$60 *$ Chapter 4}

important to explain failure and success. A more systematic approach - linking personality types, job characteristics and labour market outcomes - seems a useful endeavour in light of the huge popularity of all kinds of "soft" personality features in the day-to day employee selection practices in many organizations. In other words, we need to develop a contingency theory of the impact of personality features on labour narket and career success that helps to offer a solid rationale for the use of such screening devices. By so doing, we can hopefully move beyond the exploratory nature of the present study.

\section{Notes}

1. As the Kumeans cluster analysis on the personality data of 171 graduates would only reveal less reliable results (the larger amount of personality data available in this explorative study is considered to be more representative for the types of profiles obtained), we conduct our labour market analyses with the personality profiles as obtained by the cluster analysis on the available 308 cases.

2. For all labour market outcomes, an interaction effect of personality with gender thas been considered as well. Only for a tenured position a significant interaction affect appears for type $\mathrm{A}$ behaviour: type $A$ behaviour seems especially positive for women. This finding may be explained by the existence of a relative masculine working environment with ditto work values for graduated economists, in which especially women need to display type A behaviour to stay competitive compared to men (see, e.g., Schein, Mueller \& Jacobson, 1989; Judd \& Oswald, 1997). 


\title{
5 The role of education in selection and allocation on the labour market; an empirical study in the medical field ${ }^{+}$
}

\begin{abstract}
Summary
In this chapter, we explore the role of education in explaining the labour market outcomes for a sample of graduates in medicine. More specifically, the following research question is answered: To what extent are labour market outcomes of physicians explained by the skills acquired in education, as indicated in the theory of Human Capital, or by competences already present at the start of education, as suggested by Screening theory? In the study in this chapter the relative importance of specific competence is operationalized along the developmental process of acquisition of (merely) specific competence during medical education. This makes it possible to touch upon different labour market theoretical views on the role of education (for medical graduates) empirically. The study uses separate measurements of competence at the start and at the end of education. Moreover, we use a direct measurement of competence development during medical education. This enables us to disentangle the effects of the suggested mechanisms. The results suggest that after graduation (specific) human capital factors do not explain subsequent differences in labour market outcomes. The medical degree seems a sufficient signal of screening device as such. However, selection processes during education take place on specific and generic human capital or competence acquired before and during medical education.
\end{abstract}

This chapter is adapted from:

Semeijn, J.H., Velden, R. van der, Heijke, H., Vleuten, C. van der \& Boshuizen, H. (2005), The role of education in selection and allocation on the labour market; a study in the medical field, Education Economics, 13 (4), coming forward. 


\subsection{Introduction}

The selection and allocation process for physicians

After medical students have passed their final qualifying examination (after the Masters" program and two years of clinical clerkships), they face a rather unique selection and allocation process on the labour market. This process is different from the processes other academic graduates face, because of the typical features of the medical study: it is highly standardized for every student and it aims to prepare for further specialisation into highly professional medical jobs. These are to be obtained by following further educational trajectories that are combined with work in practice. Enpirical research on the transition from education to the labour market of physicians is scarce. One study suggests that no clear educational or human capital factors seem to explain the attainment of a specialisation position, or why one candidate is selected over another (Borghans \& Ramaekers, 1993). Another indicates that the attainment of a medical assistantship (not in training) in a hospital, after graduation, will increase the probability of obtaining a medical specialisation position (in training) afterwards (van den Berg, Holm \& van Ours, 2002). This suggests a possible human capital or screening explanation. Because the amount of the working experience as a medical assistant seems to have no differentiating effect on the probability of becoming a specialist in training, the authors conclude the effect of having worked as a medical assistant is merely a signal for employers. It signals the expected productivity in, and/or interests of the candidates for a medical career as a specialist. This is in line with screening or sorting theory (see for example Thurow, 1975; Weiss, 1995).

In our view, randomness in selection seems illegitimate without a strong link with the underlying quality of what has been learnt. It is also at odds with educational literature concerning the relationship between medical competence and (better) professional functioning (see e.g., Norcini \& Lipner, 2000; Tamblyn, Abrahamowicz, Brailovsky, Grand'Maison, Lescop, Norcini et al., 1998). Specialisation positions differ in complexity and training intensity and graduates also differ in trainability or learning competences and acquired medical competences. Although following the same medical course offers the same minimum quality, there are still differences in the competences between good and mediocre students. Why then would these differences not predict the labour market chances of physicians, such as it would be expected to make a difference for other graduates, from other study fields, as well? 


\section{Measurement probliems}

A possible reason of the apparent absence of relevant human capital predictors may be the lack of adequate measures. Trainability or learning competences and acquired medical competences are rarely measured as such, simply because assessments for these individual characteristics are scarce in labour market research (see e.g. Sorenson, 1994).

In educational research, such instruments are not easily available either. Many studies reveal that the assessment of competences during academic education is not always in line with the desired competence outcomes for students; examinations seem to direct the learning behaviour of students, leading sometimes to good study results (see e.g., Irandoust \& Karlsson, 2002), but not always to rooted (deeply incorporated) knowledge and competence (Verhoeven, 2003). It is therefore necessary to carefully consider the instruments used for measuring learning outcomes; whether they really refer to the presence of (development of) desired competence(s). Otherwise competence is measured that is not desirable and instruments will not be informative for explaining selection processes on the labour market, leading to possible wrong conclusions about the value of human capital or competences learnt in education.

\section{Purpose of the study}

In this study, we want to investigate the role of (medical) education in the selection and allocation of physicians on the labour market with empirical data concerning their learning competences and their more study specific competence development. We will do this with a rather unique data set of physicians graduated at Maastricht University. These data contain several types of assessments during the medical study. These types of assessments have different measurement properties within the educational context, thereby measuring different aspects of the medical competence students have to master at the end of the program. In addition, these different types of assessment have differential effects on the learning behaviour of the students. One type of assessment in particular, the so-called Progress Test has revealed to have the desired effects on learning behaviour in an academic educational context (Verhoeven, 2003). The test measures growth in competence of students in the medical knowledge domain as defined by the educational end-objectives (van der Vleuten, Verwijnen \& Wijnen, 1996). It is not possible to prepare oneself specifically for this test, since it measures the students" present knowledge of the complete medical domain. In other words, the test meets our criteria to measure the growth and final level in the actual acquired medical competences, at least for its knowledge component. Two other types of assessment, the so-called Block Tests and Skills Tests, are more traditional instruments in the sense of their measurement 
properties. They measure the mastery of the content of certain courses covering well-defined sub-domains of the medical knowledge domain, and the mastery of clinical procedures during diagnosis and medical practice in directly observed simulated situations, respectively. These tests have course tailored standards and do not measure growth in medical expertise components across time. For the so-called Block Tests, studies have indicated that they are related to different, and perhaps less desirable learning style aspects than the Progress Tests (wan Berkel, Nuy \& Geerligs; 1995; Verhoeven, 2003). This is something to keep in mind when analysing the data and interpreting the results. We also include available grade point averages (GPA's) of secondary school as an indicator of the competence level before the start of the medical study. In this way we are able to measure the capabilities of people that are already present upon entry in the medical study program (sucli as measured by the GPA's) separately from competence development in medical education. Both will be related to labour market outcomes of physicians in terms of the type of medical job they have obtained, a year and a half after graduation.

\subsection{Theoretical background}

It goes without saying that having attained a medical degree as such plays an important role in the selection process. This degree is needed for legal functioning in the health sector as a physician. Without the medical certificate, no employer, no hospital, no health organization can hire a candidate as a physician. The question is however what this certificate represents for the employer, and to what extent other and additional selection criteria play a role in the selection and allocation process of physicians on the labour market.

In this respect we can distinguish mainly two different perspectives on the role of education in labour market research. The first perspective points to the relation between success in education and learning capacities. When physicians enter the labour market, their learning process has far from ended. Specialisation programs and other medical jobs as well, imply further learning to extend the already acquired basics of the academic medical program. It could therefore be of interest to future employers to select the candidate with the best learning or training ability. This is especially relevant for graduated physicians, because they face a rather unique labour market compared to other graduates, with many further training positions. The candidate with the best learning ability will have the best chance for succeeding in further specialisation and learning will occur at the smallest costs. In labour market research this line of thought is actually captured by the Screening or Sorting 
hypothesis (see for example Thurow, 1975; Spence, 1974). It states that employers use educational screening devices (like diploma's or study results) as signals about the underlying learning ability. In the case of our physicians, the medical degree as such could represent such a screening device. But one might also think of more differentiating measures, such as (average) medical study achievements, or GPA's (of secondary school).

The second perspective on the role of education we distinguish pertains to the fact that individual differences in learning ability lead to individual differences in the acquisition and level of mastery of specific medical competences. These latter differences may play a role on their own in the selection and allocation on the labour market. Specialisation tracks and other medical jobs differ in length, intensity and in the type of (medical) competences required. Therefore, the more medical competences a graduate possesses, at the end of the academic medical study, the more attractive this graduate will be. This line of thought is supported by the Human Capital hypothesis (see for example Becker, 1983; McNabb, 1987). This hypothesis states that people acquire skills or competences during education that are relevant for their future jobs. These skills or competences make people more productive and thus attractive for the labour market. ${ }^{1}$ Employers may therefore well be interested in indicators of direct productive competences of physicians.

\section{Measurement problems with respect to selection criteria}

Finding relevant indicators for the role of education for selection and allocation is rather problematic in labour market research, because the different indicators are not well distinguished in sustaining the different explanations.

One important reason for this is the absence of separate measures for learning capacities on the one hand and acquired competences in education on the other hand. Most indicators for schooling, like "years of schooling", or "attained level of education', or even the already mentioned 'study results' reflect both the ability to achieve a certain level (reflecting the amount of learning ability), as well as the acquisition of certain skills. Although study achievement results may be appealing for the measurement of competence acquisition during education, the meaning of most achievement results is not beyond an indication of the performance of a student on an educational test on a given moment in time, without a longitudinal perspective on what exactly has been learnt (see for example Lindblom-Ylänne \& Lonka, 2001; Baker, 2001). Therefore, study results can reflect both learning ability and a certain type of actual acquired competences, depending on the type of test (e.g., skills test, knowledge test). 
In addition, the measurement of actual competence acquisition requires a direct monitoring of the actual learning process during education, thereby requiring certain features of the instrument, i.e. longitudinal measurement properties (standardized scale across measurements) and repeated measures. And this type of data is scarce (Sirrensen, 1994).

A third problem is that learning ability and the actual competence development during medical education may go hand in hand during the educational program. Separate effects on labour market outcomes may then be hard to determine, due to high correlations between the two. And multicollinearity may occur, that can lead to unjust inconsistent or insignificant results (see for example Ethington, Thomas \& Pike, 2002, for an explanation of the phenomenon; and Cawley, Heckman \& Vytlacil, 2001, for an example of studying separate effects of "cognitive ability" and 'education' on wages). It would require theoretically perfectly separated instruments for measuring both elements to overcome this problem. Instruments such as the Intelligence Quotient Score (IQ) or the Scholastic Aptitude score are used for measuring learning ability in terms of cognitive aptitudes (see e.g., Atkinson, Atkinson, Smith \& Hilgard, 1987). However, others argue that 'learning ability" should or can not be separated from the specific competence for which it is used (see e.g., Perkins \& Salomon, 1989; Glaser, 1990) which, in fact, implies that the development of competence during education also captures already present abilities.

\section{Some solutions to the measurement problems}

One solution put forward in this study to overcome the before-mentioned problems is the use of a specific test, the so-called Progress Test. This test is considered to measure the growth in cognitive competence (knowledge) concerning the entire medical domain (van der Vleuten et al., 1996). In section 5.3 (data and methodology) this test will be discussed in detail. However, the availability of this instrument will not guarantee a separate measurement of a specific component in the competence development process. It may also capture more generic capacities of competence of people, such as their learning ability to acquire this specific knowledge.

Therefore, another solution to the difficulties with separate measurements will be used as well; we will measure the competence level of students at the start of their medical education and the competence development and competence level at the end of their education. In this way, the competences already present before medical education and the competences actually developed in medical education can be separated. Then, under the restriction that we are able to avoid multicollinearity, we will be able to test the labour market theoretical inferences about the role of 
education for physicians. The research question then is whether medical education really adds labour market relevant competences during the educational process (human capital), or whether the competences already present before or at the start of medical education can already explain selection and the labour market outcomes (signalling and/or screening).

\section{Research model and hypotheses}

For the selection and allocation process on the labour market for physicians, we argue two elements can be measured separately: the competences learnt during medical education (by indicators of competence at the end of the academic program, i.e., the final Progress Test, the Skills Test score of the fourth year and the mean Block Test scores of the fourth year), and the level of competence already present at the start or even before the start of medical education (by indicators of competence at the start of the academic program, i.e., GPA's, the first Progress Test in the first year and the mean Block Test scores of the first year). The relations of the competence levels with labour market outcomes are presented in figure 5.1 .

\section{Indicators at the start of medied education: \\ CPAs \\ - Ist Progiess Tesis scores \\ - Ist year mean Block Test scores}

Indicators at the end of medical education:

- finall Progress Test score:

Skills Tests scores $4^{\text {hi }}$ year

$4^{\text {th }}$ year nean Block Test scores

Figure 5.1

Model of possible effects of competence levels at different times in the educational process on labour market outcomes for physicians.

The existence of a possible positive relation 1 is not exclusive for one of both theoretical assumptions. However, when medical education is merely important for its reflection of a desired competence level already present before the actual medical training takes place (as can be explained by the Screening thought), indicators of competence levels at the start of the medical program must have an effect on labour market outcomes (3). It is likely, though, that the competence level at the start of medical education will affect the competence development and subsequently the acquired level of competence at the end of medical education $(1,2)$. Therefore, 
when the medical program itself adds competences relevant for work (such as can be explained by Human Capital theory), the acquired competence level at the end of education must be of relevance (2), even after controlling for the effects of previous competence levels. It may also be possible that both the competence level at the start as well as the competence level at the end of medical education will have independent effects on labour market outcomes, resulting in positive relations 2 and 3 , after controlling for relation 1 .

In sum, the following relations will be tested:

a. Indicators of competence at the end of the medical study (acquired competence) affect individual labour market outcomes (human capital, relation 2, controlled for 1);

b. Indicators of competence at the start of the study affect labour market outcomes, even after controlling for the effects of end-level indicators (screening argument, relation 3 , and 1 through 2).

The relation between the start level indicators of competence and the end level indicators of competence (relation $\mathbb{1}$ in the research model) will be tested independently and explicitly as well, although this is not the main theoretical focus of this paper. Therefore the results of this analysis will be dealt with in Appendix D.

\subsection{Data and Methodology}

\section{Subjects}

The research population consists of medical students, who started their studies in 1989-1991. The students will be followed during their educational process and during their labour market entry, which may take different amounts of time (in education) and different routes (on the labour market). This implies that labour market entry years are more diverse than study entry years. Hence, we will control for labour market entry year and study length in the analyses.

\section{Measures}

Indicators of the competence level at the start of the medical program are:

- GPA's at the end of secondary education;

- First Progress Test score in the first year of study;

- Mean Block Test scores in the first year.

Indicators of the competence level at the end of the medical program are:

- Final Progress Test score in fourth year; 
- Mean Block Test scores in fourth year;

- Skills Test score in fourth year.

Multiple indicators are used, because of their different measurement properties and their possibly different importance in measuring what employers may be interested in (such as specific medical skills, specific medical knowledge, or a more generic indication of the learning capacity of graduates). The data will be considered for multicollinearity.

Although the medical study officially takes six years, the last two years are reserved for the so-called clinical clerkships. During these clerkships, Progress Tests are adminustered as well, although the scores on this test in the fifth and sixth year are biased in two ways: in the first place the learning environment has extremely changed, from a highly structured standardized educational program, to one of rather individualized working and learning in practice. This can affect the scores on the tests. In the second place, not every student has to pass these last tests for graduation, so only the less well scoring students will have to do these last tests. Block Tests (i.e. knowledge tests covering the contents of separate courses) are not used during the clerkships period, and a Skills Test is administered in the sixth year, although not at the end of the year, so students are still in the middle of their individual learning trajectories then, which can cause biased scores. Alternative assessments concerning the competence development of students duwing the clerkships, such as global clinical performance ratings, seem however (also) to suffer from bias (see e.g. Williams, Klamen \& McGaghie, 2003) and are only sufficiently reliable when many repeated ratings (9-12) are gathered, while in practice so many ratings are seldom available. This is also the case for our subjects. For the purpose of our study we therefore consider the final Progress Test score in the fourth year as the best available end-level indicator of competence developed in education, together with the fourth year Skills Test score, and the available mean Block Test scores of the fourth year. The competence indicators have the following features:

Progness Test scores: these are gathered during the medical program four times a year and capture the growth in specific medical competence (knowledge aspect) during the years of study, because each tests covers the total relevant medical knowledge domain. The total score on the test is expressed as a percentage of the correct answers minus the incorrect answers. The Progress. Test scores meet to a large extent the measurement criteria as proposed by Sorensen (1994) to be able to measure actual competence development in education. For detailed information 
about the Progress Test, its validity and reliability for our measurement purpose, and relevant references, we refer to $A$ ppendix $\mathrm{E}$.

Block Test scores: these are gathered six times a year and cower only course-related sub-domans of medical expertise. It is basically a knowledge test of about 150 items that is administered after every block period (curriculum unit or course) of six weeks during the doctoral phase (the four year Masters' phase). It covers the contents of the course and tests the mastery of end-objectives of the course on a percentage scale. Therefore these tests give no information on the general growth in medical competence. They reflect whether the student has passed the course successfully. We will use the mean Block Test scores of the first year and the mean scores of the fourth year as indicators of competence at the start and at the end of medical education respectively.

Skills Test scores: these are gathered only once a year during the medical program. They are aimed at testing mastery of clinical procedural skills through direct observation of students carrying out these skills across a number of simulated clinical situations. Trained examiners use checklists to score performance. Percentage scores reflect the amount of well-performed tasks as registered. The test covers an increasing amount of clinicall skills every year, in line with the skills students aue trained for.

We use the Skills tests scores of the fourth year of the medical program as an indicator of the end-level competence of students. The reason we make no use of the first year scores for an indication of start level competence is that the test is administered at the end of the first study year and therefore probably biased by leaning effects of a complete year of study.

GPAs: the grade point averages (mean final exam scores of secondary education) are a highly standardized measure in the Netherlands expressed on a scale from 110. They determine whether the student has successfully passed the secondary school (scores 5.5-10) or not (scores 1-5.4) and therefore reflect the attained schoolsuccess of the graduates before entering the medical program. In our sample, only scores between 5.5 and 10 are possibly present, since not having passed the final exam will not allow one to enter medical education.

When you have passed the final exam, students for medicine are selected on their GPA's. However, in the Netherlands, this did not mean you had no chance to enter the program when you were not scoring very high in our research sample (students starting in 1989-1991): students were grouped based on ranges of GPA-scores. Only a certain percentage of each group was allowed to enter, which was a larger percentage 
for groups with higher scores. The selection of students for these percentages was at random. When you were part of the group with the highest scores, your individual chance to enter the program was higher than for lower scoring students. We use GPA"s as an indicator of the competence level at the start of medical education.

Labour market information is gathered by a labour market survey enclosing our subjects who started their medical study in 1989-1991. This labour market survey is conducted every year by the Research Centre of Education and the Labour Market (Dutch short-cut ROA) and gathers labour market information, as well as educational evaluative data, from graduates one year and a half after graduation. The graduation cohorts of 1996-2000 (years of labour market entry) are included to obtain our research sample of about 300 physicians for whom data for all our educational variables (competence levels at the start and at the end of medical education) and our labour market outcome variables in terms of obtained position are available.

Specifically, the following labour market indicators are used from the labour market survey, pertaining to job chances and the quality of the job (van der Velden \& Wieling, 1994):

- Having a physicians' job (dummy variable);

- Having a specialisation position (dummy variable);

- Category of common types of jobs/positions; in training for social medicine jobs ${ }^{2}$ (1), for general practitioner (2), or for a hospital specialisation (3), resident not in training (4) and PhD students (5);

- Type of specialisation ordered by required training period, reflecting further investment in human capital and thereby expected lifetime income; in training for social medicine jobs (1), for general practitioner (2), or for a hospital specialisation (3).

For further argumentation on the use of these labour market indicators, see Appendix F. Note that the traditional income indicator has not been used for physicians a year and a half after graduation. Although information on income is available for most subjects in our sample, wages are particularly low for graduates in training for further specialisation (i.e. for the more successful graduates), whereas they are relatively high for non-specialisation positions. Income during the transition phase would therefore reflect a wrong indicator of professional success.

\section{Control Variables}

In addition, personal data are included in the analyses as relevant control variables. These are gender and age. After graduation mostly women are interested in part-time 
work. Possibilities for part-time work are largest in social medicine positions, even during the training period. Age may play a role because it reflects experience gained in earlier work and life (human capital argument). On the other hand, age may also have a negative effect, because the returns on investments become relative low for a candidate (human capital argument), and/or a candidate may become less flexible with age, which can interfere with the demanding learning process in specialisation (selection argument). Socialisation processes are important learning sources for physicians (Slotnick, 2001). The (self-) selection on age fits this context. In all, the age effect will depend on the range in ages among the research subjects. Study length (in months net) is a relevant control variable, because the amount of time spent in the educational process diverges between students and can bias their scores on competence indicators in the program. As a final control variable, year of entry in the labour market will be used (1996-2000), to control for fluctuations in the labour market demand of physicians for specific (specialisation) jobs.

\section{Method of analysis}

We will test the effects of education on the different labour market outcomes in different (sub)models; in the first model, we will estimate the effects of the competence level at the start of the medical education. In the second model, the effect of the competences at the end of medical education will be tested. In the third

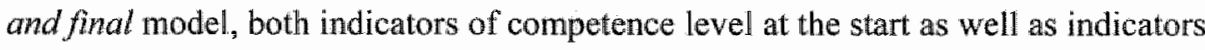
of competence level at the end of medical education are included, to measure their combined effects. In all three models we control for age, gender, study length and year of entry in the labour market. For the different labour market indicators, binary logistic regression, multi-nominal logistic regression and ordinal regression analyses are used. Before conducting the labour market analyses, the data will be controlled for muliticollinearity and selection bias in the research subjects' competence scores.

We realize there are still many individual and job heterogeneities not being controlled for in the study. Nevertheless, we like to explore the predictive value of the research model as presented, because of its tather unique nature as available. In so far selection bias is present in the scores on the competence indicators used, this bias is analysed on different moments during the educational and labour market entry process.

\subsection{Results}

\section{Descriptives for all variables}

Descriptive results of all variables used in the analyses and Pearson"s correlations are presented in table 5.1. 


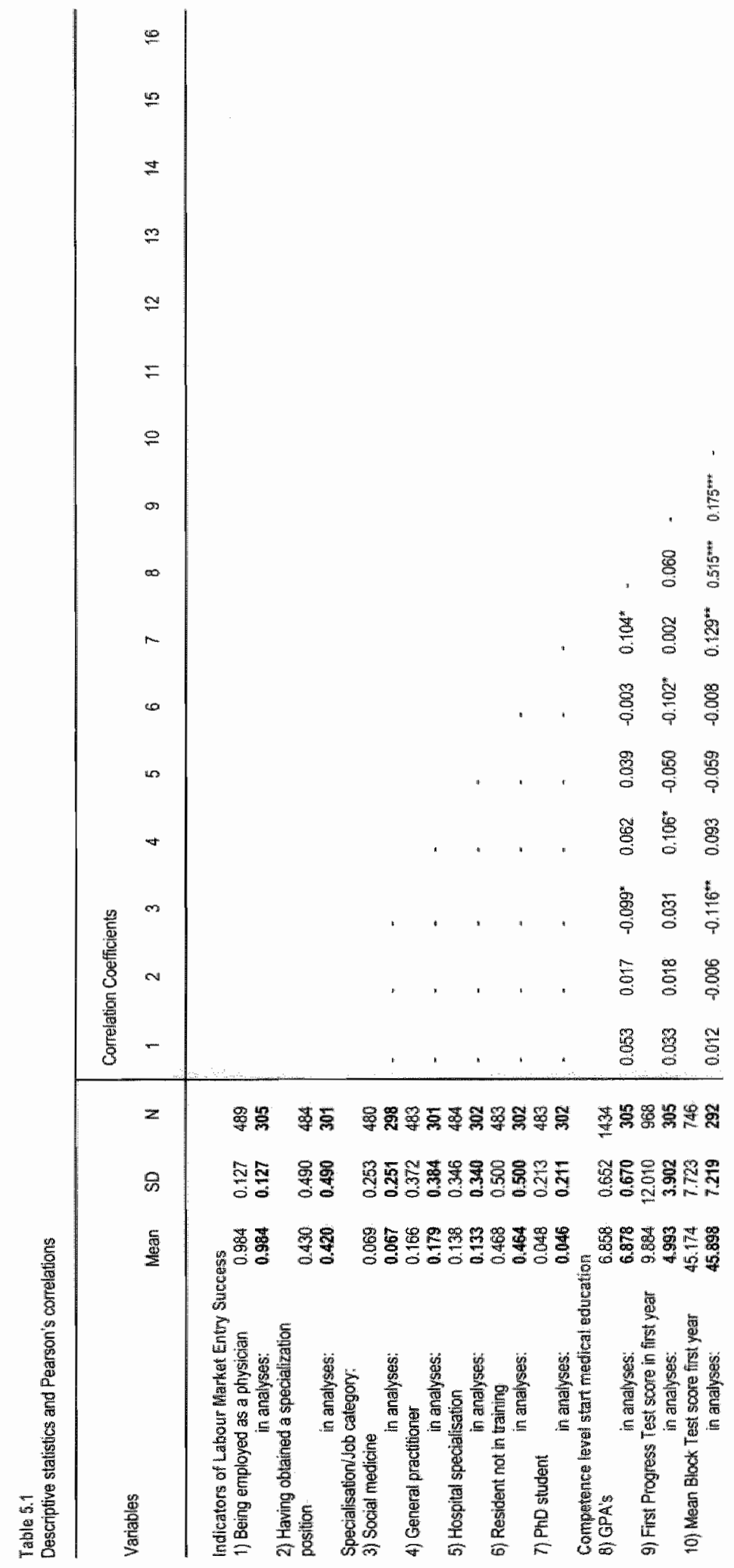




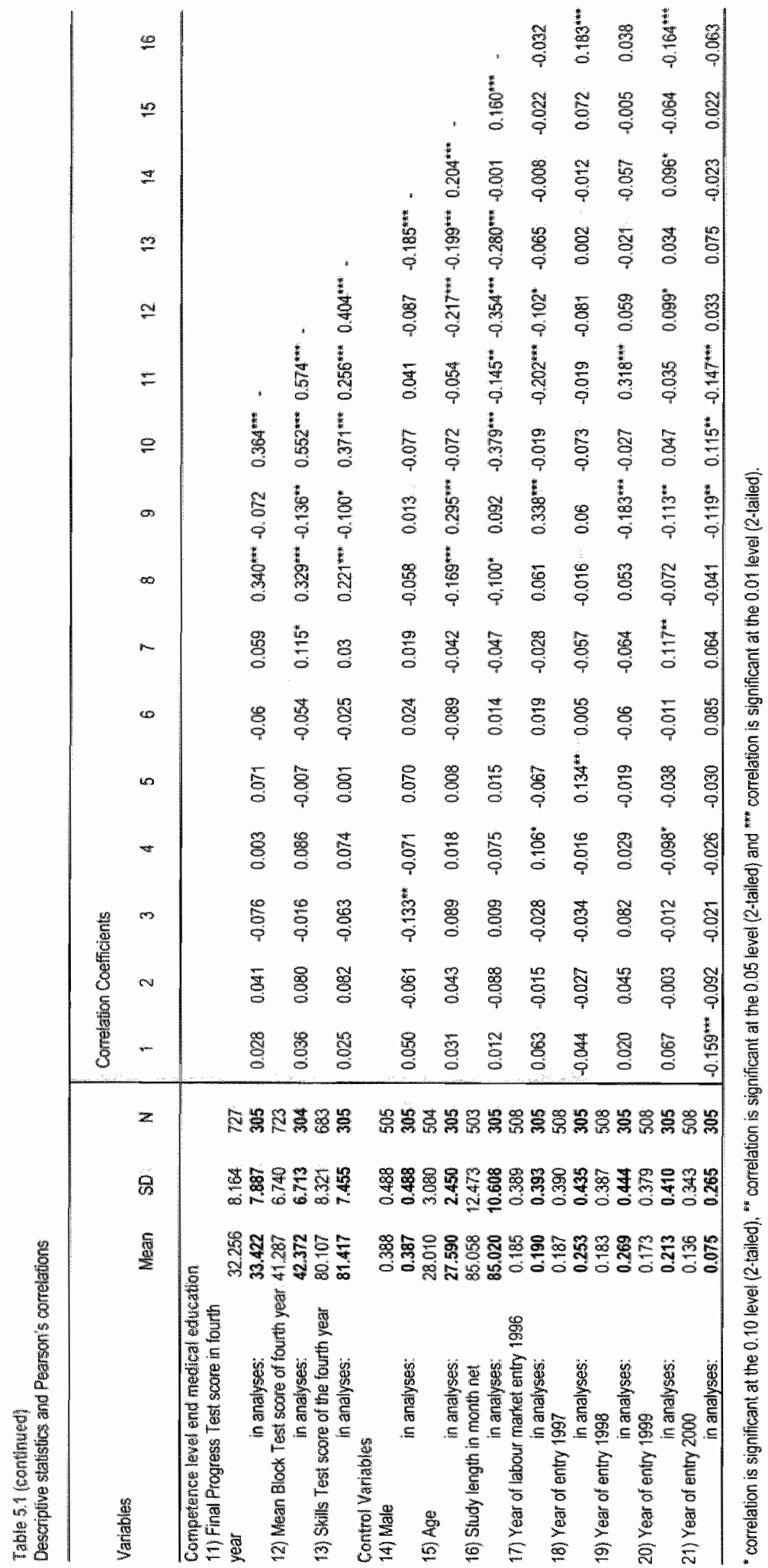


All study results variables in table 5.1 reflect percentile $\$$ cores of eorrect or correctminus-incorrect answers. However, the GPA's are on a sede from 1 - 10 and becase all students have passed the exam, only seores from 6.10 are present in our sample. Correlations between study variables are significanty positive. The langest correlation is between the final Progress Test and the mean Block Test scon of the fourth year for the end-level indicators, even larger than the considerable correlations between the first and fourth year Block Test scores, and betwen the GPA's and the mean first year Block Test scores. This suggests the measurement of common elements at both the start and end of education by different knowledge testing instruments. Because the correlations are considerably high (ranging from 0.515 to 0.574 ), we consider the presence of multicollinearity between the different instruments at the start and at the end of education before conducting further analyses. We do this by comparing the effects of the different instruments together and separately on labour market outcomes, as well as in different combinations (pairs of predictors). It appears that the effects of the Mean Block Test scores, both at the start and at the end of education, seem to cause the largest differences in parameter estimates ( $B$ "s and s.e.'s), when including more predictors in the models. These differences appear to be larger than may be expected, based on the separate effects of the different instruments. Without including the Mean Block "Test scores, the possible problem of multicollinearity seems omitted. Therefore we decide to leave the Mean Block Test scores out of further analysis. ${ }^{3}$

The otker relevant problem for the interpretation of our results refers to selection bias affecting the competence levels. Selection processes may bias the effects of competence indicators on the acquisition of competence in academic education, graduation, and responding to the labour market survey. Although internal publications indicate that drop-out (selection bias) among students in medicine is often due to other (more personal) factors than differences in competence levels (van Luijk, Wolfhagen \& de Grave, 1990; Perquin, 1999), we lik to empirically consider the possible selectivity sources in our analyses. We therefore conduct sequential logistic regression analyses with our competence indicators for three relevant selection moments, i.e. the availability of our end-level competence indicators for the students who started the medical study in the years 1989-1991, graduation before the year 2001 (which implies a maximum of 11 years of study for students entered in 1989), and response to the labour market survey. The results of these sequential analyses and the differences in the means of the competence level indicators are presented in Appendix G. They reveal that for all our competence instruments used, the subjects in our remaining research sample have already significantly higher scores due to selection processes during education, graduation before the year 2001 , 
and/or responding to the labour market survey. We should take this into account when interpreting the results of our further analyses, i.e., the effects of the scores on our instruments on labour market outcomes for physicians. It means, generally speaking, that the variation between the subjects in our remaining study sample has already become smaller, which restricts the chances to find effects of test results. We must therefore be aware of an underestimation of the effects of test results, implying an underestimation of the effects of acquired human capital.

\section{Effects of llevels of competence on obtaing a physicians job}

Based on table 5.1, we can argue that almost all graduates have obtained a physicians' job a year and a half after graduation (almost 98.5\%). This is considered and confirmed for all available (non-matching) cases in the labour market survey data as well. It is therefore almost superfluous to conduct a logistic regression for this indicator, because almost no variation is present. The binary logistic regression analyses indeed confirm this expectation, by revealing no effects of any of the (competence) variables included in the analyses. The results are presented in table 5.2.

As can be seen from table 5.2, only positive effects of year of entry (1998) in the labour market appear so far, the medicall study seems to guarantee a medical job after graduation.

\section{Effects of competence levels on obtaining a specialisation position}

For our second labour market indicator, obtaining a specialisation position (dummy), it appears from table 5.1 that $42 \%$ of those who work as a physician indeed have obtained one. Using binary logistic regression we measure the effects of competence indicators at the start and at the end of medical education on having acquired a specialisation position. The results of the analyses are presented in table 5.3.

The results show no effects for any of the included competence indicators. The findings suggest there are no explaining effects of competence levels on the chances for obtaining a specialisation as such. Only a sllightly significant negative effect of a longer study duration is found in the first model, but it disappears again when the end level competence indicators are included. Therefore we may conclude that the results so far suggest evidence for a screening argument; the medical degree as such is sufficient for a relevant job and obtaining a specialisation position is merely a matter of luck (or more probable: other sellection criteria not included in our analyses) afterwards. 
Table 5 .

Regression estimates of the effects of competence llevels at the start and at the end of medical education on having a physicians" job a year and a half after graduation

\begin{tabular}{|c|c|c|c|c|c|c|}
\hline & \multicolumn{2}{|c|}{ Model 1} & \multicolumn{2}{|c|}{ Model 2} & \multicolumn{2}{|c|}{ Model 3} \\
\hline & $\mathrm{B}$ & s.e. & $\mathrm{B}$ & s.e & B & s.e. \\
\hline Constant & -9.832 & 11.811 & -6.785 & 9.836 & -13.513 & 12.580 \\
\hline \multicolumn{7}{|l|}{$\begin{array}{l}\text { Competence level } \\
\text { start medical } \\
\text { educaton }\end{array}$} \\
\hline GPA's & 0.736 & 0.646 & & & 0.783 & 0.683 \\
\hline $\begin{array}{l}\text { First Progress Test } \\
\text { score first year }\end{array}$ & -0.291 & 0.707 & & & -0.422 & 0.746 \\
\hline \multicolumn{7}{|l|}{$\begin{array}{l}\text { Competence level } \\
\text { end medical } \\
\text { education }\end{array}$} \\
\hline \multicolumn{7}{|l|}{ Final Progress Test } \\
\hline $\begin{array}{l}\text { 4th year } \\
\text { Skills Test score }\end{array}$ & & & 0.038 & 0.590 & -0.266 & 0.666 \\
\hline 4th year & & & 0.612 & 0.529 & 0.729 & 0.609 \\
\hline \multicolumn{7}{|l|}{ Contral Variables } \\
\hline Male & 0.517 & 1.154 & 0.912 & 1.251 & 0.879 & 1.235 \\
\hline Age & 0.475 & 0.483 & 0.305 & 0.387 & $0.60 \%$ & 0.512 \\
\hline $\begin{array}{l}\text { Study length in } \\
\text { months net }\end{array}$ & -0.012 & 0.060 & 0.006 & 0.060 & -0.013 & 0.063 \\
\hline Year of entry 1996 & 9.839 & 56.470 & 10.021 & 56.595 & 10.155 & 55.123 \\
\hline Year of entry 1997 & 1.453 & 1.196 & 1.382 & 1.203 & 1.804 & 1.211 \\
\hline Year of entry 1998 & $2.352^{*}$ & 1.336 & $2.248^{*}$ & 1.332 & $2.784^{*}$ & 1.487 \\
\hline Year of entry 1999 & 40.266 & 52.499 & 9.992 & 53.343 & 10.857 & 48.794 \\
\hline \multicolumn{7}{|l|}{ Model Stavistics } \\
\hline $\begin{array}{l}\text { Number of cases } \\
\text { (n) }\end{array}$ & 305 & & 305 & & 305 & \\
\hline Model chi-square & 10.759 & & 10.583 & & 12.157 & \\
\hline d.f. & 9 & & 9 & & 11 & \\
\hline $\mathrm{P}$ & 0.293 & & 0.305 & & 0.352 & \\
\hline
\end{tabular}

Note 1: standardized values are used for all competence indicator wariables. Note 2: Year of entry 2000 is the reference category for the 'year of entry' control variables.

* significant at the 0.1 level. 


\section{6* Chapter}

Table 5.3

Regression estimates of the effects of competence levels at the start and at the end of medical education on having a specialisation Position a year and a half after graduation

\begin{tabular}{|c|c|c|c|c|c|c|}
\hline & \multicolumn{2}{|c|}{ Model 1} & \multicolumn{2}{|c|}{ Model 2} & \multicolumn{2}{|c|}{ Model 3} \\
\hline & $B$ & sie. & $B$ & se & $\mathrm{B}$ & s.e. \\
\hline Constant & -0.661 & 1.833 & -1.388 & 1.784 & -1.121 & 1.897 \\
\hline \multicolumn{7}{|l|}{$\begin{array}{l}\text { Compotence level } \\
\text { stan medical } \\
\text { aducation }\end{array}$} \\
\hline $\begin{array}{l}\text { GPA's } \\
\text { First Progress Test }\end{array}$ & 0.008 & 0.121 & & & -0.009 & 0.130 \\
\hline score of first year & 0.095 & 0.199 & & & 0.090 & 0.200 \\
\hline \multicolumn{7}{|l|}{$\begin{array}{l}\text { Competence level } \\
\text { end medical } \\
\text { education }\end{array}$} \\
\hline $\begin{array}{l}\text { 4th year } \\
\text { Skills Test score } 4^{\text {th }}\end{array}$ & & & -0.026 & 0.130 & -0.025 & 0.137 \\
\hline year & & & 0.148 & 0.135 & 0.146 & 0.137 \\
\hline \multicolumn{7}{|l|}{ Control Variables } \\
\hline Male & -0.320 & 0.252 & -0.280 & 0.256 & -0.274 & 0.257 \\
\hline Age & 0.059 & 0.059 & 0.074 & 0.055 & 0.066 & 0.059 \\
\hline $\begin{array}{l}\text { Study length in } \\
\text { months net }\end{array}$ & $-0.023^{*}$ & 0.012 & -0.020 & 0.013 & -0.020 & 0.013 \\
\hline Year of entry 1996 & 0.763 & 0.556 & 0.751 & 0.553 & 0.783 & 0.559 \\
\hline Year of entry 1997 & $0.941^{\star}$ & 0.539 & $0.953^{*}$ & 0.540 & $0.9411^{*}$ & 0.542 \\
\hline Year of entry 1998 & $0.955^{*}$ & 0.532 & $0.986^{\text {w }}$ & 0.534 & $0.979^{*}$ & 0.535 \\
\hline Year of entry 1999 & 0.756 & 0.544 & 0.774 & 0.544 & 0.766 & 0.546 \\
\hline \multicolumn{7}{|l|}{ Modell gtatustics } \\
\hline Number of cases (n) & 301 & & 301 & & 301 & \\
\hline Model chi-square & 9.349 & & 10.315 & & 10.516 & \\
\hline dif. & 9 & & 9 & & 11 & \\
\hline P & 0.406 & & 0.3926 & & 0.485 & \\
\hline
\end{tabular}

Note 1: stendardized values are used for all competence indicator variables.

Nole 2: Year of entry 2000 is the reference category for the 'year of entry" control variables.

" significant at the 0.1 levell, "* significant at 0.05 . 
However, the selection bias in our data indicates a human capital argument cannot be excluded yet. And in addition, both in specialisation positions and in nonspecialisation positions heterogeneity can be assumed to be present (see Appendix F for argumentation). Therefore we continue with considering the effects of the more qualifying and screening role of education on the chances to obtain different types of jobs (specialisation positions and non-specialisation positions).

\section{Effects of competence levels on obtaining different types of physicians' jobs} We conduct multi-nominal regression analyses. (MNRA) for the largest categories of jobs in the sample, consisting of residents not in training, medical Ph.D. students, residents in training for hospital specialisations, general practitioners in training (GP's in training), and physicians in training for specialisations in social medicine. Table 5.4 presents the results.

As table 5.4 indicates, we took the hospital specialisation positions as the reference category. The following effects are found:

The negative effect of being male for the social medicine category compared to the hospital specialists in training is in all three models consistent; being female enlarges your chance to obtain a training position in social medicine after graduation considerably. In the second model, the end-level competence indicators are tested; negative effects are found for the finall Progress Test score for physicians in a training position for social medicine (compared to the hospital specialists in training). A one standard deviation higher score on the final Progress Test leads to significant negative effects on the odds of obtaining a training position in social medicine, compared to becoming a hospital specialist in training of 0.55 , implying a decrease of $45 \%$ in the odds ratio. This is the expected change, keeping all other variables constant. In terms of what this decrease will mean for one's chance to obtain a training position in social medicine, the odds ratio can be written as the relative chance to obtain this type of job $(\mathrm{sm})$, compared to a hospital specialisation in training job $(h s)$ and calculate the differences in the chance for different values of the separate (relevant) variables, by considering a reference person (for example a female with mean age, with mean scores on the competence indicators and entering in the labour market in the reference year 2000).

These differences in the chance to obtain a training position in social medicine are presented in table 5.5 based on our reference person. We include the relevant effects of gender and the final Progress Test score from the second model of our MNRA, to show their separate effects on the chance, remaining the other variables constant. 


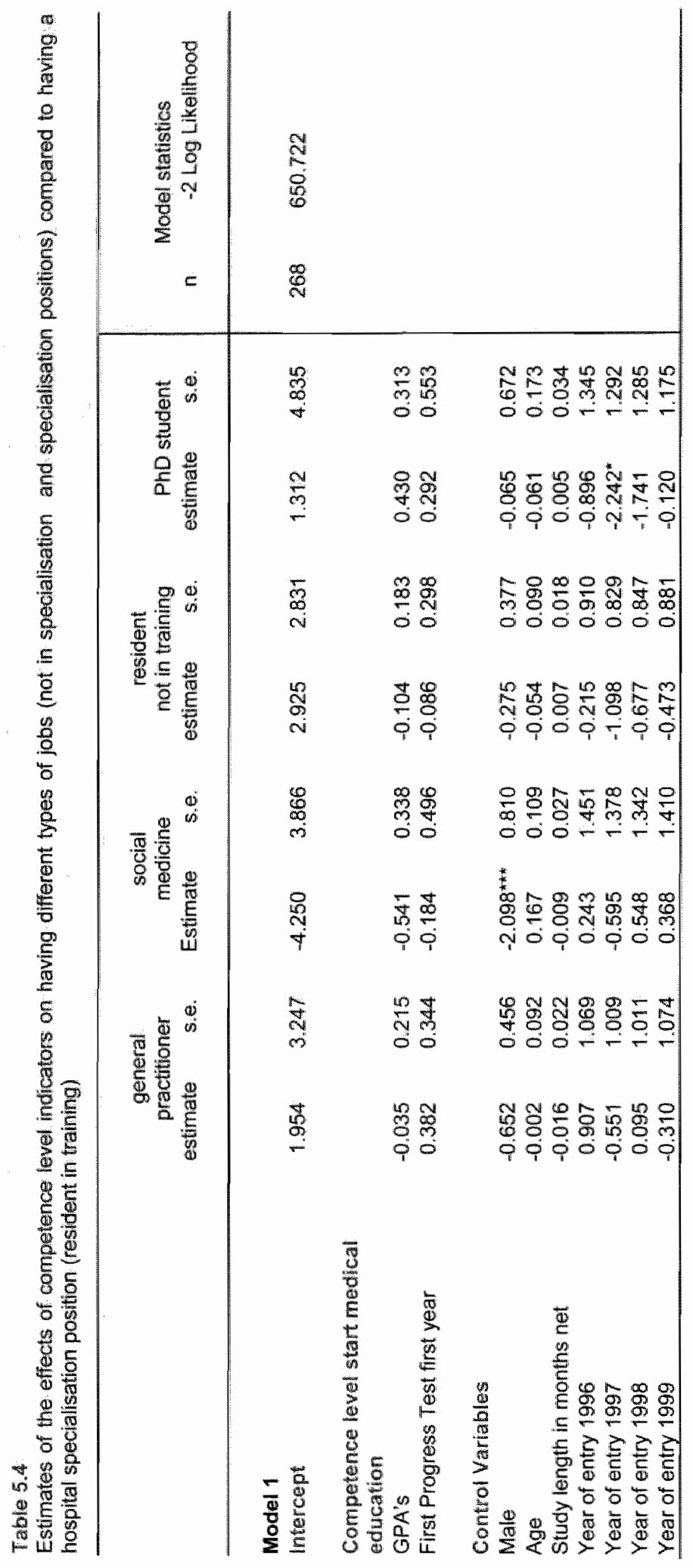




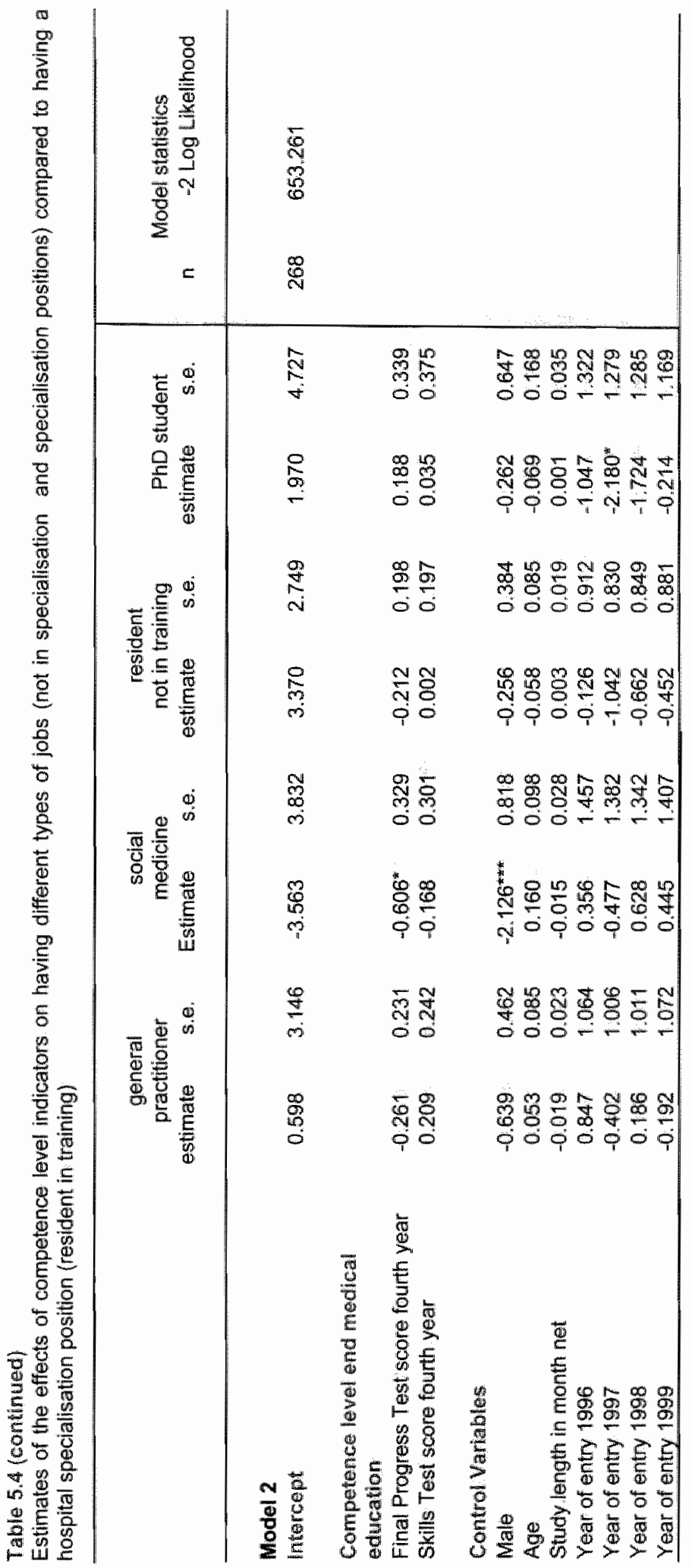




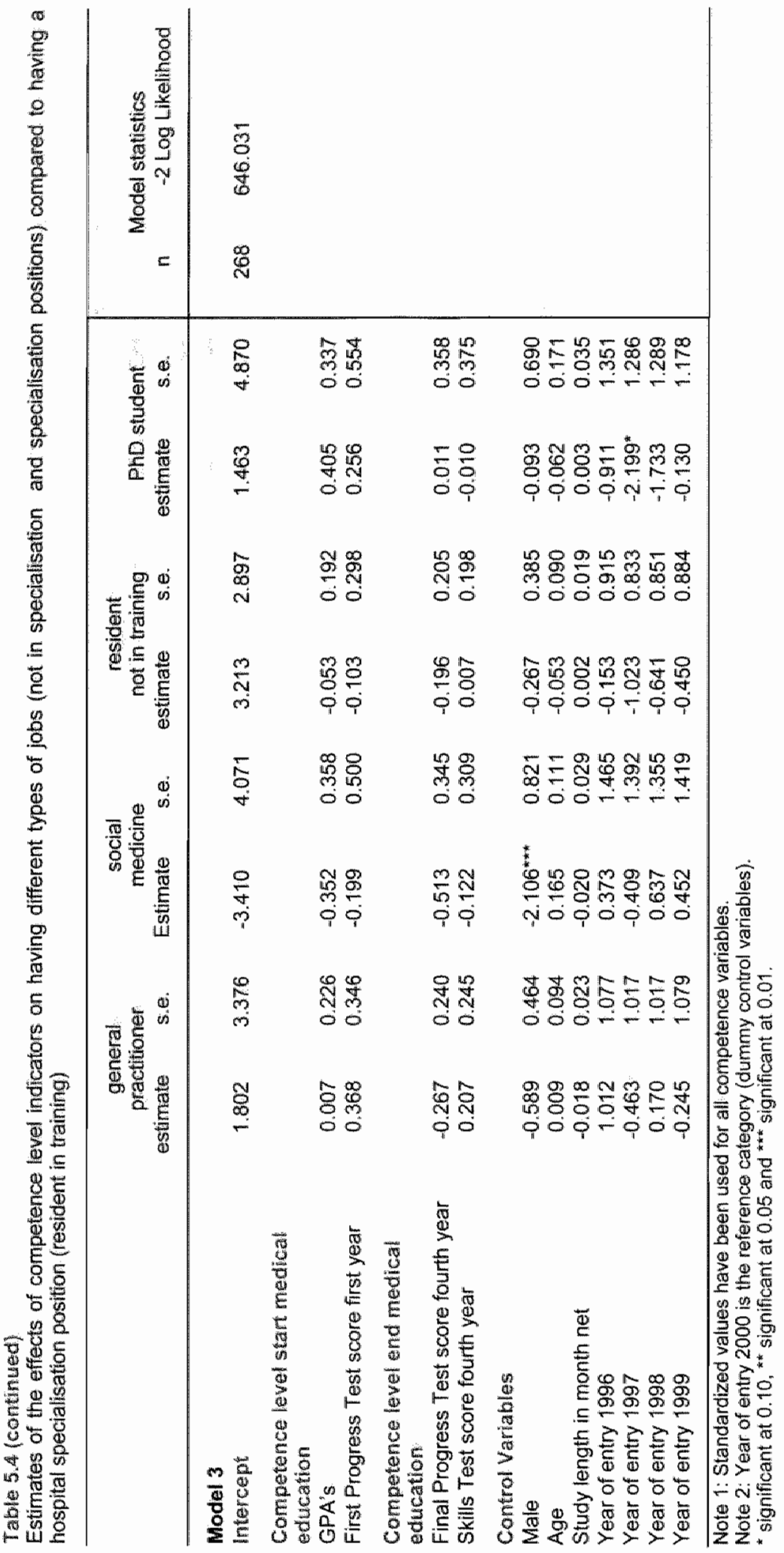


Returning to table 5.4 , in the third model of our MNRA, including both start-level and end-level competence indicators, no effects of any of the competence indicators are left. Only the already mentioned effect of gender and an effeet of labour market entry year (1997) remain present. Apparently, in the end, the selection of candidates for different physicians' jobs seems not to be regulated by their competence levels very much, at least not in our research sample.

\section{Table 5.5}

Changes in chance to obtain a training position in social medicine (sm) compared to a hospital specialisation in training position (hs)

Changes in chance for relevant predictors:

$\begin{array}{llll}\text { Gender: } & \text { Female } & \text { (reference) } & \\ & \text { Male } & & -5 \% \\ \text { fPT score fourth year: } & 0 & \text { (standardized mean) } & \\ & 1 & (+1 \mathrm{sd}) & -2 \%\end{array}$

Note 1: the reference person has mean age, is female, has mean competence indicator scores and entered the labour market in 2000 (reference category).

Note 2: $\mathrm{fPT}$ score = final Progress Test score.

Although the results of our MNRA already "predict' the outcomes of our final analysis, in which we intend to concentrate on the three specific medical specialisation (training) positions, we conduct this analysis as planned.

We order the three specialisation positions according to the duration of their training periods, reflecting the opportunity to obtain a higher expected lifetine income (see also Appendix F).

\section{Effects of competence levels on three types of specialisation positions} (ordered)

With ordinal regression analyses we test the effects of start- and end-level competence on the acquisition of a specialisation position of a longer duration, controlled for gender, age, and rellevant years of entry in the labour market again. In this respect, the social medicine in training category is considered the lowest and the hospital specialisations (residency positions in training) the highest category, while general practitioners" training lies in between. Table 5.6 presents the results. 
Table 5.6

Estumates of the effects of competence levels at the start and at the end of medical education on obtaining a thigher ranked specialisation position based on required further training irvestment (reflecting expected lifetime income)

\begin{tabular}{|c|c|c|c|c|c|c|}
\hline & \multicolumn{2}{|c|}{ Model 1} & \multicolumn{2}{|c|}{ Model 2} & \multicolumn{2}{|c|}{ Model 3} \\
\hline & estimate & s.e. & estimate & s.e. & estimmate & s.e. \\
\hline \multicolumn{7}{|l|}{ Tresholds (a) } \\
\hline General Practitioner & $-2.653^{m}$ & 1.566 & -3.101 & 1.611 & $-2.906^{:}$ & 1.709 \\
\hline Hospitiel Specialisation & -1.213 & 1.554 & -1.659 & 1.597 & -1.450 & 1.696 \\
\hline \multicolumn{7}{|l|}{$\begin{array}{l}\text { Competence level start } \\
\text { education }\end{array}$} \\
\hline GPA's & 0.189 & 0.116 & & & 0.166 & 0.122 \\
\hline $\begin{array}{l}\text { First Progress Test scare first } \\
\text { year }\end{array}$ & -0.074 & 0.165 & & & -0.073 & 0.166 \\
\hline \multicolumn{7}{|l|}{$\begin{array}{l}\text { Competence level and } \\
\text { education }\end{array}$} \\
\hline $\begin{array}{l}\text { Final Progress Test score in } \\
\text { fourth year }\end{array}$ & & & $0.207^{*}$ & 0.120 & 0.173 & 0.123 \\
\hline $\begin{array}{l}\text { Final Skills Test score of fourth } \\
\text { year }\end{array}$ & & & -0.060 & 0.124 & -0.091 & 0.126 \\
\hline \multicolumn{7}{|l|}{ Control Variables } \\
\hline Male & 0.751 & 0.249 & $0.661^{\text {* }}$ & 0.250 & $0.711^{* *}$ & 0.254 \\
\hline Age & -0.053 & 0.040 & $-0.07 *$ & 0.038 & -0.062 & 0.042 \\
\hline $\begin{array}{l}\text { Study length in months net } \\
\text { Year of labour market entry }\end{array}$ & -0.002 & 0.011 & -0.000 & 0.012 & -0.001 & 0.012 \\
\hline 1996 & -0.520 & 0.530 & -0.508 & 0.528 & -0.599 & 0.534 \\
\hline Year of entry 1997 & 0.024 & 0.544 & -0.003 & 0.522 & -0.048 & 0.549 \\
\hline Year of entry 1998 & -0.459 & 0.517 & -0.497 & 0.507 & -0.549 & 0.523 \\
\hline Year of entry 1999 & -0.30 .2 & 0.549 & -0.322 & 0.544 & -0.358 & 0.552 \\
\hline
\end{tabular}

\section{Model statistics \\ Number of cases ( $n$ ) \\ 2 Log Likelihood \\ Model Chi-square \\ Df \\ P}

Link: Probit

$\begin{array}{ccc}114 & 114 & 114 \\ 218.058 & 217.794 & 215.813 \\ 16.046 & 16.309 & 18.290 \\ 9 & 9 & 11 \\ 0.066 & 0.061 & 0.075\end{array}$

"The reference category is Social Medicine.

* Significant at $0.10^{* * *}$ significant at 0.05 and ${ }^{* * *}$ significant at 0.01 .

Note 1. Standardized values are used for all competence indicator variables.

Note 2: Year of entry 2000 is the reference category for the 'year of entry' control variables.

As can be seen from table 5.6 , the ordinal regression model is estimated as a probit linked threshold model with three categories. They represent the distances between 
ordered outcomes for which the exact distances between the categories is unknown, but for which the ordering represents an underlying continuous variable, such as in our study the amount of investment in training (see also Long, 1997; Snijders \& Bosker, 1999). The results can be interpreted as follows: being a male enlarges the chances for specialisation positions of a longer duration in all models. The effects are estimated as a part of the distance between the categories (threshold 2 threshold 1), which is $-2.653-(-1.213))=-1.440$ in the thirst model. When the effect of being male is 0.751 , this is more than a half of the distance of 1.440 . This may be interpreted as the effect of male on the job outcome is on average more than half a higher ranked job category. In the second and third model the effect of gender is related to almost a half of a one category higher outcome. It must be noted that the chance to obtain a GP in training position is the highest in general. With respect to the start level competence indicators, no effects are found. For the end-level indicators, a positive effect is found for the final Progress Test score. Its effect expects the chance to obtain a 'higher' position to increase for the distance of about only a seventh of a category, when scoring one standard deviation higher on the test. A higher age has a small negative effect to obtain a higher position in the ranked ordering of specialisation positions. However, in the third and final model, only the effect of being a male remains present, and the other effects disappear. Thus, even when ordering the types of specialisations, no real differentiation of the candidates based on their competence levels is explaining their allocation over the different positions. Gender is the most important factor in explaining the differences.

\section{Summary of results}

Overall, the effects in our regression analyses seem to suggest marginal roles of differential test results in medical education. Although the start level indicators of competence predict levels of competence at the end of education (as confirmed in the analysis in Appendix D), they reveal no further explaining effects for labour market outcomes, not even after controlling for the end level indicators of competence (relation b, i.e. our screening argument can not be confirmed). From the end-level indicators in our models, the final Progress Test scores seem to have some effects (relation a, i.e. the human capital argument is partly confirmed), but when controlling for the start level indicators of competence again, these effects disappear (relation $a$ is not fully confirmed). These are remarkable findings, merely suggesting credit for the signalling value for the medical degree as such. However, considering the already higher levels in scores on all competence indicators for the research subjects, due to selective processes, a more differentiated approach in interpreting the results is needed. Because both levels of competence at the start and at the end of education are higher for the research sample that remains available for 
our labour market analyses, it can not be denied that education both screens students on their already present competence (students dropping out from the program have lower mean scores for GPA's), as well as that education equips students with relevant knowledge that affects their labour market entry (the final Progress test reveals effects in the analyses, although the remaining research sample has already higher scores). This is an indication that the labour market outcomes for physicians are merely based on a guaranteed minimum of their competence levels, without further differentiation between good and mediocre students after graduation. In this respect, it is in fact remarkable that we still find effects of the final Progress test scores for our sample, indicating that higher final Progress Test scores increase one's chance to obtain a higher ranked specialisation position, and differentiating the social medicine in training category from other job categories. The fact that no effects are found for the start level competence indicators, nor for the end level indicators after controlling for the start level indicators, may well be explained in the light of the selection effects instead of by being insignificant in themselves.

\subsection{Conclusion}

In this chapter, an empirical study has been conducted into the role of medical education for the selection and allocation on the labour market for physicians, a year and a half after graduation. For this purpose, we measured whether medical education really adds to the human capital or competences of students (Sørensen, 1994). This type of measurement is scarce in labour market research, but we had such a measurement available in the unique form of Progress Tests scores of medical students during their medical program (van der Vleuten et al., 1996). However, to separate the effects of actual acquired competence from more general and already present capacities of physicians, we considered the effects of competence levels for physicians at the start and at the end of their medical study separately and controlled for multicollinearity and selection bias in our data. Successful labour market outcomes have been defined in terms of the chances to obtain a physicians' job, a specialisation position, for obtaining a certain type of medical job, and for the type of specialisation position obtained (sub-sample), ordered by training duration, reflecting further investment in human capital and the expected lifetime income.

The results indicate that almost $98.5 \%$ of the physicians in our research sample have found a relevant job; the medical degree therefore seems to "guarantee" the allocation to relevant medical jobs, which is also confirmed by logistic regression 
analyses, in which no effects of competence indicators appear. However, instead of being irrelevant, the required levels of competences may be of a guaranteed minimum, as illustrated by the selection bias towards higher scores in our research sample, and therefore not visible in a rather undifferentiated outcome. For the chances to obtain a specialisation position as such, no effects have been found for competence levels either. This is in line with earlier findings (see e.g. Borghans \& Ramaekers, 1993) and may be due to the unimportance of differences in competence levels of candidates again, but can also be explained by a heterogeneous composition of both specialisation and non-specialisation positions.

Distinguishing the different types of jobs physicians can obtain, and analysing whether competence levels have differentiating value for obtaining these jobs, reveals some more information. For the social medicine category it can be said that the positive effect of being female is most profound and characteristic, compared to hospital specialisation positions. The question is however, to what extent the preferences of women as a group for social medicine are the underlying reason for the gender effect, or whether selection processes and structural constraints for different job categories (such as some hospital specialisations) are the reason (see for example Gjerberg, 2002). However, controlled for gender, age, study length, and year of entry in the labour market, the actual acquired competence in education seems to differentiate the social medicine in training positions from the hospital specialists in training, and therefore in fact from the GP's in training, the residents not in training, and PhD's as well.

In all, after having passed the final medical qualifying examination, competence levels as measured in this study seem not to play an important role in the selection and allocation of physicians on the labour market. The same accounts for the findings of our last analysis, in which three specific medical training positions have been considered separately, by ordering them according to their training period, which is reflecting expected life-time income.

The measurement properties of the Progress Test seem however to reveal more predictive information than the Skills Test, possibly related to the different aspects of competence that are measured by these different tests. It is suggested that scoring higher on the Progress Test is related to learning or study style aspects of students that are considered to be desirable for academic students (see e.g. van Berkel et al,, 1995; Verhoeven, 2003).

Much effort is currently put in research into the relationships between (cognitive) ability, personality, leaming style and work performance (see e.g., Furnham, Jackson \& Miller, 1999; Austin, Deary, Whiteman, Fowkes, Pederson, Rabbitt et al., 2002; Zhang, 2003) to detect the relevant aspects and their dynamic 
behaviour. To draw more conclusions in this respect, we would need to extent the study with measurements of generic competences, such as learning style data.

Overall, our results indicate the importance of having attained the medical degree as such for selection and allocation of physicians on the labour market, without further differentiation in educational performance. Selection of students takes already place during the medical program. Therefore the more qualifying and screening role of medical education seem merely of importance to guarantee a minimum quality of the physicians before entering the labour market. However, taking the already higher scores on both start and end level competence indicators for the responding subjects on the labour market survey into account, this conclusion must be handled with care; these (already) higher scores suggest that the importance of differences in competence is probably not visible in our analyses, because the subjects who did not respond to the labour market survey scored lower on these competence indicators, on average.

To find out whether our findings are possibly underestimations of the effects of educational human capital, the labour market information of the non-responders should be recovered otherwise. More groups of medical students should be followed during their educational process and labour market entry as well, to enlarge the sample. Since we only include short-term labour market outcomes, an important question is what effects competence indicators in medical education will have on the longer-term labour market outcomes of physicians. Will short-term effects continue to exist, or will there be different outcomes with respect to the value of education? What other factors are of importance for the allocation and selection after medical education, and how do these relate to possible self-selection of students? Future research into longer-term labour market outcomes is also an interesting and necessary road to follow, considering the changing career paths of physicians (Goldacre \& Lambert, 2000). And, since criteria for labour market success may also be linked to the quality of the performance of medical doctors in their work, this would be another or related route for future research.

The role of Progress Test scores in measuring acquired competence during education and its predictive value for labour market outcome indicators should be further tested. What is the relation with generic skills, such as learning styles, what does it mean for later labour market functioning? What is the predictive value of the Progress test for later clinical performances of doctors?

We end with the notion that a first attempt has been made to empirically separate the possible effects of education on labour market outcomes, as Sørenson already pled 
for (1994). The availability of the unique Progress Test measurements, in combination with the separate indicators of the start- and end-level competence of students in their study, informed us fairly well about what role this academic study plays in the first selection and allocation of physicians on the labour market. In doing so, a step forward has been made to develop theory concerning the role of education for labour market outcomes, not only for physicians but for other graduates as well.

\section{Notes}

1. Apart from the purely selective criteria from the point of view of the enyloyer, individual preferences with respect to work and the individuals" seli-knowledge of nedical and olher work related competences will lead to a certain amount of self-selection of andidates for specialisation tracks or other medical jobs.

2. Social Medicine in the Netherlands includes occupational (and insurance) medicine on the one hand, and public health (including, a.0., mother-and-child care, sports medicine and epidemiology) on the other hand.

3. The Mean Block Test scores did not reveal significant effects on labour maket outcones. 


\title{
6 Competence indicators in academic education and early labour market success of graduates in health sciences ${ }^{+}$
}

\begin{abstract}
Summary
In this chapter, the effects of several educational and non-educationat indicators of (aspects of) competence on short-term labour market outcomes for university graduates in health sciences are investigated. The effects of both specific and more generic aspects of competence can be tested for their labour market effects more comprehensively than in the other empirical chapters in this thesis. The research question we address is: To what extent do indications of specific and generic competence during the educational program predict labour market outcomes for graduates in health sciences? Labour market outcomes pertain to employment chances and quality of the job. The data on specific and generic aspects of competence refer to test scores on the attainment of domain specific knowledge, scores on group functioning, and the Masters" thesis result, all of which were assessed during the academic study program. In addition, some other indicators of human capital acquired outside education are used, i.e. relevant work experience and managerial experience. Both specific and generic aspects of competence have their own effects on labour market outcomes of the graduates. Specific competence merely affects whether the job matches the study field, generic competence merely affects the academic level. Independently, the broadness of the study specialisation within health sciences predicts labour market outcomes as well. A broader study specialisation seems worthy for job chances and wages, whereas a narrower study specialisation within health sciences enhances the chances for a job matching the study field.
\end{abstract}

This chapter is based on:

Semeijn, J.H. Velden, R. van der, Heijke, H., Vleuten, C. van der \& Boshuizen, H. (2005), Competence indicators in academic education and early labour market success of graduates in health sciences, RM-2005-2E, Research Centre for Education and the Labour Market, Maastricht. 


\subsection{Introduction}

Today"s labour conditions have become highly changeable. People do rarely work in one firm, or for one boss during their entire working life anymore. Especially the higher educated are expected to create their own career paths, in which personal development and growth in personal responsibility seem to play an important role (Hall \& Moss, 1998). This personal growth and development is the result of at delicate mix of what people have available from innate abilities and their experiences by growing up and being educated. Labour market relevant knowledge and skills, as well as a set of personal competences are seen as crucial to successful functioning and development afterwards (see e.g. Anderson \& Marshall, 1994; Nijhof, 1998).

Education plays an important role in what people learn before entering the labour market. In our so-called knowledge society or knowledge economy, especially higher education is faced with the large responsibility to prepare students for the best functioning on the labour market in higher level and management positions. Some authors emphasize the crucial role of the so-called "specific" competence development during education: the profession- or field-specific knowledge and skills that are relevant for the type of jobs for which the educational program prepares (see e.g. Boshuizen, 2004). Other authors argue it is most important to pay attention to the so-called 'generic" competences, skills like the ability to learn (to learn), and more academically 'conceptual competence', as well as communication and teamwork skills (see e.g. Vermetten, 1999; Stasz, 1998; Mulders, 1995). This apparent contradiction may be explained by two factors. On the one hand, educational programs may have different goals regarding the preparation for the labour market. On the other hand, different priorities in education relate to different definitions and classifications of competence and different operationalizations.

Some educational programs prepare for a specific profession, or a limited set of jobs and occupations. Medicine is an example. Other programs prepare for a broad range of occupations, such as economics (de Wolf, 2000, Borghans \& de Grip, 1999). And again other programs take positions in between, resulting in differences in the priority for different types of competence. Moreover, priorities may vary when considering competences that are most important for entering the labour market versus those that are important for functioning later in the career. It seems inevitable that choices have to be made about what priorities prevail and why. These choices are more easily made when supported by empirical data about the effects of differential educational achievements of students on their labour market outcomes. 
And it is exactly here where the data are missing. A considerable lack of empirical evidence seems to exist, especially when it comes to what students acnally have learned in education, and the effects of competence development in education on labour market outcomes (see e.g. Sørensen, 1994).

Different approaches to the concept of competence constitute a second reason for divergent views on what type of competence is most important for the labour market. It is in fact a rather complicated concept for the educational context (see e.g. Westera, 2001). It is common understanding that the concept comprises knowledge, skills and attitudes of people, plus something extra that makes it more than just the sum of the separate parts. This extra refers to the more holistic character of the concept of competence. It emphasizes that human functioning in work should not only be defined in separate components of knowledge and skills, but should also be considered as a whole. However, exactly the 'extra' can not unequivocaliy, and thus satisfactory, be defined to make the concept more useful in educational research than the traditional separate knowledge, skills and attitudes components that refer to (differences in) human functioning. So, many different definitions and operationalizations of competence float around in the literature (for overviews, see e.g., Toolsema, 2003; Westera, 2001), but they offer no systematic base for future research yet. Meanwhile, both traditional and more innovative study achievement assessments of knowledge and skills have been used for decades in academic programs. These assessments have not yet been studied systematically for their labour market value.

This study is meant to offer more empirical insight into which educational indicators of competence are relevant in explaining labour market outcomes of academic graduates. More precisely, we consider several data on study achievement and other (non-educational) experiences of students during their academic study in terms of how these refer to a more specific or generic type of competence, and how they affect short term labour market outcomes. While taking into account narrow versus broad educational programs and other factors, we investigate to what extent different educational indicators of competence predict labour market outcomes.

\subsection{Theoretical background}

In labour market research, the measurement of what people actually learn in education has never been a major point of focus. Labour market research is interested in the role of education for the labour market, though. Different academic 
educational programs are considered to have different functions or roles for the labour market. So-called narrow educational programs (such as medicine) prepare for a small range of jobs, or a smaller job domain, whereas broad programs (such as economics) prepare for a broader range of functions, or a broader job domain (Borghans \& de Grip, 1999).

Seen from the perspective of a single educational program, the labour market can be divided into different parts, in which the educational program either has a tight fit (between the competence demand of this particular labour market domain and the competence supply of the educational program), or a much looser fit, or, in some cases, no fit at all (a physician is unlikely to be hired as an advocate). So, not only the width of the job domain is important to take into account when analysing the importance of certain types of competence for the labour market, but also the fit between competence supply and competence demand. So-called assignment models within the job matching theory (for an overview see Sattinger, 1993) assume that depending on the characteristics of the job, different characteristics of the worker are rewarded (such as a particular educational background, or a certain type of competence). In this sense, the quality of the match, thus the "fit' between competence supply of the individual and competence demand of the job, determines the productivity in a job (see also van Eijs \& Heijke, 2000). Recent research reveals that field-specific competences enhance the chances to obtain a matching job (which in turn raises the wages), whereas generic or academic competences enhance the chances to obtain jobs outside the own occupational domain (Heijke, Meng \& Ris, 2003) and help to acquire other competences, such as the required specific competences for the job (Heijke, Meng \& Ris, 2003) and so-called management competences (Heijke, Meng \& Ramekers, 2003) that are rewarded in the labour market.

This "competence supply" as developed in education has traditionally been measured only indirectly in labour market research by using 'proxy's'. Examples of these proxy's are: the number of years spent in education, the level of education, and the type of education (de Koning, 1998), or study field (e.g. Finnie \& Frenette, 2003). These proxy's for education and the human capital acquired in education have been used in research next to the indicators for non-educational human capital, such as managerial experience and work experiences (see e.g. Brunello \& Comi, 2004; Heijke, Koeslag \& van der Velden, 1998). The most direct indicators of what (academic) education adds to the individuals" competence base are 'study results" during education. However, these study results often refer to some grade point average (indicating the mastery of a specified set of skills or knowledge on a specific and restricted moment in time), and do not shed much light on the actually 
developed type of competence, skills, or knowledge in education over the years. Nor do they include differences between specific and generic measurements or a Iongitudinal perspective. Recently, considerable effort has been apphed to study the labour market value of skills or work related competences (learnt in education) in a retrospective manner, for example by self-reports of students (see e.g. Heijke, Meng \& Ramaekers, 2003; Allen \& van der Velden, 2001; Heijke et al., 1998). It is therefore useful to expand this type of research with contemporary educational assessments of what students have learnt in education.

The learning process in academic education is studied from different theoretical perspectives. In the expertise development view (see e.g. Boshuizen, 2004) the emphasis is on the individual and mainly cognitive development that undierties the development of professional expertise. The establishment of a solid knowledge base is considered crucial, and especially to be acquired in the academic educational phase. In this respect, the development of a rather specific type of competence in academic education, i.e. domain- or field-specific knowledge prevails.

To measure acquired domain-specific knowledge, traditionally multiple choice knowledge tests are used (Straetmans, 1998). However, these traditional knowledge tests do not go beyond the measurement of the mastery of a specified set of knowledge items, and seem to stimulate the use of short-tern memory, instead of leading to deep rooted knowledge (Verhoeven, 2003). There are other types of knowledge tests, such as the so-called Progress test, that follow the development in the acquisition of domain-specific knowledge more accurately (i.e. longitudinally). This type of test seems to stimulate more deep rooted knowledge (Verhoeven, 2003).

In self-regulated learning theories, the process of (individual) learning in academic education is the central issue (see e.g. Boekaetts, Pintrich \& Zeidner, 2000), and therefore refers to a more generic component of competence. In this sense, generic competence refers to meta-cognitive capabilities and processing strategies of students. The use and practice of these capabilities and strategles help people to learn and gain academic and conceptual competence (see e.g. Ross, Salisbury-Glennon, Guarino, Reed \& Marshall, 2003; van den Bosch \& Gerritsen, 1997). To measure these strategies, different types of study or leaning style instruments are used, such as the Study Process Questionnaire (SPQ) of Biggs (1978), the Inventory of Learning Styles (ILS) of Vermunt $(1992,1996,1998)$ and the Revised Approaches to Studying Inventory (RASI) of Entwistle and Tait (1994). Most of the instruments are used for research purposes, not for large-scale and standardized monitoring of the learning process of students during their education. 
Generic competence also refers to other general skills, such as teamwork skills and communicative skills (see e.g. Stasz, 1998). These types or aspects of generic competence are not often assessed separately in educational programs. Learning these skills is often integrated in the instructional design (working in teams to solve domain related problems, giving presentations) or in the educational philosophy as a whole, such as in Problem Based Learning (PBL; see e.g. Savery \& Duffy, 1995; Schmidt \& Moust, 1998) or in institutional approaches (see e.g. Atlay \& Harris, 2000). In some PBL curricula, group functioning scores are gathered during the educational process. Therefore, assessments of teamwork and communicative skills seem relevant.

Competence oriented education emphasizes the integrated nature of what students must learn to be prepared for working life. In fact, current competence based education integrates features of several other innovations in education (such as selfregulated learning and elements of PBL or project learning), instead of having a unique form or character itself. It merely reflects the overall vision on the objectives of education for these innovations. Advocates argue that the traditional division in separate skills; knowledge and attitudes that students must learn in education is rather artificial. And competence is what in fact has been underlying the separate elements that can be distinguished and measured in the first place (see e.g. Paulson, 2001). Although more difficult, the measurement of 'competences' instead of separate elements has the advantage that it has more day-to-day reality value. Competence oriented and competence based education have proven their value, as can be illustrated by examples worldwide (see e.g. Schlusmans, Slotman, Nagtegaal \& Kinkhorst, 1999; Boyatzis, Cowen, Kolb \& Associates, 1995; Stillman, Wang, Quang, Zhang, Yang \& Sawyer, 1997). How the integrated 'competences' should be assessed in (academic) education is a matter of ongoing discussion and development (see e.g. McMullan, Endacott, Gray, Jasper, Miller, Scholes \& Webb, 2003; Eishout-Mohr, Oostdam \& Overmaat, 2001; 2002; Bers, 2001).

An example of an integrated assessment of competence that is already widely used in (academic) education is the classical Masters" thesis. In fact, several types of knowledge and skills need to be combined and used by the student to succeed in the production process of this thesis (see also Petr, 1998, on the interaction between writing and learning). In the context of measuring competence instead of separate knowledge and skills, this instrument has some desired features and should be explored for its predictive value.

Based on the theoretical considerations above, we explore the predictive value of several educational assessments that have been used in daily practice of curricula in 
the Health Sciences faculy of Maastricht University. This implies focus of the research on individual variation in competence, acquired within a given educational context. Thereby the effect of education as such is already acknowladged, as well as the effect of the choice for a certain study field by students, and the effect of the curriculum on the type and amount of competence acquired. It must be noted that the variation in competence between students of different studies or different types of education is much larger than the variation between students within the same study field and curriculum.

The research sample has some advantages. In the first place, the seven curricula considered within this faculty have different scopes on the labour market; both narrow and broader curricula can be distinguished and studied for their effects on labour market outcomes. It must be noted, that overall Health Sciences has a restricted matching job domain in the labour market (i.e. health care), which is broader than that of medicine, but narrower than that of a study like economics.

A second advantage of the research sample is that in the curricula, test scores for the total amount of acquired domain specific knowledge, scores for group functioning and the Masters" thesis results can be used as study achievenent assessments. These assessments provide innovative or integrated measurements within the educational context.

In explorative analyses, we examine to what extent each of the competence indicators predict labour market outcomes in terms of obtaining a job, obtaining an academic job, a matching job and the wage. As the competence indicators are all considered to measure something relevant for labour market functioning, the relations are considered to be positive.

Based on the results of labour market studies, it is also explicitly considered whether more specific competence indicators are predictive for labour market outcomes in terms of obtaining a matching job for study field, in line with the findings of Heijke, Meng and Ramaekers (2003) and Heijke, Meng and Ris (2003). Since wages are also expected to be higher for matching jobs (Heijke, Meng \& Ramaekers, 2003), interactions of competence indicators and this type of jobs will be considered as well.

With respect to more generic competence indicators we explore their general positive effects on labour market outcomes (see e.g. Stasz, 1998). In this respect, we found concepts such as learning style and personality to be more predictive for labour market outcomes for economists than specific educational achievement assessments or work and managerial exparience (Semeijn, Boone, van der Velden \& van Witteloostuijn, 2005; Semeijn \& van der Velden, 2002). 
Positive effects of (relevant) work and managerial experience on labour market outcomes are expected though, as sustained by previous and other labour market studies (see e.g. Brunello \& Comi, 2004).

Finaly, we like to explore explicitly to what extent the Master's thesis will have predictive value for labour market outcomes. Since the Masters thesis measures the mastery of an integrated set of both specific and generic types of knowledge and skills (also generic academic competence), we expect higher scores to be valuable for obtaining matching and academic jobs (in turn leading to higher wages), in both narrow and broad programs.

In the following section, our instruments, the data and models of analysis will be outlined.

\subsection{Data and methodology}

\section{Subjects}

The research population consists of graduates in Health Sciences who started their studies in the years 1991-1993.

\section{Competence measures}

Indicators of competence that are considered to measure more specific aspects are:

- Final Progress Test score in the fourth year of study;

- Relevant work experience during study (dummy; yes/no).

Indicators of competence that are considered to measure more generic aspects are:

- Total amount of points for group functioning (GF-score), gathered during the study (dummy's for low, high and missing scores);

- Managerial experience during study' (dummy; yes/no).

And a more integrated indicator of competence is:

- Masters" thesis result at the end of education.

The competence indicators have the following features:

Progress Test scores refer to an educationall assessment of the growth of knowledge in the entire educational (health sciences) study domain (see van Berkel, Sprooten \& de Graaff, 1993; van Berkel, Nuy C Geerligs, 1995). It therefore mainly refers to a specific component of competence (educational domain knowledge). The test consists of several hundreds of (knowledge) items that are administered to all students of all study years of the program. The qualification of a students' know- 
ledge is defined in terms of its actual distance to the level that has to be reached at the end of the educational program. As a consequence, the final Progress rest score of the fourth (nominal) study year reflects the acquired level of knowledge of a student at the end of the educational progiam. The total score on a Progress Test is expressed as percentage score of the correct answers ninus the false answers: The assessment qualification for the student is relative to the scores of all students in the same study year.

Group Functioning scores (GF-scores) refer to the number of points that has been gathered by students because of desired specific features in their behaviour in (educational) groups. This behaviour refers to capacities in communication and teamwork, such as participation in discussion, leadership skills, stimulating otlyers, and presentation of information and knowledge. The points (one per student) are assigned by the teacher at the end of each course period (i.e. 6 weeks), and are available for not more students than half of the educational group. This is to only reward the behaviour that has especially been positive to the group functioning. The total amount of GF-scores (at a maximum of 1 per course period per student) refers to the amount of points as gathered and administered by the end of the study program. Reliability and validity of the GF-points assessment method have been studied and reveal satisfactory results (Nuy, van Berkel \& van Til, 1994). Since the competence that is assessed by this instrument is considered to have value for almost every contemporary job that can be obtained after graduation (i.e. for teamwork, collaborative learning, and communication), we assume that this instrument measures generic competences. The dummy's are based on whether the scores are below or above the mean total score among the cases in the analyses (low and high scores) and separately, one is defined for the missing values. Students who started their studies in 1991 automatically have missing values, because the GF-Scores have only been gathered from 1992 on. Students who started their studies in 1992 and 1993 have missing values whenever doubt arose about the correctness of the total amount of GF-scores as registered. When no doubt was present, i.e. the registration was complete, students without GF-points obtained the total value of 0 (zero) points in the data file.

The Masters "thes is result refers to a qualification on a four-point scale $(1=$ poor, 2 = insufficient, $3=$ sufficient, $4=$ good), based on the averaged judgement of different teachers (most often two professors) who have guided the production (process) of the final thesis. Lnless the final result is 3 or 4 , graduation is rrot possible. This considerably restricts the actual range in final thesis results in our data. Thesis writing requires both generic (academic skills, communication skills, 
independency) and specific (field knowledge, statistical skills) types of competence and therefore indicates a rather comprehensive type of performance at the end of academic education.

Managerial experience and relevant working experience are two dummy variables $(y e s=1$, no $=0$ ), referring to traditional non-educational human capital indicators. They are often included in labour market research and have proven their relevance for individual labour market outcomes (see e.g. Brunello \& Comi, 2004; Heijke, Meng \& Ris, 2003). Managerial experience as such may be considered a rather generic type of competence, whereas relevant working experience refers to more (domain/job) specific competence. The variables are available from two direct questions asked in a labour market survey. From this labour market survey, we also use the measurements of the labour market outcomes and some control variables.

\section{Instrument for the measurement of labour market outcomes}

Labour market outcomes are measured by a labour market which is conducted by the Research Centre for Education and the Labour Market (ROA) every year. It gathers labour market information from graduates a year and a half after graduation. The graduation cohorts of 1995-1999 (years of entry in labour market) are used, enclosing the majority of our subjects who started their studies in the years 1991 1993. Our research sample consists of about $n=250$ graduates for whom data concerning the educational variables, as well as labour market outcomes are available.

More specifically, the following labour market indicators are used from the survey, pertaining to the chances for and the quality of the job, relevant for graduates in the transition phase from education to work (Müler \& Gangl, 2003; van der Velden \& Wieling, 1994):

- Having a job (dummy);

- Having a matching job for study field (dummy for having a job for which the own or a comparable educational program is requested by the employer according to the graduate);

- Having an academic job (dummy for having a job for which an academic degree is requested by the employer, according to the graduate);

- Gross hourly wage (log).

\section{Control Variables}

Several control variables are included in the study, to avoid bias that may be ascribed to personal characteristics, pre-university education, the occupational scope 
of the educational program on the labour market, or the labour market situation itself (fluctuations in supply and demand). These are:

- Age;

- Gender;

- Pre-university educational level (dummy for highest general secondary education);

- Year of entry in the labour market (dummy's);

- Narrowness of the occupational scope of the study specialization ${ }^{2}$ (dummy with reference category broad specializations);

- Type of educational program: short or part-time program versus regular doctoral program (dummy for irregular program).

And for the wage estimations:

- Whether the job matches the own occupational domain (dummy);

- Academic level job (dummy).

\section{Method of Analysis}

First, we consider the statistical descriptives of our variables, and discuss possible selectivity and multicollinearity in our data. Second, we explore the relations of our research model with binary logistic and ordinary linear regression (OLS) estimations.

We use a stepwise method: in the first model we estimate the effects of the control variables (model 1). In the second model, we add the effect of the competence indicators (model 2). In the third model all variables are included, as well as interaction effects between competence indicators from the educational context and narrowness of the study field (model 3 ). In the wage estimations, the dummies for matching and academic jobs are included in model 3 and a fourth model includes the interactions between competence indicators and narrowness of study fields on the one hand, and between matching jobs and competence indicators on the other hand.

\subsection{Results}

\section{Descriptives for all variables}

Descriptive results for all variables in the research sample are presented in table 6.1 and 6.2 . 


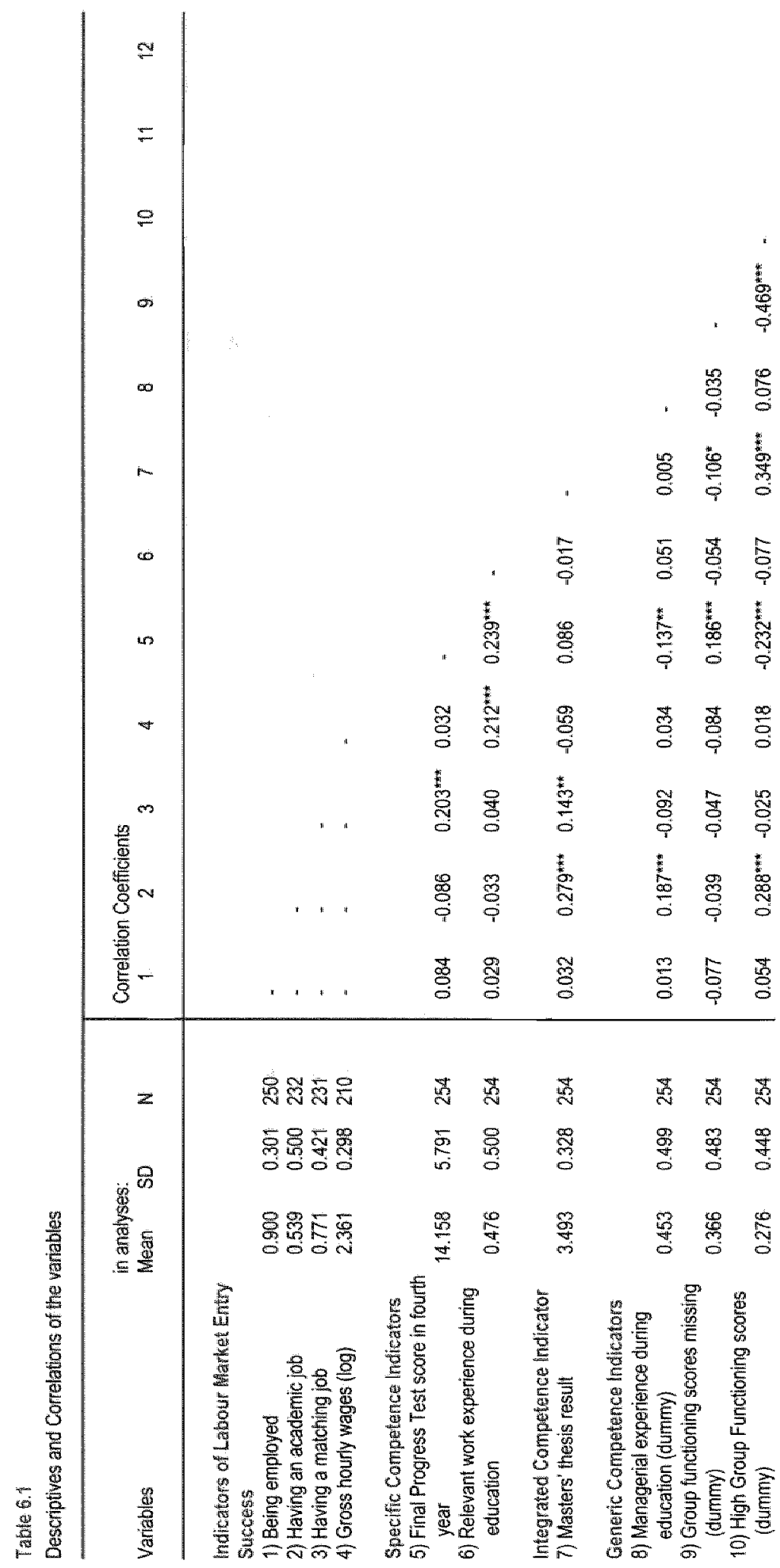




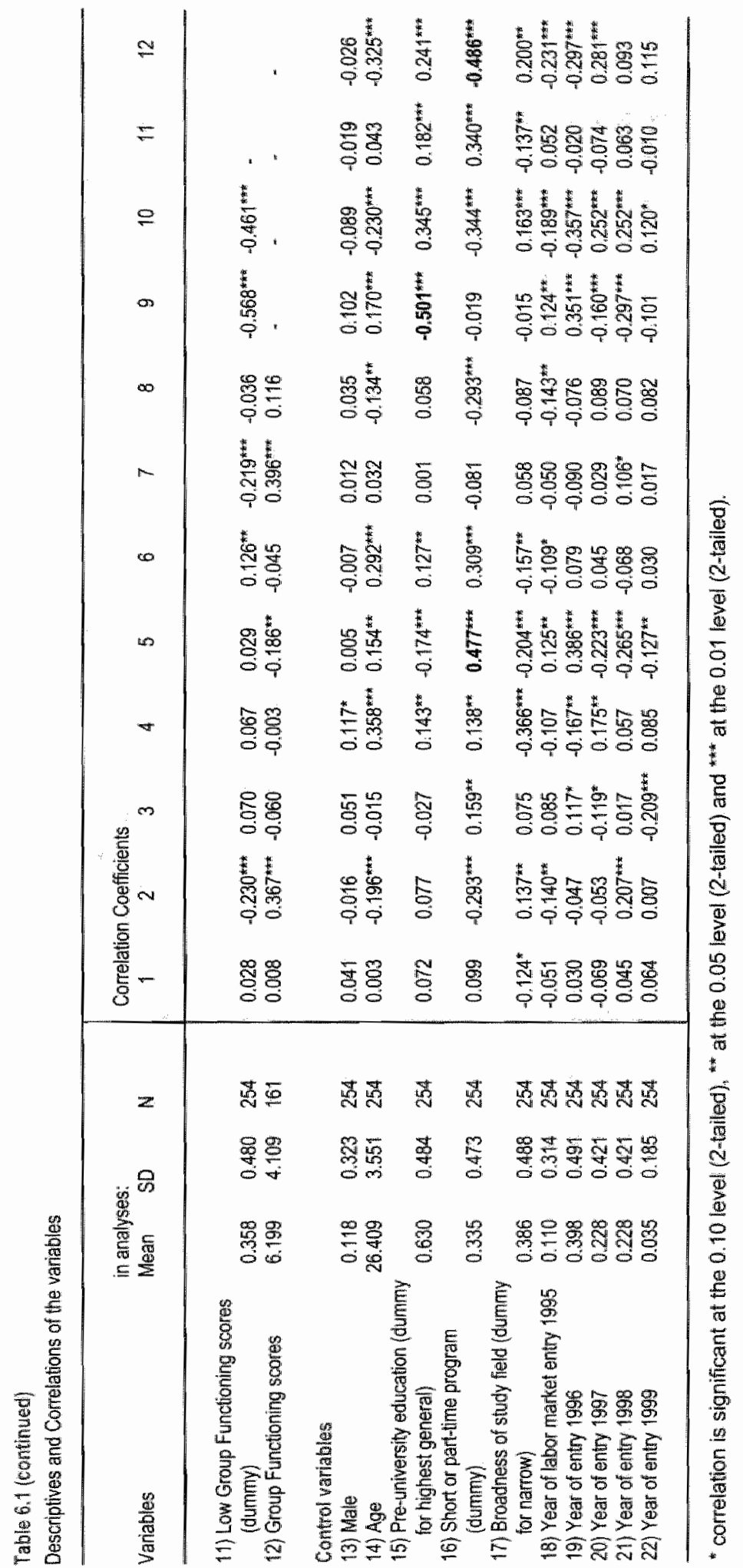


Table 2

Correlations between control variables

13

14

15

16

17

13) Mals

14) Age

15) Premunversily education

16) Short or part-time program

17) Narrow study field

18) Year of labour market entry 1995

$19)$ Year of entry 1996

20) Year of entry 1997

21) Year of entry 1998

22) Year of entry 1999

\section{-}

\begin{tabular}{|c|c|c|c|c|}
\hline $0.240^{\text {th }}$ & - & & & \\
\hline-0.023 & -0.082 & - & & \\
\hline 0.102 & $0.488^{* \cdots *}$ & 0.025 & - & \\
\hline-0.051 & -0.034 & $-0.459^{\ldots}$ & $0.203^{1 k+1}$ & - \\
\hline 0.101 & -0.062 & $-0.210^{* * *}$ & $0.259^{\star * * *}$ & 0.005 \\
\hline 0.033 & $0.146^{*}$ & $0.262^{*}$ & $-0.147^{16 \cdot 1}$ & -0.082 \\
\hline$-0.112^{*}$ & -0.087 & $0.300^{-}$ & $-0.286^{\text {tik: }}$ & 0.031 \\
\hline .0 .004 & 0.086 & 0.059 & -0.046 & 0.070 \\
\hline-0.014 & $-0.265^{*}$ & -0.063 & $-0: 339^{* * * *}$ & -0.021 \\
\hline
\end{tabular}

* correlation is significant at 0.10 level, ** at 0.05 . at 0.01 .

The data indicate that the majority of the graduates is female; almost $88 \%$. On a national level, female majorities in health education are a normal finding (see e.g. Allen, Ramaekers \& Verbeek, 2000). Mean age at a year and a half after graduation is about 26 years. Having attended other than the regular educational Health Sciences program has been indicated by the "short or part-time program" dummy wariable, showing this is the case for $33 \%$ of our research sample. Because correlations between this variable and the finall Progress test in the fourth year, as well as the nominal Group Functioning scores are rather high $\left(.477^{* * *}\right.$ and $.486^{* * *}$, respectively), we decided to leave this variable out of further analysis. ${ }^{3}$ The Group Functioning scores are only available for a subset of the subjects (about $63 \%$ ), and therefore presented and included in the analyses by three dummies: for the missing values, the high scores (above mean total amount of points), and the low scores (below mean total amount of points; reference category). Because the correlation between the dummy for Pre-university education and the Group Functioning Scores Missing-dummy is high (-.501***), a multicollinearity problem may occur. By comparing the separate and combined effects of the competence indicators on labour market outcomes, and switching the reference category from low GF scores to missing GF scores as a check, multicollinearity appears not to influence the results. ${ }^{4}$

To control for selectivity in our data, two issues should be considered: in the first place the characteristics of the research sample as such, and second, the possibly systematic processes underlying missing values in the educational competence indicators, and on labour market outcome indicators. With respect to the first selectivity issue, the sample has been taken from a Problem Based Learning 
(PBL) environment, in which curricula are organized around field related problems and issues. Students learn and work in tutorial groups, and self-directed learning is stimulated by the type of tasks and examinations, such as the Progress test and writing assignments. The PBL context can be considered an innovative learning context, in which the learning of generic competence is stimulated by its organization and curricular design (Savery \& Duffy, 1995; Schmidt \& Moust, 1998). This implies that students attracted to this type of education are possibly already more generically competent and/or develop generic competence more easily and integrated with the specific study contents, as compared to students from more traditional organized universities. Research among medical graduates reveals effectiveness of the integrated longitudinal approach in PBL with respect to the development of communication skills (van Dalen, Kerkhofs, van Knippenberg-van den Berg, van den Hout, Scherpbier \& van der Vleuten, 2002). This may be taken into account when interpreting our results.

With respect to the second selectivity issue (in the available educational data) we conducted several $t$-tests for the cases that are not included in the research sample because of missing values, versus the cases that remain available for analysis, in combination with labour market information. The results of these selectivity tests are presented and discussed in Appendix I. The findings indicate that the subjects that are included in the analyses score higher on Masters" theses, and on Group Functioning. To analyse the bias effect of the higher Masters' thesis results in the remaining sample, analyses have been checked for a larger sample with the lower scoring cases on the Masters' thesis as well. No other results were found as compared to our higher scoring sample. The higher Group Functioning scores seem mainly due to drop out during education. This may be a sign of a selective process during education on this type of competence. And it will turn out that the remaining Group Functioning scores have enough predictive power to assume selective processes related to this indicator after graduation, thus for the labour market, as well.

The descriptive statistics of our labour market outcomes in table 6.1 reveal that $90 \%$ of our responding subjects have a job, almost $54 \%$ an academic job, $77 \%$ a matching job, while the mean hourly wages is 10.59 euro $\left(=\mathrm{e}^{2.361}\right)$.

\section{Effects of competence levels on obtaining a job}

Our first labour market analysis is concerned with the chance of having a job, a year and a half after graduation, for those who are part of the labour force. Table 6.3.a presents the results.

As can be seen from Table 6.3.a, a so-called narrow study field reveals to have a steady negative effect on having a job. In the second model, no effects are found for competence indicators on having a job. Including the interaction effects in model 
3, a positive effect for the Progress test scores appears, together with a negative effect for those scores in a narrow study fileld, as compared to a broader study field. In terms of how large the effects are, we calculate the changes in the chance to find a job for this variable, based on the chance to find a job for a reference person ${ }^{5}$ in model 3. The chance to find a job is expressed in chance model 6.4 .1

$$
P_{i}=1 /\left(e^{-(a+p y x)}+1\right)
$$

Table 6.3.a

Regression estimates of the effects of competence indicators on having a job

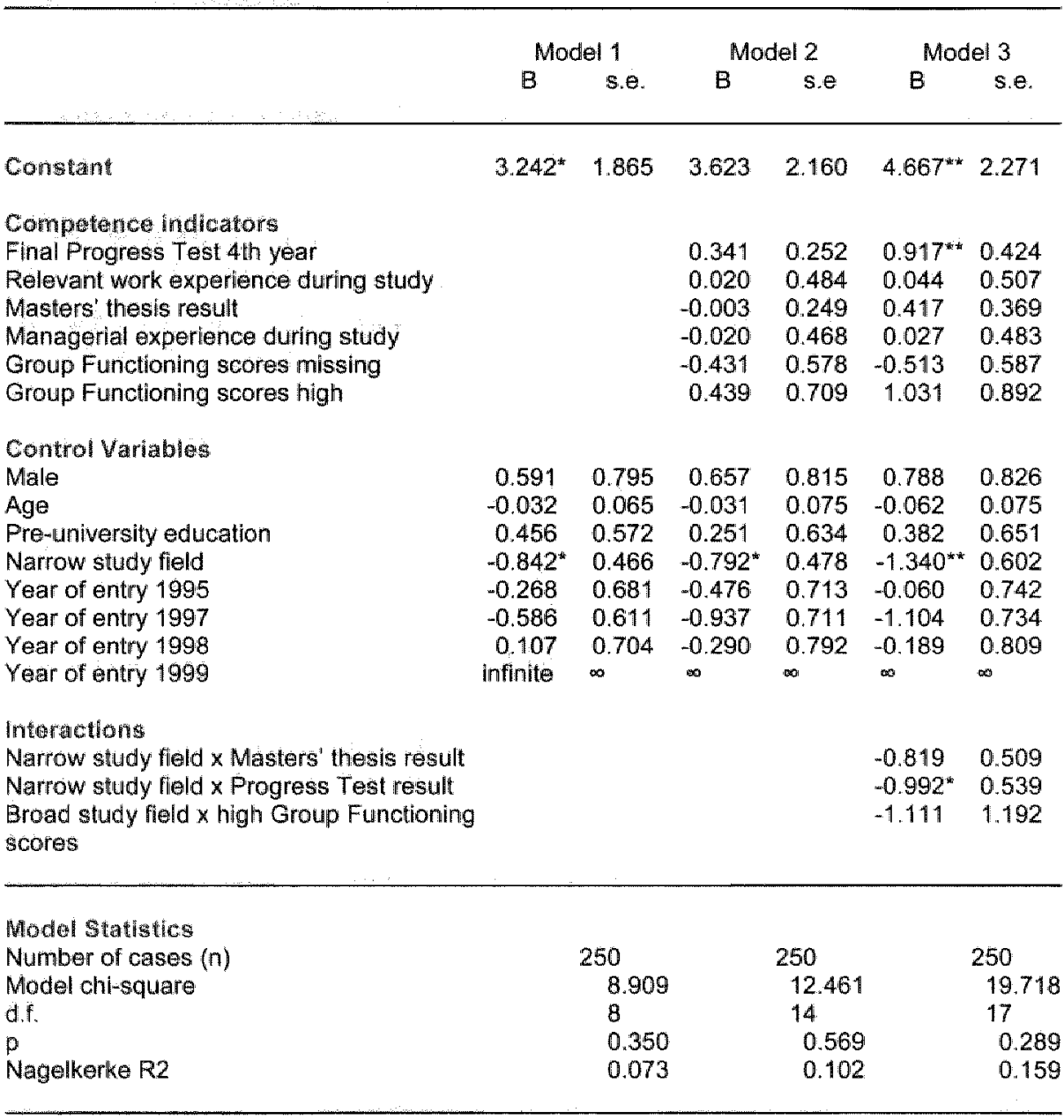

* significant at 0.10, ** at 0.05 .

Note 1: standardized values are used for final Progress Test scores and Masters" thesis results.

Note 2: Year of entry 1996 is the reference category for the "year of entry" control warilables. 
Transforming our estimated logistic model 3 in table 6.3 , a, the chance model 6.4 .1 reveals a chance to find a job for our reference person of $95 \%$. The effect of having followed a narrow study specialization instead of a broader one, leads to a chance of $85 \%$, which means a change of about $-10 \%$ of finding a job compared to the reference person, keeping all other variables constant. The effects of the Progress test and the interaction effect of the Progress test with narrow study field lead to changes in the chance of obtaining a job of $+3 \%$ and $-6.5 \%$ respectively. This means that the effect of the Progress test scores is positive in a broader study field and negative in a narrower study field. These results are summarized in Table 6.3.b.

Table 6.3.b

Changes in the chance to obtain a job for different values of the relevant variables

Chance for the reference person:

Changes in chance for

Model 3 of Table 6.3.a

Narrow study field (instead of broad study field)

Progress Test score (one sd increase)

Progress Test scores $x$ narrow study fieid (interaction term)

\section{Erfects of competence levels on obtaining an academic job}

The effects of competence indications on obtaining an academic job are presented in table 6.4.a.

In the first model, a negative effect of age and the entry year 1995 are found, as well as a positive effect of entry year 1998 . In the second model, including the competence indicators, positive effects are found for higher Masters' thesis results, having attained managerial experience during education and the higher (and missing) Group Functioning scores as compared to the lower scores. No effects are found for the narrowness of the study field. In the third model, no interaction effects appear to be significant, while the main effect of Masters" thesis result now drops just below the 0.10 significance level. The significance of the effect of the high Group Functioning scores has disappeared after introducing the interaction term with broad study field. And the estimate (and effect) of high Group Functioning scores itself is much smaller, because of controlling for this interaction term. The third model does in fact not add much information (see also the model statistics). In terms of what the effects mean for the changes in the chonce to obtain an academic job, we calculate these changes for our reference person again, based on the estimates in model 2 with main effects. The results are presented in table 6.4.b. 


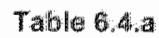

Regression estimates of the effects of competence indicators on obtaining an aciademic job

\begin{tabular}{|c|c|c|c|c|c|c|}
\hline & \multicolumn{2}{|c|}{ Model 1} & \multicolumn{2}{|c|}{ Model 2} & \multicolumn{2}{|c|}{ Model 3} \\
\hline & $\mathrm{B}$ & s.e. & $\mathrm{B}$ & s.e & $\mathbf{B}$ & s.e \\
\hline Consant & $3.319^{\text {*at }}$ & 1.376 & 1.483 & 1.549 & 1.262 & 1.518 \\
\hline \multicolumn{7}{|l|}{ Competence ind hoator } \\
\hline Fina Progress Test 4th year & & & -0.010 & 0.162 & .0 .061 & 0.197 \\
\hline Relevart work experience during study & & & 0.196 & 0.332 & 0.223 & 0.335 \\
\hline Masters" thesis result: & & & $0.465^{2}$ & 0.169 & 0.322 & 0.196 \\
\hline Managerial experience during study & & & $0.650^{* *}$ & 0.314 & $0.656^{\text {*i }}$ & 0.319 \\
\hline Group Functioning scores missing & & & $0.710^{\star \prime}$ & 0.390 & $0.715^{*}$ & 0.391 \\
\hline Group Functioning scores high & & & $1.137^{* *}$ & 0.452 & 0.677 & 0.6 .48 \\
\hline \multicolumn{7}{|l|}{ Comprol Vartablas } \\
\hline Male & 0.343 & 0.447 & 0.277 & 0.485 & 0.259 & 0.489 \\
\hline Age & $-0.127^{i}$ & 0.050 & .0 .096 & 0.056 & -0.089 & 0.0 .56 \\
\hline Pre-university education & -0.212 & 0.353 & 0.122 & 0.419 & 0.103 & 0.419 \\
\hline Narrow study fileld & 0.335 & 0.305 & 0.376 & 0.337 & 0.626 & 0.419 \\
\hline Year of entry 1995 & $-0.886^{*}$ & 0.522 & -0.484 & 0.557 & $=0.601$ & 0.577 \\
\hline Year of entry 1997 & 0.034 & 0.383 & -0.448 & 0.453 & -0.425 & 0.456 \\
\hline Year of entry 1998 & $1.030^{\mathrm{j} *}$ & 0.407 & $0.826^{\circ}$ & 0.466 & $0.790^{*}$ & 0.469 \\
\hline Year of entry 1999 & 0.477 & 0.729 & -0.122 & 0.855 & -0.005 & 0.855 \\
\hline \multicolumn{7}{|l|}{ Interactions } \\
\hline Narrow study field x Masters' thesis result & & & & & 0.534 & 0.381 \\
\hline Narrow study field $x$ Progress test score & & & & & 0.183 & 0.356 \\
\hline Broad study fleld $\times$ Group Functioning high & & & & & 0.690 & 0.783 \\
\hline \multicolumn{7}{|l|}{ sciores } \\
\hline \multicolumn{7}{|l|}{ Model Statistics } \\
\hline Number of cases $(\mathrm{n})$ & & 232 & & 232 & & 232 \\
\hline Madel chi-square & & 24.562 & & 52.373 & & 55.025 \\
\hline d.f. & & 8 & & 14 & & 17 \\
\hline P & & 0.002 & & 0.000 & & 0.000 \\
\hline Nagekerke $\mathbb{R}_{2}$ & & 0.134 & & 0.270 & & 0.282 \\
\hline
\end{tabular}

Note 1: Standardized values are used for the final Progress Test scores and the Masters' thesis result.

Note 2: Year of entry 1996 is the reference category for the "year of entry" controll variables.

" significant at $0.10, * *$ at $0.05, * * *$ at 0.01 .

Table 6.4.b

Changes in the chance to obtain an academic job for different values of relevant variables

Model 2 of Table 6.4.a

Chance for the reference person:

Changes in chance for Masters" thesis result (one sd increase)

Managerial experience (instead of no managerial experience) 
Effects of competence levels on obtaining a matching job for study field

The effects of competence indicators on obtaining a matching job are presented in table 6.5.a.

Table 6.5:a

Regression estimates of the effects of competence indicators on obtaining a matching job

\begin{tabular}{|c|c|c|c|c|c|c|}
\hline & \multicolumn{2}{|c|}{ Model 1} & \multicolumn{2}{|c|}{ Model 2} & \multicolumn{2}{|c|}{ Model 3} \\
\hline & $\mathrm{B}$ & $s_{n} \dot{e}$ & $\mathrm{~B}$ & s.e & $\mathrm{B}$ & s.e. \\
\hline Cunstant & 0.054 & 1.484 & 1.257 & $\$ .687$ & 0.950 & 1.706 \\
\hline \multicolumn{7}{|l|}{ Comprence indicators } \\
\hline $\begin{array}{l}\text { Final Progress Test } 4 \text { th year } \\
\text { Relevant work experience during }\end{array}$ & & & 0.426 & 0.208 & 0.260 & 0.234 \\
\hline $\begin{array}{l}\text { Relevant work experience oung } \\
\text { study }\end{array}$ & & & 0.117 & 0.382 & 0.120 & 0.385 \\
\hline Masters" thesis result & & & $0.446^{* \text { *it }}$ & 0.200 & 0.363 & 0.225 \\
\hline Nanagerial experience during & & & & & & \\
\hline study & & & -0.159 & 0.362 & -0.177 & 0.371 \\
\hline Group Functioning scores missing & & & -0.732 & 0.464 & -0.719 & 0.466 \\
\hline Group Functioning scores high & & & -0.358 & 0.524 & -0.954 & 0.837 \\
\hline \multicolumn{7}{|l|}{ Comtrol Variabies } \\
\hline Male & 0.396 & 0.571 & 0.598 & 0.608 & 0.543 & 0.608 \\
\hline Age & 0.040 & 0.053 & 0.015 & 0.060 & 0.026 & 0.061 \\
\hline Pre-university education & 0.549 & 0.425 & 0.460 & 0.476 & 0.458 & 0.478 \\
\hline Narrow study field & 0.588 & 0.369 & $0.744^{*}$ & 0.396 & $1.426^{10}$ & 0.685 \\
\hline Year of entry 1995 & 0.646 & 0.709 & 0.609 & 0.750 & 0.528 & 0.763 \\
\hline Year of entry 1997 & $-1.149^{-}$ & 0.455 & $-1.318^{\text {tik }}$ & 0.528 & $-1.305^{* i x}$ & 0.529 \\
\hline Year of entry 1998 & -0.511 & 0.478 & -0.677 & 0.564 & -0.740 & 0.562 \\
\hline Year of entry 1999 & $-2.545^{* * *}$ & 0.796 & -2794 & 0.864 & $-2.723^{* * * * *}$ & 0.871 \\
\hline \multicolumn{7}{|l|}{ Interactions } \\
\hline $\begin{array}{l}\text { Nariow study field } \times \text { Masters' } \\
\text { thesis result }\end{array}$ & & & & & 0.476 & 0.504 \\
\hline $\begin{array}{l}\text { Narrow study field x Progress test } \\
\text { score }\end{array}$ & & & & & 0.781 & 0.507 \\
\hline $\begin{array}{l}\text { Broad study field } \times \text { Gircup } \\
\text { functioning scores high }\end{array}$ & & & . & & 0.686 & 0.95 \# \\
\hline \multicolumn{7}{|l|}{ Model statistics } \\
\hline Number of cases (n) & & 231 & & 231 & & 231 \\
\hline Model chil-square & & 48.346 & & 33.944 & & 37.327 \\
\hline d.f. & & 8 & & 14 & & 17 \\
\hline p & & 0.019 & & 0.002 & & 0.003 \\
\hline Nagelkerke R2 & & 0.116 & & 0.207 & & 0.226 \\
\hline
\end{tabular}

Note 1: Standardized values are used for final Progress Test scores and Masters' thesis results. Note 2: Year of entry 1996 is the reference category for the 'year of entry' control variables.

" significant at $0.10,{ }^{* *}$ at 0.05, at 0.01 . 
Negative effects are found for the years of labour market entry 1997 and 1999 . In the second model, positrve effects are found for the Masters" thesis results and the Progress test scores. Also a positive effect is found for the narrower study fields, when controlled for competence indicators. Later labour market entry years reveal negative effects. Including the interaction effects in model 3 does not add much information compared to model 2. The significance of the Masters' thesis result drops just below the 0.10 level again. The significant elfect of the Progress Test has disappeared. We therefore illustrate the changes in chances to obtain a matching job based on the differences in the relevant competence variables of model 2 for our reference person, in table 6.5 .b.

Table 6.5 .5

Changes in the chance to obtain a matching job for different values of relevant variables

Chance for the reference person:

Model 2 of Table 6.5.a

Changes in chance for

Progress Test score (one sd increase)

$84 \%$

Masters' thesis result (one sd increase)

$+5 \%$

Nerrow study field (instead of broad study field)

$+5 \%$

$+7.5 \%$

\section{Effects of competence levels on wage}

The effects of competence indicators on wage are presented in table 6.6.a. The most extreme outliers in wages have been left out of analysis $(n=5)$. PhD students are left out of this analysis as well, since their wage is kept low by contract.

As can be seen from the table, age has a positive effect on wage. Later labour market entry years also reveal positive effects. A negative effect is found for the narrow study fields. In the second model, only a positive effect of relevant work experience appears, in addition to the effects of the control variables from the first model. In the third model, no extra effects are found for the academic level of the job, or for jobs matching the study field. Including the interaction terms, the effect of an academic job becomes significantly positive. Also a positive effect of high Group Functioning scores appears, in combination with a negative effect of these scores in broad study fields as compared to those in narrow study fields.

This time the interaction model reveals extra information in addition to a model with only main effects. Therefore we calculate the changes in wage for the relevant variables again for our reference person, based on model 4 . The results are presented in table 6.6 b. 


\section{Competence indicators and labour market success in 119}

Table 6.6.a

Regression estimates of the effects of competence indicators on gross hourly wages (log)

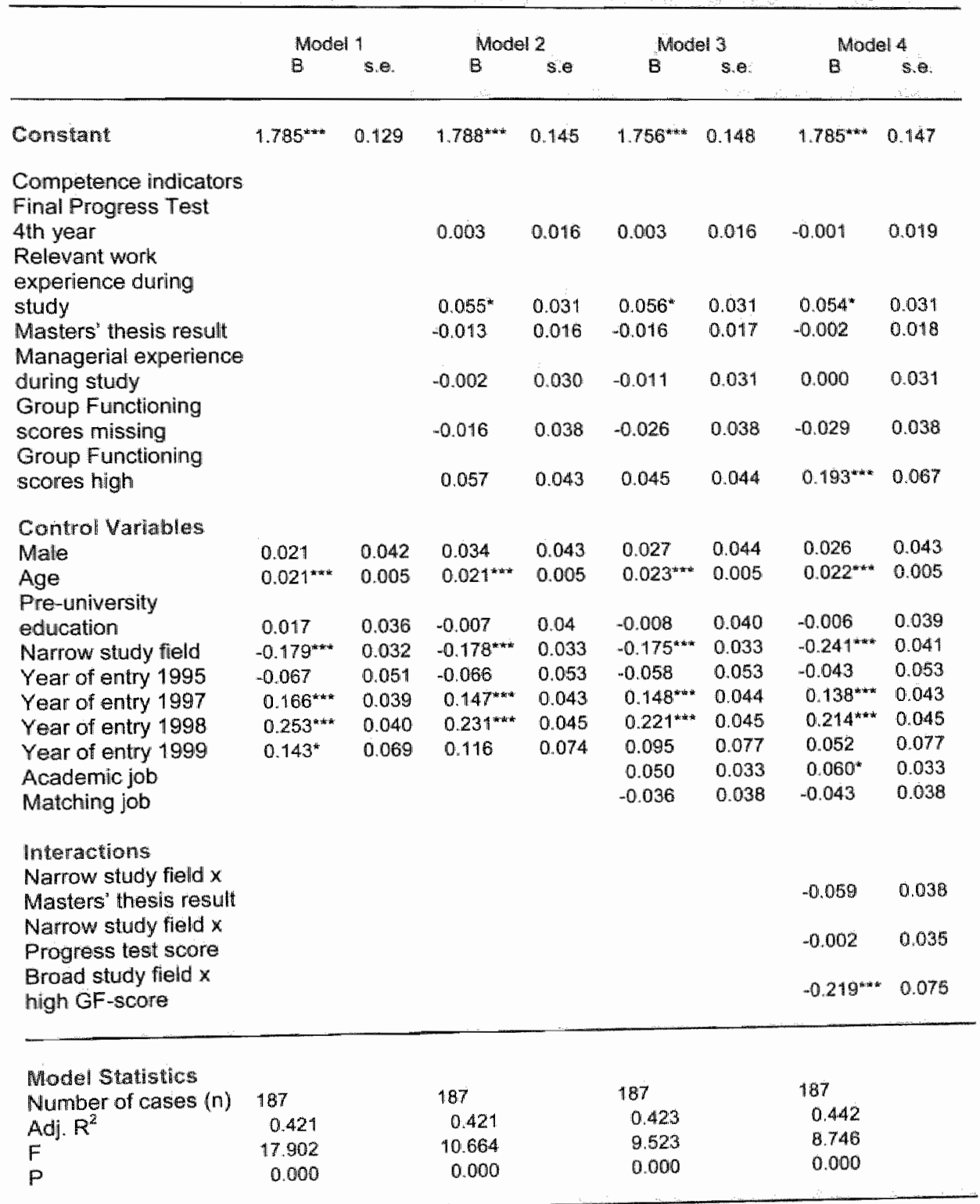

Note 1: Standardized values are used for the Progress Test scores and the Magters' theasts remults.

Note 2. Year of entry 1996 is the reference categon for the 'year of entry' control variables.

"significant at $0.10^{* *}$ at $0.05, "$ att 0.01 . 
Table to.t.tib

Changes in the wage for different values of relevant variables

Gross hourly wage for the reference person:

Model 4 of Table 6.6.a

10.65 euro

Changes in wage for

Relevant work experience, (instead of no experience)

+0.59 euro

Acadenic job (instead of lower level job)

+0.66 euro

High Group Functioning scores (instead of low scores)

*2.27 euro

Narrow study field (instead of broad study field)

-2.28 euro

Interaction Broad study field $x$ high Group Functioning scores

-2.10 euro

\section{Summary of results}

In table 6.7 the significant results of this study are presented together.

Table 6.7

Summary of significant results

\section{Competence indicators \\ Progress test scores \\ Work experience \\ Masters' thesis result \\ Manageriall experience \\ Group Functioning scores.}

\section{Control variables}

Narrow study field

Age

\section{Interactions}

Narrow study field $x$ Progress test

scores

Narrow study field x Masters' thesis

result

Broad study field $x$ Group Functioning

scores
$(+)$

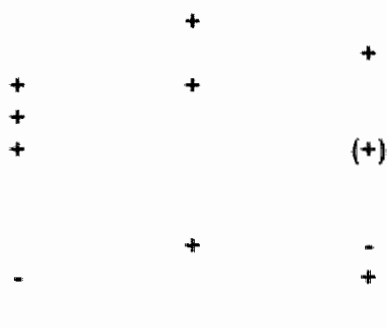

Note: + is positive effect, - is negative effect.

For obtaining a job, no single competence indicator has a significant main effect. Having attended a broad study program seems positive, however. For the other labour market outcomes, competence of students is relevant with mostly main effects: a higher Masters' thesis result is enhancing the chances to obtain an academic and a matching job, as expected, but does not lead to a higher wage. Managerial experience is relevant for obtaining an academic job. However, high 
Group Functioning scores seem to double the chances for a higher level (academic) job compared to subjects with low Group Functioning scores. These effects appear to have consequences for the wage as well; when controlling for interaction effects, both Group Functioning scores and the academic level of the job are positively related to wage. Higher Progress test scores have predictive value for obtaining a matching job. This is in line with our expectation and the findings of Heijke, Meng and Ramaekers (2003), that more specific competence enhances the chance to obtain a matching job. A narrow study field enhances the chance for a matching job as well. It is argued that in narrow programs the emphasis is more on specific competence (Heijke \& Meng, 2003), which in turn can enhance the chance for a matching job. However, no higher wage is found for matching jobs, which is in fact unexpected and in contradiction with matching theory that these jobs are better paid because of the direct productivity the worker can display. Work experience and ageing are leading to a higher wage, whereas a narrow study field leads to a lower wage. It seems that fluctuations in labour demand and supply play an important role, especially in the narrow study fields. Labour market entry years have considerable effects on labour market outcomes and the interactions between type of study field and competence indicators appear especially relevant for job chances and economic returns. ${ }^{7}$

\subsection{Conclusion}

In this study, we analyse the effects of different competence indicators, both specific and generic types of educational competence, on labour market outcomes of health sciences graduates. The aim of this empirical study has been to offer information on what types of competence students develop in education and what value these competences have for the labour market apart from more traditional human capital variables, such as work experience and managerial experience. The research question is: to what extent do specific and generic indicators of competence predict labour market outcomes? A number of conclusions can be drawn.

First, the resuits suggest that, especially for the quality of work (indicated by job level, horizontal mismatch and wages), educational competence of students is relevant and the indicators reveal a differentiated pattern. The Masters' thesis result, referring to the most integrated measurement of competence in this study, seems to have predictive value for both level and matching type of job. Furthermore, there is a tendency for specific indicators to be relevant for matching jobs, and generic indicators for obtaining higher level jobs. These findings are in line with other labour market studies that consider specific and generic competences retrospec- 
tively, by self-reports of graduates in a labour market survey (see e.g. Heijke, Meng \& Ris, 2003; Heijke, Meng \& Ramaekers, 2003).

Second, graduates differ in more aspects than is usually measured with traditional 'knowledge' and 'skills' tests. The high Group Functioning scores reveal large effects on labour market outcomes, which are independent of the other test scores. The instrument seems to distinguish the academic level workers from the non-academic level workers very well. This may be explained by the fact that scoring high on Group Functioning, reflecting a high participation in group discussion, the ability to work in a team and a good presentation of information and knowledge, refers to a pro-active attitude and a tendency to take responsibility for successful functioning of the group. Note that only the better students can obtain a point per course period. We think the aspects underlying the GF-scores contribute to an academic working attitude and therefore help to obtain an academic level job after education. Both self-selection and selection by employers may play a role in this process.

Third, the results with our Health Sciences sample seem to indicate that a narrow study field rewards its students with a better matching job, although they must look harder to find this job, and their wages are likely lower than those of their broader educated health sciences colleagues. Apparently, these graduates are more motivated to find such a matching job and are willing to wait longer and being paid less. This effect may point to a differentiation in intrinsic and extrinsic rewarding study fields, which can be relevant information for starting health sciences students. However, labour market demand and supply fluctuations are likely to play a role as well. In the first years of the 1990 s there was a period of high unemployment. And as long as the labour market demand is poor for academics, they seem to obtain jobs at a lower level (paying less) and outside their own domain (ROA, 2002). In the second half of the nineteen nineties the labour market demand recovered, especially for the higher educated. Our results indicate that the later years of labour market entry (in the second half of the 1990s) have positive effects on labour market outcomes, which reflects this increasing labour demand. However, the increasing demand seems to be the most profitable for the broad study fields. For graduates of narrow programs there is only an advantage in chances to find a matching job. It could therefore be argued that the recovering labour market demand has not (yet) reached the narrow domains and these graduates need to wait for better times and better wages, because they lack the flexibility to obtain other jobs, outside their own domain. From the perspective of an educational program, a lack of flexibility of its graduates on the labour market may be considered counter-productive. Already since the $1980 \mathrm{~s}$ all graduates have a general broader orientation on the labour 
makket. This is related to a larger need for and amphasis on employability and Rexbuly for the whour force in general (Versloot, Olaude $\&$ Thissen, 1998 ).

Related to future research, it seems vahable to continue research into the flects of educational competence indicators on labour markel outcomes. Avallable competence instruments and other assessments of knowledge and skils from daily practice of modem education need to be explored for their predictive walue for labour maket outcomes and functioning of graduates. Thereby the reserarch can butd on the avallability of emptrical data and contribute to the debate about what types of competence graduates need the most for work and how to measure them. Not only short term, but also longer-term labour market outcones refe of importance. What, for example, would the predictive effect of our instruments be on longer-term labour market success? And what are the efects of the indicators for other research samples, from other study fields, or from other learning enviromments than PBL curricula? Other indicators of labour market success, such as further learning possibilities, or the achievement of personal career goals could be interesting as well, to enlarge the value of the research outcomes for other research domains.

\section{Notes}

1. Although we realize that gaining managerial experience can be a motivated choice of studenis in the first place, this choice is not dividable from having gained the experience as such, in the data. We however argue this does not interfere with the parpose of our study to explore the value of different indicators of more specific and more generic types of competence.

2. Study specialisations can be considered as having a narrow of broad occupational scope. For our sample the following study specializations are considered having on narrow scope: biological health sciences, (human) movement sciences and mental health sciences. The following sixdy specializations are considered to have a broad scope: managentent of health care, nursing sciences, health promotion and education, and theory of health sciences. In Appendix $H$ the occupational scope of the specialisations is illustrated by the findings of a study of the Health seiences faculty (1996) into the type of jobs all graduates of the faculty (graduated until august 1995) had obtained.

3. The research sample may be considered heterogeneous with respect to the type of program attended, but we chose not to leave out one third of the sample. The correlations with test scores may be explained by previously attended vocational programs or work experiences. In the analysis, the wariables pre-university education versus other programs (dummy for highest level of secondary school) and rellevant work experiences (dummy yes/no) control for this. Multicollinearity seems not to be present among the remaining variables.

4. The estimates of the competence indicators all remain within ranges of plus or minus one standard error.

5. Our reference person is characterized by belonging to the reference categories of the dummy variables and having mean scores when relevan. Therefore our reference person is female, ages 26 years, followed other than pre-university education before entering the Health Scientices program, entered the labour market in 1996 , obtained no working nor managerial experience. followed one of the broader study specializations, and sconed average on all educational competence indicators 


\section{$124 \cdot$ Chapler}

6. The interaction effects of competence indicators with types of jobs (academic and matching) have been estinnated as well, but did not reveal new or extra information. Therefore this estimation is not presented separatelly.

7. Labour rarket demand and supply fluctuations seem larger and therefore more significant for nairrow study fields than fior broad fields (e.g. Allen, de Jong, Roeleveld, Verbeek \& de Vries, 2003). 


\section{Conclusions}

In this final chapter, the findings of the empirical studies will be summarized and an answer will be given to our research question: "To what extent do different types of competence predict labour market success of academic graduates?" In the first section, the contribution of the research will be discussed. Next, the main findings of the studies will be presented and the answer to our research question discussed. In the third section, theoretical implications of the research will be addressed, and some implications for academic educational policy and practice. Finally, the limitations of the research will be considered and some interesting roads for future research will be explored.

\section{Contribution of the research}

In four empirical studies, different indicators of competence are related to labour market outcomes of academic graduates. These indicators are assessments of learning results in academic programs, together with more traditional human capital variables as used in labour market research, such as managerial and work experience. In addition, the psychological concept of personality is used. The research therefore uses existing and more or less established, scientifically accepted instruments, indicating different types of competence, from different disciplinary fields. Linking these measures to individual labour market outcomes has formed an empirical contribution to the question what types of competence predict labour market outcomes.

On the one hand, most labour market research did not yet use direct measuress of competence. On the other hand, most educational research did not yet use labour market outcome indicators to obtain more insight in the relevance of what is learnt in education. In this thesis a first attempt has been made to empirically cross these borders.

\section{Main research findings}

The studies among economics graduates reveal that learning style and personality are better predictors of labour market success than individual differences in study results.

A striking finding is that a memorizing style of information processing (learning things by heart, literal recall) seems not dysfunctional during the academic 
study, but is negatively rewarded on the labour market afterwards, by a smaller chance to obtain an academic job. Differences in study results among these economics graduates only have an effect on the chance of obtaining a job as such. Learning style also seems related to the different types of jobs economists can obtain, although this relationship is harder to interpret: a global information processing style (grasping the most important points) seems more functional for managers than for accountants, which is in line with the expectation. But holism, for example (grasping the main point in short time, intuitive knowledge and broad associations) seems more functional for accountants than for managers.

Personality appears to have considerable predictive value for labour market outcomes among economics graduates. A successful personality profile consists of 'being ambitious, ascribing success and failure experiences to one's own responsibility, and being rather flexible (but not too much) and only willing to take reasonable risks'. This profile is positively related to both labour market chances and quality of the job. When measuring separate personality traits, the locus of control concept (which refers to experiencing self-responsibility for success and failures) and type A behaviour (displaying ambitious and striving behaviour) have the strongest effects on labour market outcomes, except for the academic level of the job. On obtaining an academic job, the Masters' thesis result and managerial experience have positive effects. Although the Masters' thesis result is considered a specific competence indicator, it has more 'generic' competence properties as compared to e.g. the Progress Test and skills tests in education, as has been argued in the health sciences study as reported in chapter 6 . So, among economists, generic competence like learning style, personality and managerial experience seems most important. Of the more specific indicators, it is the relative generic Masters' thesis that has the most profound effect. Note that some of these competences, like the personality profile, are not even explicitly related to, or affected by the educational context. In all, generic competence predict labour market success of economists better than domain-specific competence. This is in line with our expectations for economists, based on the broadness of their occupational domain.

The main findings for medical graduates are that the specific indicators do not make much difference for their labour market outcomes. The indicators of competence that are used are more precise in assessing relevant medical skills acquired in education (accumulation of domain knowledge, practical medical skills tests) as compared to traditional knowledge tests or other GPA"s. Nevertheless, we can not confirm their predictive validity in explaining differences in labour market outcomes of medical doctors. This is contrary to our expectations. The medical degree as such 
seems therefore an entrance ticket for their labour market. These results can be explained as follows.

The medical study prepares for a highly regulated labour market where the medical degree as such is conceived as a suffieient quality indicator for the required degree of specific competence. And because the medical program is very standardized, the variation between students in their specific competences is relatively small. The selection and allocation process will therefore be rather based on individual preferences and social networks, or on generic competences such as communication skills and professional attitude. This explanation would be in line with the importance of the social learning processes for medical doctors, at least from the moment on that the educational program is combined with practice in the professional field in the so-called clinical clerkships (see e.g. Slotnick, 2001).

For health scientists, both generic and specific competences affect labour market outcomes. The more generic competences, such as high Group Functioning scores (referring to a students' productive contributions to the learning in, and functioning of educational groups) and managerial experience during education, enhance the chance for an academic job, whereas the specific competences, like the Progress Test scores (referring to the accumulation of domain knowledge) enhance the chance to obtain a matching job for study field. Specific competence related to relevant work experience during education increases wages. The Masters" thesis result (which, although closely related to the study domain, requires several generic and specific types of skills and knowledge), enhances both the chances for a higher level (academic) job and a matching job. The narrowness of the study field within health sciences has its own main effects, but reveals no meaningful interaction effects with competence indicators. This means that specific competence is important for health scientists, but not specifically in narrow study specializations. And generic competence is important as well, but not specifically in broad study specializations. A narrow study field is mainly important for obtaining a matching job (independent from specific competence), whereas the broader fields improve the chance for a job and the wages. The academic level of the job is not dependent on the broadness of the study field. Within the field-specific labour matket domain of health sciences, both specific and generic competence are therefore important, independent from the narrowness of the study specialisation within this field.

\section{Answer to the research question}

This thesis has tried to find an answer to the following research question: What indicators of specific and generic competence of academic graduates affect successful labour market entry? It can be answered as follows: both generic and 
specific indicators of competence predict labour market success. The effects of generic competence are the largest within the broadest or generic labour market domain (economics). This is in line with our expectation. At the same time, and contrary to our expectation; the effect of specific competence indicators is the smallest in the narrowest or professional job domain (medicine).

In the field-specific labour market domain of health scientists, both generic and specific competence have positive effects, although the effect of the generic competence seems to exceed the effect of the specific competence. Therefore it can be stated in general terms that generic competences seem most important during labour market entry of academic graduates.

Furthermore, it can be argued that the effects of what is learnt in education are substantial, but not crucial. Effects of study results are the largest within the health sciences study where the indicators are the most diverse and have the most innovative characteristics, i.e. the Group Functioning scores and the Progress Tests (longitudinal and cumulative measurements). In the study among medical doctors (where the Progress test is used as well), the study results do not really add something to the value of the degree as such. And among economists, although study results reveal positive predictive effects, especially the personality profiles of the graduates, indicators that are considered not to be much influenced by education, appear to have the most predictive value for better labour market outcomes.

\section{Implications}

The research findings and conclusions lead to several implications that are related to theoretical considerations, and educational practice and policy.

First, the findings and conclusions have some implications for labour market theory. If we conclude that individual differences in competence acquired in education is important but not crucial for labour market entry, what role does education play for labour market entry, then? How can we put this in perspective?

The importance of generic competence in general for success after graduation is in line with developments in society and on the labour market (globalisation, unlimited access to knowledge and information for everyone) in which employability and life-long learning have become the standard (see e.g. Worldbank, 2003). It can however be stated that the academic educational programs legitimise the entrance to the relevant labour market domains for their graduates by giving them a comparative advantage in these domains, based on the acquisition of the relevant field-specific human capital.

As argued in the theoretical section in chapter 2, so-called assignment models within job matching theory (Sattinger, 1993) specify conditions under which the role of education, and thereby the development of certain types of competence, are 
relevant and lead to comparative advantages for individuals on the labour market. The comparative advantages based on human capital in our three sesearch samples can be related and differentiated to the three labour market domantws wat are distinguished for academics: the professional, the field-specific and the genertic labour market domain (de Wolf, 2000). Notably, the variation in acquired competence among students between different educational programs is larger than the variation in acquired competence among students with educational programs.

But this does not diminish the importance of the variation in competence development among students within study programs, as our explorative empirical studies reveal.

Among economists, both specific and generic competence measurements provide additional value to the educational degree in explaining labour market outcomes. But in their generic domain, more generic and relative stable competence items seem to make most of the difference in the selection and allocation process.

Among our medical doctors, specific competence indicators do not provide additional information in explaining differences in labour market outcomes. However, practically every medical graduate obtains a physicians' job. Therefore the medical degree functions as an entrance ticket for the professional medical domain, assuming the presence of the required minimum of profession-specific competence.

And among health scientists, both generic and specific indicators of competence contribute to the explanation of labour market outcomes. The competence assessments therefore reveal predictive information in addition to the educational degree as such. Specific competence mainly helps to obtain work in the relevant field. Generic competence helps to obtain work at an academic level. And independently, a narrow study specialisation within the field of health sciences enluances the chance for a matching job as well.

Although generic competence is highly relevant for all graduates, the three studies (economics, medicine and health sciences) revealed a different emphasis on the importance of their field-specific competence, corresponding to the requirements of the labour market domain that the graduates are prepared for.

For education, the implications of the research are merely related to the use of the competence concept and competence measurements.

In the first place, academic education does not take the labour market relevance of competence as a first priority when formulating educational goals and objectives. The concept of competence in fact remains controversial for the educational context, especially in academic education (Westera, 2001; van Merrienboer et al., 2002). Often separate aspects (knowledge and skills) are 
measured and assessed, in traditional formats, such as multiple choice tests (Stratmans, 1998). But the competence concept triggers a more integrated view on what students learn in education and on what makes them productive in labour and socilety afterwards. It seems therefore legitimate and even profitable to pay attention to assessments that are not only functional within the educational context, but have predictive value for the labour market, for functioning of the students after graduation as well.

Second, measurement properties of instruments used in education (such as those used in this research) affect the way students learn and study, which in turn affects labour market outcomes. As educational research into the relation between assessment and learning behaviour of students has shown (see e.g. Seegers, 2004; Verhoeven, 2003, Frederikson, 1984), students are more likely to be driven by the way of examination in the educational program, than by the curriculum as such.

For example, our study among economists shows that a reproductive information processing style does not harm progression within the academic program. But it is negatively rewarded afterwards on the labour market by a lower chance to obtain an academic job. A reconsideration of instruments that assess learning results in a way which does not punish the reproductive learning style seems therefore warranted. This is especially relevant in the light of the renewed interest in examination in higher education in general. As expressed in one of the advisory reports of the Dutch Council for Education (the Onderwijsraad), the quality of the examination will play a role of importance in the new accreditation procedures (Onderwijsraad, 2004).

A third implication is that what students learn in education is probably best assessed by using diverse instruments. These instruments should measure integrated, as well as more separate competences and competence aspects. This can bring about a rich information base on the competence acquired in education by students and on the developmental process as such. It seems well possible to distinguish more generic and speefific competence measurements separately (compare for example the Group Functioning scores for skills in teamwork and communication, and the Progress Tests scores for knowledge acquisition) with each having additional value in revealing information on the competence of students. And as we saw, these different competences have different rellationships with labour market outcomes as well. Remarkably though, these instruments have now been abandoned from the assessment practice in health sciences without replacing it with new alternatives.

As a linal and rather practical implication of the research, it is therefore recommended that universities and other educational institutes manage the information on learning results and competence of students consistently and systematically. This makes it possible to conduct evaluations that can help to make policy decisions on curricula and examinations more evidence-based. 


\section{Linitations and future research}

The research in the context of this thesis is designed as a first step on the empirical road to explore the labour market value of competence indicators for academic graduates. The generalizability of the findings is therefore limited. In addition, a direct comparison between the three types of graduates is difficult, due to the dissimilar compentence indicators, available for each group. Furthemore, it should be noted that we examined the effects on the labour market entry phase, while neglecting the longer term outcomes.

To overcome these limitations, the amount of empirical material should be enlarged: to compare the findings within and between different types of graduates, and with other universities and to explore the longer term outcomes of competence in education. The new Bachelor / Master structure in higher education should be helpful and leading in a more structured and even internationally comparable database. Because of the current lack of uniform and systematic data gathering within departments and universities, this empirical material is still widely diverse and incomplete, and a challenge for interpretation in the near future. As an illustration: current assessment practices in education at Maastricht University have already changed since the data collection for this dissertation. In the medical curriculum, for example, nowadays the 'professional attitude' is assessed, every six weeks (course period) by the tutor (teacher) with a short item list. And portfolios are used for the assessment of metacognitive and reflective skills. This implies more generic assessment instruments that would have had value in the research as conducted in this thesis as well. This could have given the opportunity to measure generic competence as acquired in medical education. To what extent would the indication of professional behaviour predict outcomes for physicians? This is just one example for possible new empirical hindings.

Future research could contimue to explore assessment practices in educational programs and consolidate findings on the relation between indicators of competence and learning results on the one hand and individual labour market outcomes on the other hand. There is still a considerable lack of such material. Sorenson (1994) already pled for this type of research more than a decade ago. And recently Bills. (2003) expressed the need again to gain more insight into the value of competence for the labour market.

The assessment of the labour market value of competence indicators seems valuable because the environment for which people are educated changes and welcomes constant innovation. Academic graduates are to be prepared for that. And 
education needs the empirical material to adapt to these changes and react in a thoughtful (evidence-based) way.

It seems interesting for further research, and for student and graduate counselling as well, to create a more detailed roadmap on the relation between competence development in education and labour market outcomes of graduates: In What domains, what type of jobs and in competition with what other types of graduates do they enter the labour market and create their careers? In times of rapid changes in both education and on the labour market, such a roadmap should be kept up to date to stay informative, of course.

It seems also valuable to look at other assessments of competence than the ones we used here, for example self-reports of students on their own competence. This gives the opportunity to validate the findings by applying different research methods. Employer reports on the relevant competence items could be used as an alternative data source as well.

The evaluation of labour market success can also be extended towards indicators of performance quality, i.e. from the employers' perspective, or towards more subjective indicators of labour market success.

And last but not least, the "in vivo" selection and allocation process itself on the labour market of academic graduates is still an intriguing area for research. All kinds of questions about the relative importance of specific and generic competence for labour market entry are in fact answered by what happens in the fairly unknown mechanism of selection and allocation itself, i.e. the interaction between the employer and the potential employee. Is it a matter of self-selection of graduates to opt for a certain job, or a matter of preference of the employer for a certain employee? What is the relative importance of these two factors, under what conditions? What is their relation with labour market demand and supply?

So far, and as expected, more questions arise from the research than answers can be given. Therefore, in this time of continuous development and changes on many levels of functioning of people and society, research into competence of people, the role of education and labour market productivity has only begun. 


\section{Summary}

What type of competences of academic graduates affect and predict successful labour market entry? This question is central to the research in this dissertation. The research has been conducted among graduates in economics, medicine and health sciences of Maastricht University. Four empirical studies elaborate the predictive value of different indicators of individual variation in specific and generic competence for labour market success. The research includes several new indicators of competence to predict labour market outcomes. Generic competence refers to learning style of students, personality, group functioning, managerial experience and GPA's in secondary education. Specific competence is closer related to the study domain and refers to the amount of acquired domain-specific knowledge, the Masters' thesis result, work experience and GPA's during academic programs.

In chapter 2, the main expectations for the three research samples are formulated based on labour market theory concerning the (segmented) labour market for academic graduates and the comparative advantages of graduates of different study programs on the labour market.

In chapters 3 to 6 , the empirical studies are described. They all four explore the effect of different types of competence on labour market success. This success is measured by indicators referring to job chances and the type and quality of the job. These include, for instance, whether graduates have a job, whether the job matches the level and field of the study program, the wages and the job category, such as accountants among economists and general practitioners among physicians. All of these indicators refer to the situation one year and a half after graduation.

The overall conclusion is that generic competence is most important for graduates" entry on the labour market. Among economists, learning style aspects reveal more predictive effects on labour market outcomes than their study results (chapter 3). And compared to study results and other traditional human capital variables, personality has the most profound predictive value for labour market success among economists (chapter 4). Among medical doctors, there are in fact no significant effects of the individual differences in competence on labour market outcomes. Selection and allocation seem regulated by factors other than the specific types of competence we have been able to measure (chapter 5). The individual differences in specific competence, i.e., in the acquired domain-specific knowledge and clinical medical skills, may be interpreted as being less important than having 
attained the medical degree as such. For health scientists both generic as well as specific indicators are predictive. The generic indicators, i.e. group functioning of students during the study, and whether they have acquired managerial experience or not, affect the (academic) level of the job. The specific indicators, i.e. the acquired domain-specific knowledge and the Masters' thesis result, affect whether the job fits the study program followed (matching job). The chances for having a matching job are also affected by having followed narrower and therefor tighter field-specific specialisations within health sciences (chapter 6).

In the conclusions (chapter 7) the implications for the theoretical role of education are addressed and the use of the competence concept and its assessment within academic education. The theoretical considerations refer to the additional value of individual differences in specific and generic competence within an educational program for labour market outcomes, as compared to the educational program as such. This value seems larger for broader programs than for a narrow professional program such as medicine. In addition, generic competences seem to have more profound effects for labour market outcomes than specific competences as measured in this research.

With respect to the use and assessment of the competence concept in academic education, the following recommendations are made: competence assessments should have labour market value, in addition to their value within educational context. In this respect, the learning style of students is informative and worth the effort to measure. It can be affected and directed within education and has not only effects on learning outcomes of students, but on labour market outcomes as well. Second, assessments need to align with the desired learning style and learning outcomes for students. This implies for instance implementing assessments that requite an academic learning style (writing assigniments instead of multiple choice exams). Third, assessments should measure both integrated components as well as separate aspects of competence. Integrated components are measured by, for example, the Masters' thesis. Writing assignments also require more integrated types of knowledge and skills. Separate aspects of competence are reflected by, for example, group functioning scores of students (a generic type of competence), or knowledge tests, such as the Progress test (specific type of competence). Diverse and evidence-based assessments of learning results could bring about a rich information and data base, which is, last but not least, a prerequisite for further research into and development of competence measurement in education. 


\section{Samenvatting}

Welke soorten competenties van academisch afgestudeerden beïnvloeden en voorspellen een succesvolle arbeidsmarktintrede? Deze vraag staat centraal in het onderzoek van dit proefschrift dat verricht is onder economen, artsen en gezondheidswetenschappers van de Universiteit van Maastricht. In een viertall empirische studies is nagegaan in hoeverre verschillende indicatoren van specifieke en generieke competentie een voorspellende waarde hebben voor arbeidsmarktsucces. In het onderzoek wordt een aantal nieuwe indicatoren gebruikt om arbeidsmarktsucces te voorspellen. Generieke competentie betreft hier de leerstijl, de persoonlijkheid, het functioneren in groepen van studenten, besturlijke ervaring en gemiddelde eindexamencijfers van de middelbare school. Specifieke competentie heeft een veel nauwere relatie met het studiedomein en betreft de verworven domein-specifieke kennis, de scriptie, relevante werkervaring en gemiddelde studieresultaten in het academische programma.

In hoofdstuk 2 worden de belangrijkste verwachtingen voor de drie onderzoeksgroepen geformuleerd. Dit gebeurt op basis van theorie over de rol van het onderwijs en hoe academici van verschillende studies comparatieve voordelen hebben op de arbeidsmarkt. Tevens worden de gebruikte data beschreven. In hoofdstuk 3 tot en met 6 zijn de empirische studies opgenomen die elk voor een aparte groep afgestudeerden exploreren welke soort competentie de meeste voorspelkracht heeft voor objectieve indicatoren van arbeidsmarktsucces. Deze zijn gerelateerd aan de kans op een baan, het type baan en de kwaliteit van het werk.

De belangrijkste conclusie is dat over het algemeen de generieke competenties of competentie aspecten de belangrijkste zijn. Bij economen laat de leerstijl meer woorspellende effecten zien op arbeidsmarktuitkomsten dan hun studieresultaten (hoofdstuk 3). En vergeleken met studieresultaten en andere traditionelere indicatoren van menselijk kapitaal heeft persoonlijkheid het grootste aandeel in de voorspelkracht bij economen. (hoofdstuk 4). Bij artsen is nauwelijks effect te vinden van de gemeten competentie-indicatoren en lijkt de selectie en allocatie op de arbeidsmarkt dus gereguleerd te worden door andere dan de gemeten specifieke factoren (hoofdstuk 5). De individuele verschillen in specifieke competentie, in de verworven domeinkennis en klinisch-medische vaardigheden, lijken daarmee ondergeschikt aan het belang van het artsendiploma zelf. Bij gezondheidswetenschappers zijn zowel generieke als ook specifieke indicatoren voorspellend, 
maar dit is onafhankelijk van de breedte van de studierichting. Hierbij voorspellen de generieke indicatoren (functioneren in groepen, bestuurservaring) met name het (academische) niveau van de baan en de specifieke indicatoren (verworven domeinspecifieke kennis en scriptiebeoordeling) of de baan past bij de opleiding. De kans op een passende baan wordt ook verhoogd door het volgen van smallere, dus meer vakspecifieke afstudeerrichtingen binnen de studie (hoofdstuk 6).

In de conclusies (hoofdstuk 7) wordt aandacht geschonken aan de implicaties voor de theorie over de rol van het onderwijs voor de arbeidsmarkt en voor het gebruik van het competentieconcept en mogelijke metingen in academisch onderwijs. De theoretische implicaties betreffen de toegevoegde waarde van individuele verschillen in specifieke en generieke competenties binnen een studieprogramma voor arbeidsmarktuitkomsten. Deze waarde lijkt groter voor bredere programma's dan voor een smal professioneel programma zoals geneeskunde. Bovendien lijkt generieke competentie hierbij dan meer of grotere effecten te hebben op arbeidsmarktsucces dan specifieke competentie.

Voor wat betreft het gebruik en toetsing van het competentieconcept in academisch anderwijs worden de volgende aanbevelingen gedaan: metingen van competentie zouden behalve waarde binnen de onderwijscontext ook arbeidsmarktwaarde moeten hebben. Leerstijl b.v. is informatief en de moeite waard om te meten in het onderwijs, omdat het beïnvloed en (bij)gestuurd kan worden. Het heeft effect op de leeruitkomsten van studenten, maar ook op hun arbeidsmarktuitkomsten. Ten tweede dienen metingen zodanig afgestemd te worden dat ze het effectueren van de gewenste leerstijl en leeruitkomsten van studenten bevorderen. Dit betekent bijvoorbeeld dat er (meer) metingen geïmplementeerd moeten worden die een academische leerstijl bevorderen (schrijfopdrachten i.p.v. multiple choice tests). Ten derde lijkt toetsing beter als ze divers is, dus als er zowel meer geïntegreerde componenten als ook aparte aspecten van competentie gemeten worden. Meer geinntegreerde componenten van competentie worden gemeten met schrijfopdrachten, zoals b.v. met de seriptie. Aparte aspecten van competentie kunnen gemeten worden met kennistoetsen, zoals de Voortgangstoets (specifieke competentie) of met een malat woor het werken in groepen (generieke competentie). Diverse en onderbouwde (z.g. evidence-based) metingen van leerresultaten van studenten kunnen bijdragen aan een rijke bron van informatie en data voor onderzoek. Deze bron van data is nodig om het onderzoek en de ontwikkelingen op het gebied van competentiemetingen in het onderwijs verder richting te geven. 


\section{References}

Allen, J., Jong, U. de, Roeleveld, J., Verbeek, F. \& Vries, R. de (2003), Wo-Monitor 2000. 2001: Arbeidsmarksucces van academici: verschillen en determinanten, VSNU, Utrecht.

Allen, J., Ramaekers, G. \& Verbeek. A. (2000), WO-Monitor 1999, Kengetallen Reeks, VSNU, Utrecht.

Allen, J. \& Velden, R. van der (2001), Educational mismatches versus skill mismatches: effects on wages, job satisfaction, and on-the-job search, Oxford Economic Papers, 3 : 434-452.

Anderson, A. \& Marshall, V. (1994), Core versus occupation-specific skills, Horslam, The Host Consultancy, Labour Market Intelligence Unit.

Appels, A. (1985), De Jenkins Actinity Sunvey, Lisse: Swets \& Zeitlinger.

Arnold, L. (2002), Assessing Professional Behavior: Yesterday, Today, and Tomorrow, Academic Medicine, 77(6): 502-515.

Atkinson, R. L., Atkinson, R. C., Smith, E. E \& Hilgard, E. R. (1987), Introduction ro Psychology, Orlando, Florida, U.S.A., Harcourt Brace Jovanovich Publishers.

Atlay, M. \& Harris, R. (2000), An institutional approach to developing students' "transferable" skills, Immovations in Edwcation and Training Imernational, 37(1): 7684.

Austin, E. J., Deary, I. J., Whiteman, M. C., Fowkes, F. G. R., Pedersen, N. L., Rabbitt, P., Bent, N. \& McInnes, L. (2002), Relationships between ability and personality: does intelligence contribute positively to personal and social adjustment? Personality ana Individual Differences, 32: 1391-1411.

Baker, E. L. (2001), Testing and Assessment: A Progress Report. Educational Asseswment, 7(1): $1-12$

Barrick, M. R. \& Mount, M. K. (1993), Autonomy as a moderator of the relationships between the Big Five personality dimensions and job performance, Journal of Applied Psychology; 78: 111-118.

Barrick, M. R. \& Mount, M. K. (1991), The Big Five personality dimensions and job performance: a meta-analysis, Personnel Psychology, 44: 1-26.

Becker, G. S. (1983), Human Capital: A Theoretical and Empirical Analysis, with special reference to Education, New York, National Bureau of Economic and Social Research.

Becker, G. S. (1964), Munan Capiral, New York: NBER.

Berg, G. J. van den, Holm, A. \& Ours, J. C. van (2002), Do stepping-stone jobs exist? Early career paths in the medical profession, Joumal of Population Economics, 15; 647-665.

Berg, P. T. van den (1992), Persoonlijkheid en werkbeleving: de validiteit vam persoonlijkheidswagenlijsten, in het bijzonder die wan een spanningsbehoeftelijst, Doctoral Dissertation, Amsterdam: Centrale Huisdrukkerij Vu. 
Berkel, H. J. M. wan, Nuy, H. J. P. \&. Geerligs, T. (1995), The influence of progress tests and block tests on study behaviour, Insiructional Science, 22: $317-333$.

Berkel, H. J. M. van, Sprooten, J. \& Graaff, E. de (1.993), An individualized assessment test consisting of 600 items, The development of a progress test for a multi-master program health sciencess curriculum, In: Bouhuijs, P. A. J., Schmidi, H. G. \& Berkel, H. J. M. van (eds), Problem-Based Learning as an Educational Strategy, Maastricht, Network of Community-Oriented Sciences.

Bers, T. (2001), Measuring and reporting competencies, New Directions for Instifutional Research, 110: $29-40$.

Biggs, J. B. (1993), What do inventories of student's learning processes really measure? A theorefical review and clarification, British Jownal of Educational Psychology, 63: 3 19.

Biggs, I. B. (1978), Individual and group differences in study processes, British Jowmal of Educational Psychology, 48: 266-279.

Bills, D. B. (2003), Credentials, Signals and Screens: explaining the relationship between schooling and job assignment, Review of Educational Research, 73(4): 441-469.

Blau, G. J. (1987), Locus of control as a potential modierator of the tumover process, Joumal of Occupational Psychology, 60: 21-29.

Boekaerts, M., Pintrich, P. R. \& Zeidner, M. (2000), Handbook of selfregulation, San Diego, CA, Academic Press.

Boone, C. (1992), Onderzoek naar het verband tussen de perceptie van controle van bedriffsleiders en de strategite en de ressultaten wan ondernemingen in de meubelindustrie, Doctoral Dissertation, Antwerpen: University of Antwerpen.

Boone, C., De Brabander, B., Gerits, P. \& Willemé, P. (1990), Relation of scores on Rotter's I-E scale to short-term and long-term control expectancies and fatalism, Psychological Reports, 66: 1107-11.11.

Boone, C., De Brabander, B. \& Witteloostuijn, A. van (1999), The impact of personality on behavior in five prisoner's dilemma games, Journal of Economic Psychology, 20: 343 377 .

Boone, C., De Brabander, B. \& Witteloostuijn, A. van (1996), CEO locus of control and small fintm performance: an integrative framework and empirical test, Journal of Management Srudies, 33: 667-699.

Borg, M. O. \& Shapiro, S. L. (1996), Personality type and student performance in principles of Economics, Jownal of Econonic Education, 27: 3-25.

Borghans, L. \& Grip, A. de (1999), Smal en Breed opleiden: productiviteit versus flexibilliteit, Gids voor de opleidingspraktijk, 28: 1-33. Deventer, Samson.

Borghans, L. \& Ramaekers, G. W. M. (1993), De doorstroom van limburgse basisarisen naar medische beroepsopleidingen, Maastricht, Research Centre for Education and the Labour Market.

Bosch, H. van den, \& Gerritsen, R. (1997), Het werwerven van conceptuele competentie als doelstelling van wetenschappelijk onderwijs, Tijdschiff Voor Het Hoger Onderwijs, 15: $365-389$. 
Boshuizen, H. P. A. (2004), Does Practice make Perfect? A slow and discontinuous process, In: Bostraizen, H. P. A., Bromme, R. \& Gruber, H. (eds), Professional Lewming: Gaps and Transinons on the way from nowice to expew, Dordrecht, Kluwer Academic Publishers.

Boshuizen, H. P. A., Bromme, R. \& Gruber, H. (eds) (2004), Professional Leaming: Gops and Transitions on the way from movice to expert, Dordiecht, Kluwer Academic Publishers.

Boshuizen, H. P. A. \& Schmidt, H. G. (2000), Development of clinical reasoning expertise; implications for teaching, in: Higgs, J. J. \& Jones, M. (eds), Chincal reasoning in the healh professions. second completely revised edinon, Oxford, Butterworth Heineman.

Boudreau, J. W., Boswell, W. R. \& Judge, T. A. (2001), Effects of personality on executive career success in the United States and Europe, Jounal of Vocational Behavior, 58: 5381.

Boyatzis, R. E., Cowen, S. S., Kolb, D. A. and Associates (1995), Immowation in

Professional Education. Steps on a Joumey from Teaching to Leaning, The Siory of

Change and Invention at the Weatherhead School of Mamagement, San Francisco: Jossey-Bass Publishers.

Breen, $\mathbb{R}$., Velden, R. van der \& Willems, E. (1997), Opportwities for School-teavers in different segments of the dutch labour market, Paper presented at the Transition in Youth Workshop, Dublin, September 1997.

Brunello, G. \& Comi, S. (2004), Education and earnings growth: evidence from 11 European countries. Economics of Education Review, 23: 75-83.

Burke, R. J. \& Deszka, E. (1982), Preferred organizational climates of type A individuals. Journal of Vocational Behovior, 21: 50-59.

Caspi, A. \& Roberts, B. W. (2001), Personality development across the life course: the argument for change and continuity, Psychological Inquiny, 12: 49-66.

Cawley, J., Heckman, J. \& Vytlacil, E. (2001), Three observations on wages and measured cognitive ability, Laboum Economics, 8(4): 419-442.

Cellini, H. R. \& Lorenz, J. R. (1983), Job club group training with unemployed offenders, Federal Probation, 46: 46-50.

Chiswick, B. R., Liang Lee, Y. \& Miller, P. W. (2003), Schooling, literacy, numeracy and labour market success, The Economic Record, 79(245); 1654181.

Chizmar, J. F. \& Ostrosky, A. L. (1998), The one-minute paper: some empirical findings, Journal of Economic Education, 29: 3-10.

Crombag, H. F., Gaff, J. G. \& Chang, T. M. (1975), Study behaviour and academic performance, Tijdschriff wor Onderwijsresearch, 1: 3-14.

Dalen, J. van, Kerkhofs E. Knippenberg-Van den Berg, B. W. van, Hout, H. A. van den, Scherpbier, A. J. J. A. \& Vleuten, C. P. M. van der (2002), Longitudinal and concentrated communication skills programmes: two Dutch medical schools compared, Advances in Healih Sciences Education, 7: 29440.

De Brabander, B., Boone, C. \& Gerits, P. (1992), Locus of control and Cerebral asymmetry. Perceptual \& Motor Skills; $75: 131-143$. 
Dolmans, D. H. J. M., Wolfhagent, H. A. P., Vleuten, C. P. M. wan der \& Wijnen, W. H. F. W. (2000), Probleemgestuurd onderwijs in het hoger onderwijs: een hype of paradigmawerandering? In: Lunden, J. van der \& Roelofs, E. (eds), Leren in Dialoog: een discussie over scanenwerkend leren in onderwits en opleiding, pp. 179-195, Wolters-Noordhof, Groningen.

Dreyfus, S. E. (2004), The five stage model of adult skill acquisition, Bulletin of Science, Technology \& Society, 24: 177-181.

Duncan, G. I. \& Dunifon, R. (1998), Soft Skills and long-run labor market success. In: Polachek, S. W. \& Robst, J. (eds), Research in Labor Economics, 17: 123-149, London: JAI Press.

Eijs, P. wan \& Heijke, H. (2000), Mismatch between Occupation and Education and the Costs and Benefits of Job-related Training. In: Heijke, H. \& Muysken, J. (eds), Educatrom and Training in a Knowledge-Based Economy, Houndmills/London and New York, Macmillan Press / St.Martin's Press: 159-189.

Eklund-Myrskog, G. (1997), The influence of the educational context on student nurses" conceptions of learning and approaches to learning, British Journal of Educational Psychology, 67: 371-381.

Elshout-Mohr, M., Oostdam, R. \& Overmaat, M. (2002), Student assessment within the context of constructivist educational settings, Studies in Educational Evaluation, 28: 369-390.

Elshout-Mohr; M., Oostdam, R. \& Overmaat, M. (2001), Assesment wan beroepscompetenties; beslissingen bij het invoeren van integratieve beoordelingen in de opleiding, Tijdschrift Voos Het Hoger Onderwijs, 19(3): 205-221.

Entwistle, N... Hanley, M. \& Hounsel1, D. (1979), Identifying distinctive approaches to studying, Higher Education, 8: 365-380.

Entwistle, N. J. \& Tait, H. (1994), The Revised Approaches to Studying Inventory, Edinburgh, Centre for Research into Learning and Instruction, University of Edimburgh.

Ethington, C. A., Thomas, S. L. \& Pike, G. R. (2002), Back to the Basics; Regression as it schould be. In: Smart, J. C. \& Tiemey, W. G. (eds), Higher Edwcation: Handbook of Theory and Research, Dordrecht, Kluwer Academic Publishers.

European Commission, (1996), Teaching and Learning: Towards the Learaing Society, White Paper, Luxembourg: European Commission.

Faculty of Health Sciences, Department of Promotion and PR (1996), Study labour Market posilion graduates, Maastricht, Rijksuniversiteit Limburg.

Feather, N. T. \& Volkmer, R. E. (1988), Preference for situations involving effort, time pressure, and feedback in relation to type A behavior, locus of control, and test anxiety, Jownal of Persionality and Social Psychology, 55: 266-271.

Feij, J. A. \& Zuilen, R. W. van (1984), Handleiding bij de spanningsbehoeftelyst (SBL). Lisse: Swets \& Zeitlinger.

Filer, R. K. (1981), The influence of affective human capital on the wage equation. In: Ehrenberg, R. (ed.), Research in Labor Economics, 4: 367-416, Greenwich CT: JAl Press. 
Finnie, R. \& Frenette, M. (2003), Earning differences by major field of study: evidence fron three cohorts of recent Canadian graduates, Economics of Education Review, 22:179. 192.

Frank, M., Lavy, 1. \& Elata, D. (2003), Implementing the Project-Based Learning Approach in an academic engineering course International Jownal of Technology and Design Education, 13: $273-288$.

Franken, R. E. (1988), Sensation seeking, decision making styles, and preference for individual responsibility, Personality and Indioidual Differences, 9:139-146.

Frederiksen, N. (1984), The real test bias: influences of testing in teaching and learning, American Psychologist, 39 (3): 193-202.

Friedman, M. \& Rosenman, R. H. (1974), Type A Behavior and Your Hart, New York: Knopf.

Fruyt, F. de \& Mervielde, 1. (1999), RIASEC types and big five traits as predictors of employment status and nature of employment, Persomel Psychology, 52: 701-727.

Furnham, A., Jackson, C. J. \& Miller, T. (1999), Personality, leaming style and work performance, Personality and Individual Differences, 27: 1113-1122.

Gijselaers, W. H. (1999), Is PGO millenniumproof? Renovatie en innovatie van een succesvoll onderwijsmodel, Tijdschrift Voor Het Hoger Onderwijs, 17: 69-82.

Gijselaers, W. H., Nuy, H. \& Mullink, J. P. M. (1989), Studie-aanpak en sndierendement: deelrappont 1 wan studies naar het propedeuserendement wan de FdEW, Vakgroep Onderwijsontwikkeling em Onderwijsresearch.

Gjerberg, E. (2002), Gender similarities in doctors" preferences - and gender differences in final specialisation, Social Science \& Medicine 54: 591-605.

Glaser, R. (1990), Towards New Models for Assessment, International Journal of Educational Research, 14: 475-483.

Gleick, 1. (1999), Faster: The accelaration of just abowt ewerything, New York: Pantheon Books.

Goldacre, M. J. L. \& Lambert, T. W. (2000), Stability and change in career choices of junior doctors: postal questionnaire surveys of the United Kingdom qualifiers of 1993 , Medical Education, 34: 700-707.

Goldsmith, A. H., Veum, J. R. \& Darity, W. (1997), The impact of psychological and human capital on wages, Economic Inquiry, 35: 815-829.

Grave, W. S. de, Schmidt, H. G. \& Boshuizen, H. P. A. (2001), Effects of problem-based discussion on studying a subsequent text: a randomized trial among first year medical students, Instructional Science, 29:33-44.

Hall, D. T. \& Moss, J. E. (1998), The New Protean Career Contract: Helping Organizations and Employees Adapt, Industrial Relations, 26(3): 22-37.

Hansen, W. L. (1998), Integrating the practice of writing into economics instruction, In: Becker, W. E \& Watts, M. (eds), Teaching economics to undergraduates: alternatives to chalk and talk, Cheltenham, U. K., Edward Elgar: 79.118.

Hartog, J. (2001), On human capital and individual capabilities, Review of Income and Wealh, 47(4): 515-540. 
Hayes, J. Allison, C.W. (1997), Leaming styles and training and development in work setings: lessons from educational research, Educational Psychology, 17 (182): 185193.

Heijke, H., Koeslag, M. \& Velden, R. van der (1998), Education, Skills and Wages. In: Heijke, $\mathbb{H}$ \& Borghans, L. (eds), Towards a Transparant Labour Market for Educational Decisions, Aldershot, Ashgate Publishing Ltd.

Heijke, H. \& Meng. C (2003), The effects of higher edncaton programme characteristics on allocation and performance of the graduates: A European view Paper prepared for the Workshop Human Capital december 2003, Maastricht University, Maastricht.

Heijke, H., Meng, C. \& Ramaekers, G. (2003), An investigation into the role of Human capital competences and their pay-off. International Journal of Mompower, $24(7): 750 \times 773$.

Heijke, H., Meng, C. \& Ris, C. (2003), Fitting to the job: the role of generic and vocational competencies in adjustment and performance, Labour Economics, 10:215-229.

Heijke, H. \& Ramakers, G. (1998), The knowledge and skills of economics graduates and their significance in the labour market. In: Nijhof, W. J. \& Streumer, J. N. (eds), Key Qualifications in Work and Education, Dordrecht, Kluwer Academic Publishers: 221246.

Hogan, R., Hogan, J. \& Roberts, B. W. (1996), Personality measurement and employment decisions: questions and answers, American Psychologist. 51: 469-477.

Hogerheide, R. P. (1994), De beroepskeuzetheorie wan John L. Holland. In: Spijkerman, $\mathbb{R}$. M. H. Vincken, A. J. R. \& Weekenborg, M. J. M. (eds), Handboek Studie- en Beroepskeuzebegeleiding, Alphen aan den Rijn: Samsom H.D. Tjeenk Willink.

Holland, J. L. (1985), Making Vocational Choices: a theory of vocational personalities and work enviromments, Odessa, Florida: Psychological Assessment Resources.

Huigen, T. (2002), Methodiek Schoolverlatersinforwatiesysteem 2001, ROA working papers, Maastricht, Research Centre for Education and the Labour Market.

Huigen, T. \& Wolbers, M. (1999), Methodiek Schoolverlatersinformatie-systeem 1998, ROA working papers, Maastricht, Research Centre for Education and the Labour Market.

Industrial Research and Development Advisory Committee (IRDAC) (1991), Skill Shorrages in Furope, Bruissels.

Irandoust, M. \& Karlsson, N. (2002), Impact of Preferences, Curriculum and Learning Strategies on Academic Success, Education Economics, 10 (1): 41-47.

Judd, P. C. \& Oswall, P. A. (1997), Employment Desirability: the interactive effects of gender-typed profile, stimulus sex, and gender-typed occupation, Sex Roles, 37: 467476.

Judge, T. A. B Bretz, R. D. (1992), Effects of work values on job choice decisions, Joumal of Applied Psychology, 77 (3): 261-271.

Kilduff, M. \& Day, D. V. (1994), Do chameleons get ahead? The effects of self-monitoring on managerial careers, Academy of Management Joumal, 37: 1047-1060.

Kilduff, M: \& Krackhardt, D. (1994), Bringing the individual back in: a structural analysis of the intermal market for reputation in organizations, Academy of Management Joumal, 37: 87-108. 
Kolb, D. A. (1976), Leaming Style Inventory: rechmical manual, Englewood Chifs, NJ; Prentice-Hall.

Kolb, D. A. (1984), Experiential Learning; experience as a source of leaning and development, Englewood Cliffs, NJ, Prentice-Hall.

Koning, J. de (1998), The Return to Education. In: Heike, H. \& Borghans, L. (eds), Towarws a Transparant Laboui Market for Educational Decisions, Aldershot. Ashgate Publishing Litd.

Lancaster, S. J., Colarelli, S. M., King, D. W. \& Beehr, T. A. (1994), Job applicant similarity on cognitive ability, vocational interests, and personality characteristics: do similiar persons choose similiar jobs? Educational and Psychological Measurement, 54 (2): 299-316.

Lindblom-Ylänne, S. \& Lonka, K. (2001), Students' Perceptions of Assessment Practices in a Traditional Medical Cuniculum, Advances in Health Sciences Edwcation, 6: 121-140.

Linden, A. S. R. van der \& Velden, R. K. W. van der (1998), The effects of anemployment and mismatches on future job match and earnings: In: Lange, T. (ed.), Undersianding the School-1o-Work Transition: An International Perspective, Commack NY: Nova Science Publishers, 109-124.

Long, J. S. (1997), Regression Models for Categorical and Limited Dependent Variables, Thousand Oaks, Sage Publications Inc.

Loo, J. B. van \& Semeijn, J. H. (2004), Defining and Measuring Competences: An Application to Graduate Surveys, Qwality \& Quantity, 38(3): $331-349$.

Luijk, S. van, Wolfhagen, H. A. P., \& Grave, W. S. de (1990), Het woortijdig beeindigen van de studie Geneeskunde aan de Rijksuniversiteit Limburg, Inteme rapportage van de vakgroep Onderwijsontwikkeling \& Onderwijsreseareh; Maastricht, Rijksuniversiteit Limburg.

McMullan, M., Endacott, R., Gray, M. A., Jasper, M., Miller, C. M. L., Scholes, J. \& Webb, C. (2003), Portfolios and assessment of competence: a review of the literature, Joumal of Advanced Nursing, 41(3): 283-294.

McNabb, R. (1987), Labour Market Theories and Education. In: Psacharopoulos, G. (ed.), Economics of Education: Research and Sthdies, Oxford, Pergamon Press.

Meng, C. \& Heijke, H. (2004), Student time allocation, the learning environment and the acquisition of competencies, Working paper, Research Centre for Education and the Labour Market, Maastricht.

Merrienboer, J. van, Klink, M. R. van der \& Hendriks, M. (2002), Competenties: Van Complicaties tot Compromis, Oner schwiffers en begrenzers, Een studie in opdracht van de Onderwijsraad, Den Haag, Onderwijsraad.

Mulder, R. (1997), Leren Ondernemen, Ontwerpen wan Prakijkleersituaties voor het Beroepsonderwijs, Doctoral Dissertation, Rotterdam, EUR: 200.

Mulders, W. J. (1995), De generieke meerwarde van academische kwaliteiten, Nijmegen, JOWO; KU Nijmegen.

Muller, W. \& Gangl, M. (eds) (2003), Transitions from education to work in Europe; the integration of youth into EU labour markets, Oxford, Oxford University Press. 
Murnane, R. J., Willet, J. B., Braatz, M. J. \& Duhaldeborde, Y. (2001), Do different dimensions of male high school students' skills predict labor market success a decade later? Evidence from the NLSY, Economics of Education Review, 20:3 11 1-320.

Nicholson, N. (1996), Towards a new agenda for work and personality: traits, self-identity. "strong" interactionism, and change, Guest Editors" Introduction, Applied Psychology: An Internathonal Review, 45 (1): 1-28.

Nijliof, W. J. (1998), Qualifying for the future, In: Nijhof, W. J. \& Streumer, J. N. (eds), Key Quallications in Work and Education, Chapter 2, pp. 19-38, Dordrecht: Kluwer Academic Press.

Norcini, J. J. \& Lipner, R. S. (2000), The relationship between the nature of practice and performance on a cognitive examination, Academic Medicine, 75 (10 Suppl.): 68-70.

Nordhaug, O. (1993), Human Capital in Organizations, Competence, Training, and Learning, Bergen, Oxford University Press.

Noman, G. R. (1988), Problem-solving skills, solving problems and problem-based learning, Medical Education, 22: 279-286.

Nuy, H. P. J. (1991), Interactions of study orientation and student's appreciation of structure in their educational environment, Higher Education, 22: 267-274.

Nuy, H. J. P., Berkel, H. J. M. van \& Til, C. T, van (1994), Evahalie wan de FOG-procedure aan de FdGW, Maastricht, Rijksuniversiteit Limburg: vakgroep Onderwijsontwikkeling \& Onderwijsresearch.

Nuy, H. P. J. \& Moust, J. H. C. (1990), Students and problem-based learning: how well do they fit in? Joumal of Professional Legal Education, 8 (2): 97- 1. 14.

Onderwijsraad (2004), Advies Examinering in het Hoger Onderwijs, Den Haag.

Paulson, K. (2001), Using competencies to connect the workplace and postsecondary education, New Directions for Institutional Research, 110: 41-54.

Pervin, L. A. (1990), Personality: Theory and Research $\left(5^{\text {th }}\right.$ ed.), London: John Wiley and Sons.

Perkins, D. \& Salomon, G. (1989), Are cognitive skills context-bound? Educational Researcher, Jan-Feb: 16-25.

Perquin, M. L. F. (1999), Stwdiestakersenquete studiejaar 1997/1998, Interne rapportage van de capaciteitsgroep Onderwijsontwikkeling \& Onderwijsresearch, t.b.v. de examencommissie. Maastricht, Universiteil Maastricht.

Petr, J. L. (1998), Student writing as a guide to student thinking, In: Walsad, W. B. \& Saunders, P. (eds), Teaching undergraduate economics: a handbook for instructors. Boston, Irwin/MeGraw-Hill.

Presland, J. (1994), Learning styles and CPD, Educational Psychology im Practice, 10 (3): 179. 1184.

Psacharopotilos, G. (1979), On the weak versus the strong version of the screening hypothesis, Economics Letter, 4: 181-185.

Quinn, R. P. \& Price, J. (1998), The Demand for Medical Education: an Augmented Human Capitall Approach, Economics of Education Review, 17 (3): 337-347.

Ramaekers, G. W. M. (1997), WO-Monitor' economie 1996: basismeting cohort '95, ROA-R1997/4. Maasricht: Research Centrum voor Onderwijs en Arbeidsmarkt. 
Ramaekers, G. W. M. (1996a), WO-scanner economie 1995, Basismeting colhorf 94, ROAR-1996/15, Maastricht: Research Centrum voor Onderwijs en Arbeidsmarkt:

Ramaekers, G. W. M. (1996b), WO-scamer econome 1994, Basismeting cohori 93, ROAR-1996/, Maastricht: Research Centrum voor Onderwijs en Arbeidsmarkt.

Ramaekers, G. W. M. (1994), Arbeidsmarkiscanner Rijksuniversiteit Limburg: Basismeting cohort "92, ROA-R-1994/7, Maastricht: Research Centrum voor Onderwijs en Arbeidsmarkt.

Ramaekers, G. W. M. \& Heije, J. A. M. (1993a), Arbeidswarktscanner Rijkswiwersiteit Limburg: Basismeting cohort 91, ROA-R-1993/13, Maastricht: Research Centrum voor Onderwijs en Arbeidsmarkt.

Ramaekers, G. W. M. \& Heijke, J. A. M. (1993b), Arbeidsmarktsconmer Rijksumersiteit Limburg: Basismeting cohort 90. ROA-R-1993/1, Maastricht: Research Centrum voor Onderwijs en Arbeidsmarkt.

Ramaekers, G. W. M. \& Welters, R. A. M. H. M. (1998), Start wan de loopbaan na de Universiteit Maastricht 1996-1997, ROA-R-1998/7, Maastricht: Research Centrum voor Onderwijs en Arbeidsmarkt.

Raymark, P. H., Schmit, M. J. \& Guion, R. M. (1997), Identifying potentially useful personality constructs for employee selection, Persomel Psychology, 50: 723-736.

Rayner, S. \& Riding, R. (1997), Towards a categorisation of cognitive styles and learning styles, Educational Psychology, 17: 5-27.

ROA (2002), Schoolverlaters iussen onderwijs en arbeidsmarkt 2001, ROA-R-2002/8, Maastricht, FdEWB, Universiteit Maastricht.

Ross, M. E., Salisbury-Glennon, J. D., Guarino, A., Reed, C. J. \& Marshall, M. (2003), Situated Self-Regulation: Modelling the Interrelationships Among Instruction, Assessment, Learning Strategies and Academic Performance, Edhcational Research and Evaluation; $9(2)$ : 189-209.

Robbins, S. P. (1996), Organizational Behavior: Concepts, Controversies, Applications $\left(7^{\text {th }}\right.$ ed.), Englewood Cliffs NY: Prentice Hall.

Robertson, I. T. (1994), Personality and personnel selection, In: Cooper, C. L. \& Rousseau, D. M. (eds), Trends in Organizational Behawior, London: John Wiley, 84-93.

Rotter, J. B. (1966), Generalized expectancies for internal versus external control of reinforcement, Psychological Monographs, 80: Number 609.

Schein, V. E., Mueller, R. \& Jacobson, C. (1989), The relationship between sex role stereotypes and requisite management characteristics among college students, Sex Roles, 20: 103-110.

Sattinger, M. (1993), Assignment models of the distribution of of earnings, Journal of Economic Literature, 31 (june): 831-880.

Savery, J. R. \& Duffy, T. M. (1995), Problem Based Learning: and instructional model and its constructivist framework, Educational Technology, sept/oct: $31-38$.

Schlusmans, K., Slotman, R., Nagtegaal, C. \& Kinkhorst, G. (1999), Competentlegerichte leeromgevingen, Utrecht, Lemma B.V. 
Schmeck, R. R, Ribich, R. \& Ramanaiah, N. (1977), Development of a self-report inventory for assessing individual differences in leaming processes, Applied Psychological Measurement, 1: 413-431.

Schmidt, H. G. \& Molen, H. T. van der (2001), Self-reported Competency Ratings of Graduates of a Problem-based Medical Cumiculum, Academic Medicine, 76(5): 466468 .

Schmidt, H. G. Moust, J. H. C. (1998), Probleemgestuurd onderwijs; praktijk en theorie, Groningen, Wolters-Woordhoff.

Schmid, H. G., Norman, G. R. \& Boshuizen, H. P. A. (1990), A cognitive perspective on medical expertise: theory and implications, Academic Medicine, 65: 611-621.

Schmidt, A. G. \& Vermeulen, L. (2004), Longuterm effects of problem-based learning: evidence based on gradwates" self-ratings, Working paper, Rotterdam, Erasmus Uniwersity.

Schneider, B. (1987), The people make the place, Personnel Psychology, 40: 437-453.

Schouwenburg, H. C. (1996), Een onderzoek naar leerstijlen, Tijdschrift voor Onderwijsresearch, 21 (2): $151-161$.

Schultz, T. W. (1961), Inwestment in Human Capital, American Economic Review, 51: 1-17.

Seegers, M. S. R. (2004), Assessment en leren als twee-eenheid: onderzoek naar de impach wan assessment op leren, Inaugurale rede (inaugural speech). Leiden, Universiteit Leiden.

Semeijn, I. H., Boone, C., Velden, R. wan der \& Witteloostuijn, A. van (2005), Graduates' personality characteristics and labour market entry; an empirical study among Dutch economics graduates, Econowics of Education Review, 24 (1): 67-83.

Semeijn, J. H. \& Velden, R. K. W. vain der (2002), Aspects of Learning style and labour market entry; an explorative study. In: Johannessen, T.A., Pedersen, A. \& Petersen, K. (eds), Teaching Today the Knowledge of Tomorrow, 6, Dordrecht, Kluwer Academic Publishers.

Shrauger, J. S. \& Osberg, T. M. (1981), The relative accuracy of self-predictions and judgement by others in psychological assessment, Psychological Bulletin, 90 (2): 322 351.

Simons, P. R. J. (1997), Ontwikkeling van leercompetenties, Opleiding en Oniwikkeling, 6: $17-20$.

Simons, P. R. J. Linden, J. L. wan der \& Duffy, T. (eds), (2000), New Learning, Dordrecht, Kluwer Academic Publishers.

Slotnick, H. B. (2001), How Doctors learn: Education and Learning across the Medicalschool-to-practice Trajectory, Academic Medic ine, 76 (10): 1013-1026.

Smit, W. \& Os, W. wan (1985), Van studeergedrag nar studieresultaat, In: Lodewijks, J.G. \& Simons, P.R.J. (eds), Zelfstandig Leren (bijdragen aan de ORD'84), Lisse: Swets \& Zeitlinger.

Smith, M. \& George, D. (1994), Selection Methods. In: Cooper, G.L. \& Robertson, I.T. (eds), Key Reviews in Managerial Psychology: Concepts and Research for Practice, London: John Wiley and Sons. 
Snijders, T. B. \& Bosker, R. (1999), Multhlevel Analysis. An introduchon to basio and advanced mulinlevel modelling, Trowbridge, Wiltshire, The Cromwell Press Ltd:

Snyder, M. (1974), Self-monitoring of expressive behavior, Jownal of Parsonality and Social Pychology, 30: 526-537.

Snyder, M. \& Copeland, J. (1989), Self-monitoring processes in organizational seftings, In: Giacalone, R.A. \& Rosenfeld, P. (eds), Impression Management in the Organization, Hilsdale NY: Erlbaum, 7-19.

Snyder, M. \& Gangestad, S. (1986), On the nature of self-monitoring: matters of assessment, matters of walidity, Journal of Pensomality and Social Psychology. 51: 125-139.

Serenson, A. B. (1994), Opportunity and Training Effects on Careers, Network on Transitions in Youth.

Spector, P. E. (1982), Behavior in organizations as a function of employee's locus of control, Psychological Bulletin, 91 : 482-497.

Spence, A. M. (1974), Market Signalling: Informational Tramsfer in Hiring and Related Screening Processes, Cambridge, Harvard University Press.

Spencer, L. M. \& Spencer, S. M. (1993), Competence at Work: Models for Superior Performance, New York: John Wiley and Sons.

Spenner, K. I. (1985), The upgrading and downgrading of occupations: issues, evidence, and implications for education, Review of Educational Research, 55: 125-154.

Stasz, C. (1998), Generic Skills at Work: Implications for Occupationally-Oriented Education. In: Nijhof, W. J. \& Streumer, J. N. (eds), Key Qwalifications in Work and Education. Dordrecht, Kluwer Academic Publishers: 187-206.

Stillman, P. L., Wang, Y., Quang, Q., Zhang, S., Yang, Y. \& Sawyer, W. D. (1997), Teaching and assessing clinical skills: a competency-based programme in China, Medical Education, 31: 33-40.

Stoof, A., Martens, R. L., Merriënboer, J. J. G. van \& Bastiaens, T. J. (2002), The Boundary Approach of Competence; A Constructivistic Aid for Understanding and Using the Concept of Competence, Human Resource Developmen Review, 1 (3): 345-365.

Stratmans, G. (1998), Toetsing wan Comperenties. Arnhem, CITO: 41.

Tamblyn, R., Abrahamowicz, M., Brailowsky, C., Grand"Maison, P., Lescop, J., Norcini, J, Girard, N. \& Haggerty, J. (1998), Association between licensing examination scores and resource use and quality of care in primary care practice, Joumal of the Academic Medical Association, 16, 280 (11): 989-996.

Tett, R. P., Jackson, D. N. \& Rothstein, M. (1991), Personality measures as predictors of job performance: a meta-analytic review, Personnel Psychology, 44: 703-742.

Thomas, J. W. (2000), A Review of research on Project-Based Learning, San Rafiel, CA, Autodesk Foundation.

Thornton, J. (2000), Physician choice of medical specialty: do economic incentives matter? Applied Economics, 32: 1419-1428.

Thurow, L. C. (1975), Geweraing Inequality, New York: Basic Books.

Timmers, W. (1997), Persoonlyjkheid, leerstijl en studieresultat, Los Conact, 17:9-10. 
Toolsena, B. (2003), Werken met Competenties, Naas een instrument woor de identificatie van competemites, Doctoral Dissertation. leerstoelgroep CBB. University of Twente, Enschede.

Tsang, M. M. (1993), Shifts of students' leaming styles on a social work course, Social Work Education, 12 (1): 62-76.

Velden, R. K. W. van der \& Wieling, A. (1994), De arbeidsmarktkansen per opleiding. In: Scholten, H. De Groot, S. C. (eds), Arbeidsmarkt en sociale zekerheid: beleid en beweging, Tilburg / Delf: IVA / Eburon, 106-114.

Verhoeven, B. H. (2003), Progress Testing: The utility of an assessment Concept, Doctoral Dissertation, Maastricht, Malastricht University.

Vernetten, Y. (1999), Consistency and Variability of Student Leaming in Higher Education, Tilburg, Katholieke Universiteit Brabant: Doctoral Dissertation 153.

Vermunt, J. D. (1998), The regulation of constructive learning processes, British Journal of Educational Psychology, 68: 149-171.

Vermunt, J. D. (1996), Metacognitive, cognitive and affective aspects of learning styles and strategies; a phenomenographic analysis, Higher Education, 31: 25-50.

Vermunt, J. D. H. M. (1992), Leerstijlen en sturen vaw leerprocessen in het hoger onderwijs: natr een procesgerichte instructie in zelfstomdig denken, Doctoral Dissertation. Amsterdam/Lisse: Swets \& Zeitlinger.

Versloot, A. M., Glaudé, M. Th. \& Thijssen, J. G. L. (1998), Employability: een pluriform arbeidsfenomeen, Rotterdam, Drukkerij Brinkman, BV.

Vleuten, C. van der, Luijck, S. J. van \& Beckers, H. J. M. (1989), A written test as an alternative to performance testing, Medical Education, 23: 97-107.

Vleuten, C. P. M. van der, Verwijnen, G. M. \& Wijnen, W. H. F. W. (1996), Fifteen years of experience with progress testing in a problem based learning curriculum, Medical Teacher, $18(2): 103-109$.

Weinert, F. E. (2001), Concept of Competence: A Conceptual Clarification, In: Rychen, D. S. \& Salganik, L. H. (eds), Defining and selecting key competencies, Göttingen, Hogrefe \& liviber Pubishners.

Weiss, A. (1995), Human Capitall vs Signalling Explanations of Wages, Jownal of Economic Perspectives, $9(4) ; 133-154$.

Westera, W. (2001), Competences in education: a confusion of tongues, Journal of Cumpiculum Studies, $\mathbf{3 3}$ (1): 75-88.

Wetenschappelijke Raad voor het Regeringsbeleid (WRR) (1995), Hoger onderwijs in fasen, Rapporten aan de Regering, 47, Den Haag: SDU.

Willians, R. G, Klamen, D. A., MeGaghie, W. C. (2003), Cognitive, social and environmental sources of bias in clinical performance ratings, Teaching and Learning in Medicine, 15: 270-292.

Wolf, I. de (2000), Opleidingsspecialisatie en arbeidsmarktsucces van sociale wetenschappers, ICS dissertation, Utrecht.

World Bank (2003), Lifelong Learning in the Global Knowledge Economy, Challenges for Developing Countries, Washington DC, The World Bank. 
Young, G. (1999), Using portfolios for assessment in teacher preparation and health sciences, In: Brown, S. \& Glaser, A. (eds). Assesswem Matters in Higher Education: Choosing and Using Diverse Approaches, Buckingham, Society for Research into Hugher Education \& Open University Press, 122-131.

Zang, L. (2003), Does the big five predict learning approaches? Personality and Individual Differences, 34: 1431-1446.

Zolingen, S. J. van (1995), Gewraagd: Slewtelkwalificaties (Wanted: Key Qualifications), Doctoral Dissertation, Nijmegen, Katholieke Universiteit Nijmegen.

Zuckerman, M. (1991), Psychobiology of Personality, Cambridge MA: Cambridge University Press.

Zuckerman, M. (1979a), Sensarion Seeking: Beyond the Optimal Level of Arousal, Hillsdale NY: Erlbaum.

Zuckerman, M. (1979b), Sensation seeking and risk taking. In: Izard, C.E. (ed.), Emotions in Personality and Psychopathology, New York: Plenum Press, 163-197. 



\section{Appendices}

\section{Appendix A}

Job Classification for economics graduates (chapter 3 )

The classification of jobs used in chapter 3 was designed to distinguish a limited number of meaningful categories. To make the categories of jobs as meaningful as possible, an approach is used, which combines ideas of Holland (1985), the division used by Spenner (1985), and the knowledge of job experts working at the Research Centre for Education and the Labour Market (Dutch shortcut ROA).

Based on the findings of Holland (1985) a distinction can be made in six personality types and their preferences for six different environments. Consequently, the work environment type can also be translated in terms of jobs or functions. Holland distinguishes the artistic, the realistic, the intellectual, the social, the entrepreneurial and the conventional type (of personality, environment, job). Being dominantly characterized by one type, persons, environments and jobs do also have characteristics of the other types, to a certain extent. In fact, the typology represents a framework: a hexagram. Persons, environments and jobs can be described by their position on this figure. The characteristics determine the position and some characteristics do relate easier than others, which means they are more consistent than others. In this hexagram there are three 'opposite' characteristics: conventional with artistic, realistic with social and intellectual with entrepreneurial. In formulating a classification of three different groups of jobs, it seems plausible to avoid to cluster these opposite, or inconsistent types. More related types are found more often empirically (Hogerheide, 1994).

In this way, it is defendable to cluster conventional with realistic, intellectual with artistic, and social with entrepreneurial, or conventional with entrepreneurial, social with artistic and intellectual with realistic. In both situations these combinations do have the least distance, which means the largest consistency. However, the first classification appeals more to our approach with respect to differentiating jobs, than the second. Spenner (1985) is talking about "working with people, data, and things" in a study with respect to comlexity in work. Working with people can be related to the entrepreneurial/social cluster, working with data to the intellectual/artistic cluster, and working with things to the conventional/realistic cluster. When using the other cluster possibility of Holland"s hexagram, the 
difficulties arise obviously in the intellectual/realistic cluster, where data and things mix. However, in this study a sample of graduates in economics is at hand, for whom possible jobs are by definition of a higher degree in complexity than just deviding them in working with people, things or data. But, when trying to elassify the jobs which are hold by our graduates in economics, we can define jobs in which these categories could be reflected by accountants-jobs or computer-jobs (things, conventional/realistic), research-jobs, or didactic jobs (data, intellectual/artistic), and managers-jobs or policy maker/advisory jobs (people, social/entrepreneurial). This classification was double checked by a panel of job experts from ROA. 


\section{Appendix B}

Detailed information on table 3.2.a (chapter 3)

As can be seen from Table 3.2.a, 87.5\% of the graduates were employed at the time of the labour market survey. The other $12.5 \%$ were unemployed. Some $75 \%$ of the graduates did find a job very soon after graduation, and were unemployed less than three months. The other $25 \%$ were unemployed for more than three months. Of all employed graduates more than a half $(56 \%)$ had tenure at the moment of the survey. Additionally, $60 \%$ of the graduates held a job for which an academic degree was required, whereas the other $40 \%$ were working in a job for which higher vocational education or less was sufficient. The mean gross monthly wages amounted to 3790 Dutch guilders. Of all academically employed graduates, $35 \%$ was working in a managing job, $30 \%$ in a research or teaching job, and another $32 \%$ in an accounting job. A small group of graduates of about $3 \%$ was employed in another kind of job, which wasn't defined by the former three categories. 'The largest part of our sample consists of men (72\%), and the mean age at the moment of the labour market survey was nearly 26 years. Most respondents graduated in Business Administration $(61 \%)$, with equal shares of the core subjects accounting/financing and organisation/ marketing. The other $39 \%$ consists of graduates in International Management (about $23 \%$, also divided over the two core subjects, and graduates in other subjects, which aren't defined further (the remaining $16 \%$ ). The mean study length of the graduates in our sample is approximately 66 months, or 5.5 years. 


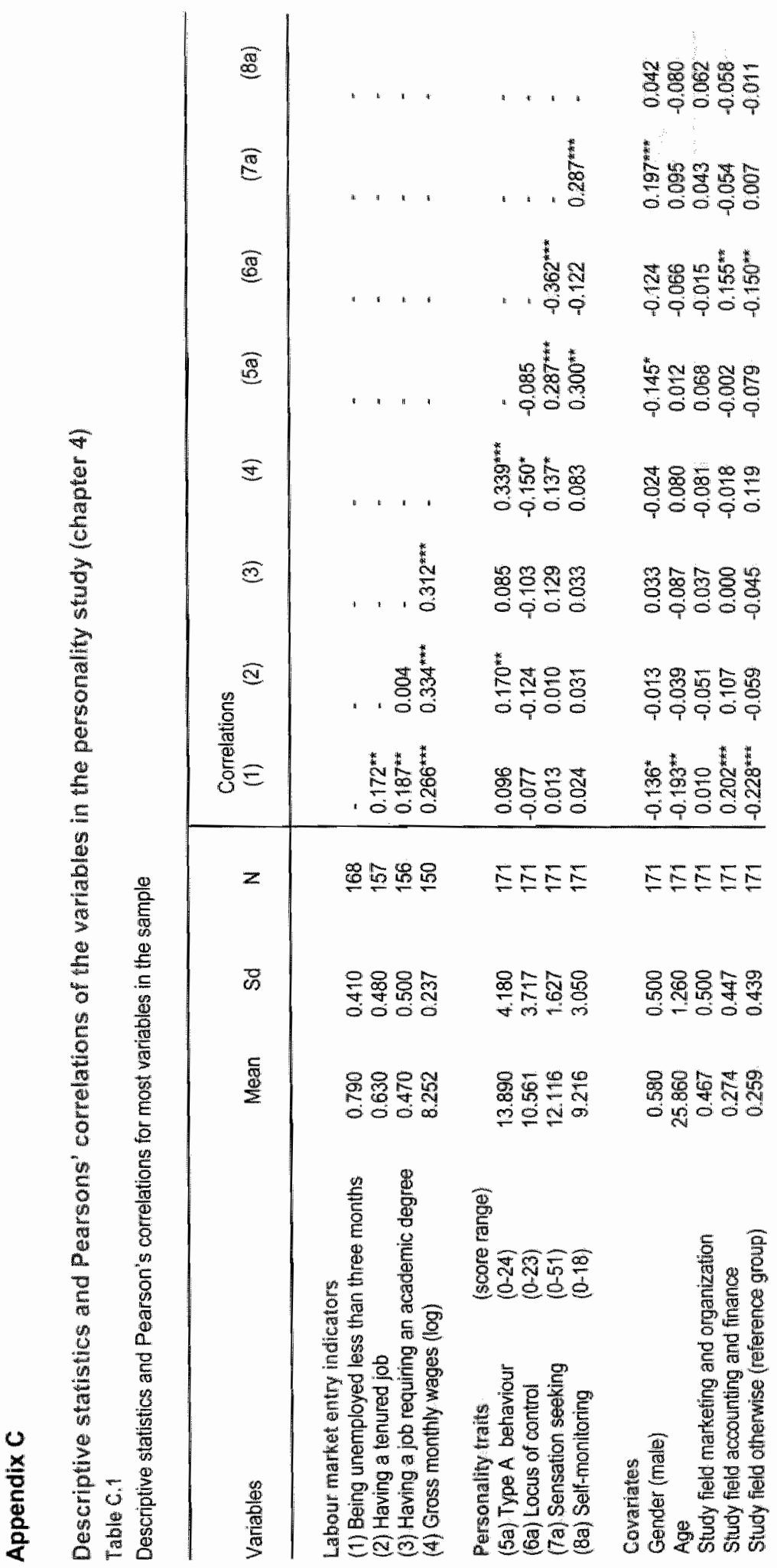




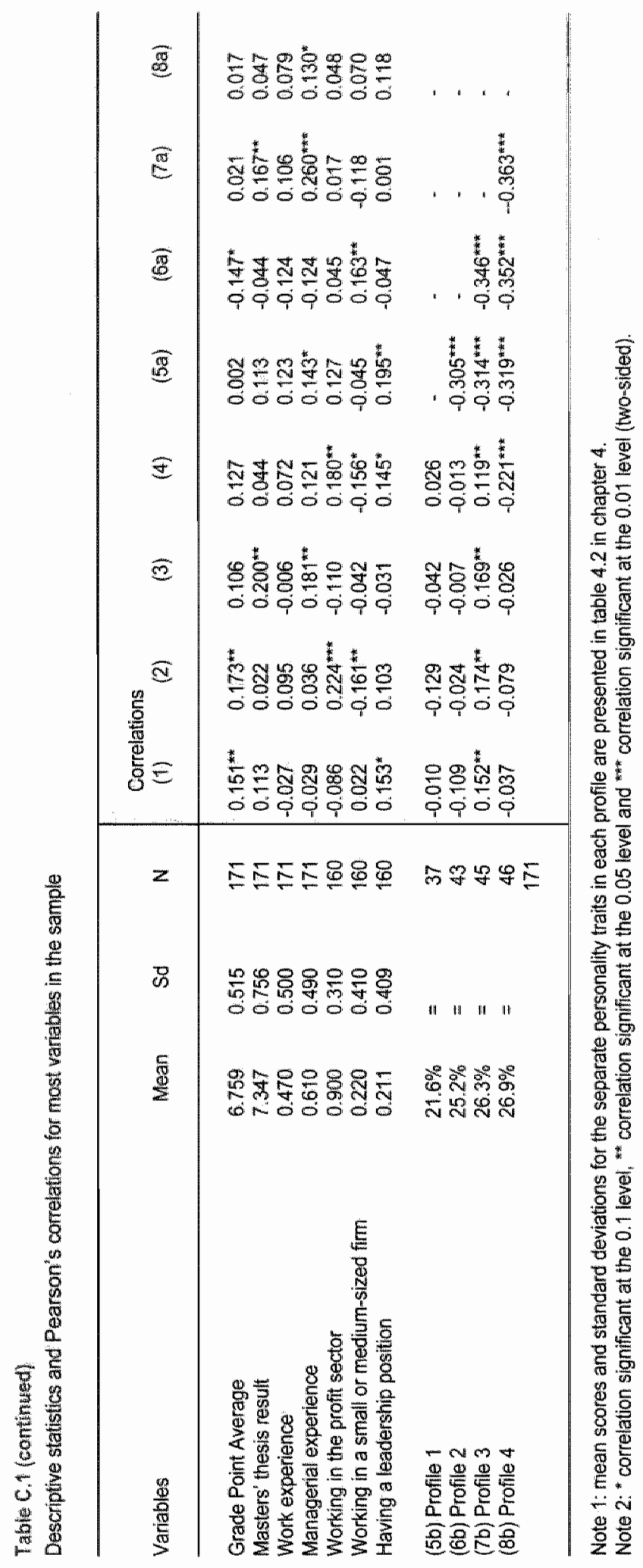




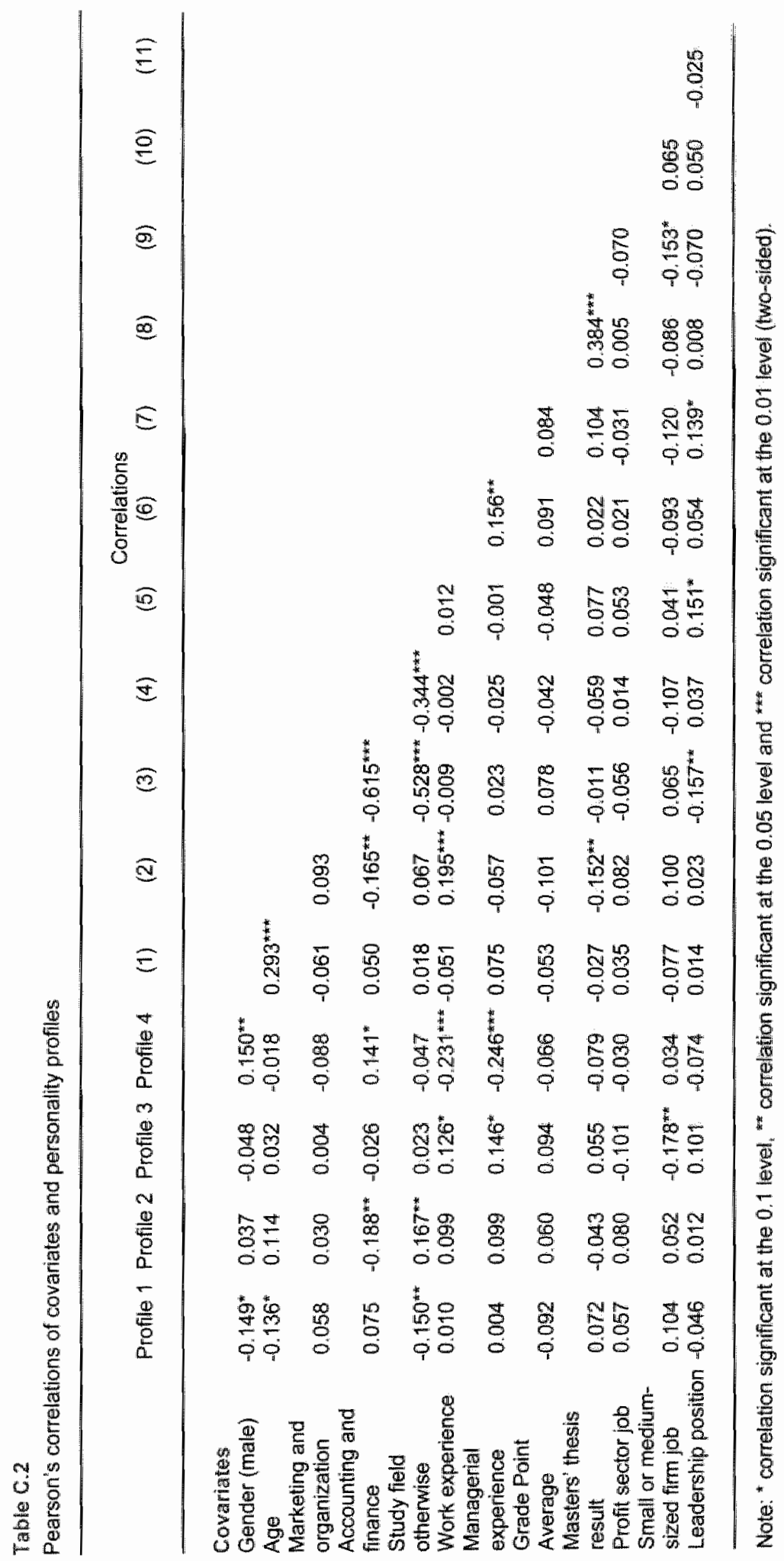




\section{Appendix D}

Effects of competence levels at the start of medical educiation on competence levells at the end (chapter 5)

The effects of start-level competence indicators on end-level competence indicators are tested by linear regression analyses; for the Progress Test scores at the end of the fourth year, and for the Skills Test scores of the fourth year. The results are presented in table D. 1.

\section{Table 0.1}

Regression estimates of the effects of competence indicators at the start of medical education on competence indicators at the end of medical education

\begin{tabular}{|c|c|c|c|c|}
\hline & \multicolumn{2}{|c|}{$\begin{array}{l}\text { Final Progress Test } \\
\text { fourth year }\end{array}$} & \multicolumn{2}{|c|}{$\begin{array}{l}\text { Skills Test } \\
\text { fourth year }\end{array}$} \\
\hline & $\mathbb{B}$ & s.e. & $\mathrm{B}$ & s.e. \\
\hline Constant & $0.261^{* * *}$ & 0.075 & $0.129^{*}$ & 0.078 \\
\hline \multicolumn{5}{|l|}{$\begin{array}{l}\text { Competence level start } \\
\text { medical aducation }\end{array}$} \\
\hline GPA's & $0.315^{* * *}$ & 0.039 & $0.196^{\text {wat* }}$ & 0.041 \\
\hline $\begin{array}{l}\text { First Progress Test score 1st } \\
\text { year }\end{array}$ & $0.415^{* * * *}$ & 0.144 & 0.189 & 0.149 \\
\hline \multicolumn{5}{|l|}{ Model Statistics } \\
\hline Number of cases ( $n$ ) & & 573 & & 573 \\
\hline Add.R2 & & 0.120 & & 0.041 \\
\hline $\mathrm{F}$ & & 40.135 & & 13.343 \\
\hline$P$ & & 0.000 & & 0.000 \\
\hline
\end{tabular}

Note: standardized values are used for all variables.

* significant at $0.10,{ }^{* *}$ significant at 0.05 and ${ }^{* * *}$ significant at 0.01 .

As can be seen from Table D.1, higher GPA's have a positive effect on both competence indicators at the end of education. Higher first Progress Test scores of the first year have a positive effect on the final Progress Test scores of the fourth year, but not on the Skills Test scores of the fourth year. Taking the type of instrument (general versus specific medical knowledge and skills) into account, our first assumed relation seems confirmed; the competence level just before or at the start of medical education affects the level of competence at the end of medical 
education. This means: differentiation in the competence levels at the end of medical education is indeed partly predicted by the differences in start levels of the students. And apparently, the types of competence that are measured by Progress tests and Skills tests are much more different than both of them differ from the competence that is already measured by GPA"s. This is suggested by the descriptives (correlations) in table 5.1 of the results in chapter 5 as well. 


\section{Appendilx E}

The value of Progress Test scores for measuring actual competence development in medical education (chapter 5 )

The Progress Test in medical education can best be conceived of as a final examination: a comprehensive examination reflecting the (cognitive) end-objectives of the curriculum (van der Vleuten et al., 1996). We now literally recall a part of the text in this article by van der Vleuten et al. (1996): "Each Progress Test consists of approximately 250 (multiple) true/false questions stratified in categories based on the International Classification of Diseases (ICD). It samples knowledge across all disciplines and content areas in medicine relevant for the medical degree. Four times per year the progress test is given to all students in the curriculum, regardless of their class. For each occasion a newly constructed version is prepared. A single test question may be answered with either true or false, or with an "I do not know" option (the question mark). The latter option is not penalized or rewarded. A correct answer is rewarded with one mark while an incorrect answer is given a negative mark. To discourage guessing a total test score is expressed as the number of correct answers minus the number of incorrect answers. To allow comparison across tests, scores are expressed on a percentage scale. The freshmen year students are not able to answer as many questions as the second-year students, who are not able to answer as many as the thind-year students and so on..."

Measurement with the Progress Test reveals satisfactory reliability coefficients (across years usually alphas above 0.95, within years alphas between $0.70-0.80$ ) and test construction is highly standardized. Test difficulty variations remain present though. Validity in measuring the development in relevant medical competence as an indicator for the actual learning process that takes place in education seems although satisfactory, as we argue as follows:

The measurement is congruent with the educational findings with respect to competence development of medical students and physictans; the knowledge component is crucial for this process. The development of medical expertise is considered the same as learning to solve problems within the medical knowledge domain (Boshuizen \& Schmidt, 2000). However, the knowledge domain has to be solid enough to facilitate the expertise development process. This implies the explicit importance of knowledge and the acquisition of this knowledge during education. In fact, two types of knowledge are relevant for physicians; conceptual and experiential knowledge (Schmidt, Norman \& Boshuizen, 1990). The conceptual type is merely acquired during formal education, and experiential knowledge is acquired based on the conceptual knowledge, during work (Norman, 1988). 
Based on the findings concerning medical knowledge, we assume the specific conceptuall knowledge acquisition in education to be of major importance to the competence development process in education we like to measure. We assume the growth in conceptual medical knowledge to be captured and monitored satisfactory with the "Progress Test".

To underline the value of the final Progress Test scores of the fourth year in measuring the attained level of medical competence and the difference in this respect with the more traditional study results in our sample, we refer to figure El-3.

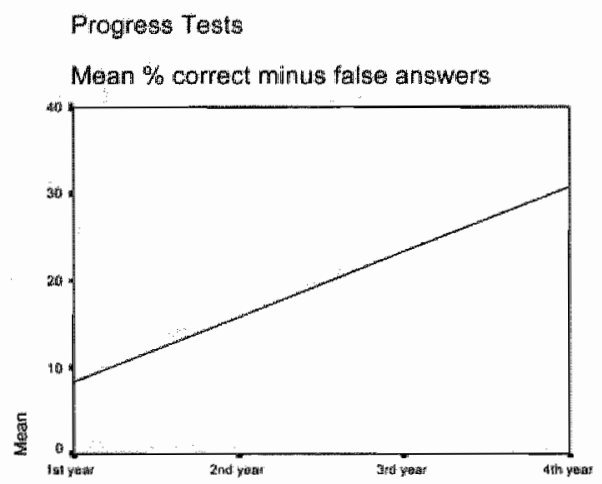

Figure E.1

Grow curve mean sample scores year $1-4$ for Progress Tests.

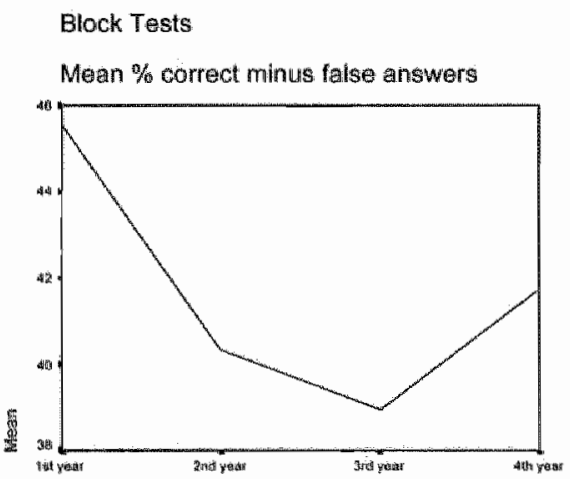

foure E.2

Grow curve mean sample scores year 1-4 for Block Tests. 
Skills Tests

Attained level of correct answers (\%)

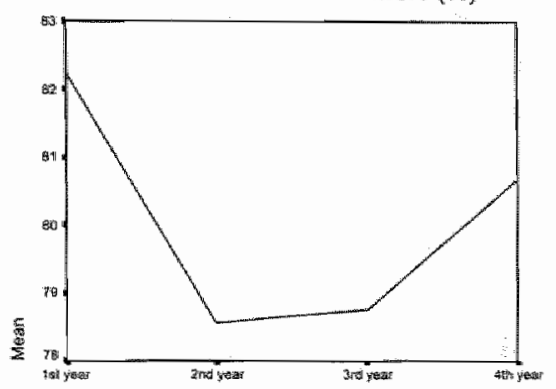

Figure E.3

Grow curve mean sample scores year $1-4$ for Skills Tests.

The Progress test scores from our sample reveal comparable findings with respect to growth curves on the cohort level, such as presented in the study of Van der Vleuten et al. (1996). In addition, no bias was found in growith between the cases in our research sample (restricted by the availability of relevant labour market information) and our total data set of students that had taken the Progress tests during the relevant cohort periods. 



\section{Appendix F}

\section{Indicators of labour market success for physicians (chapter 5 )}

Labour market outcomes for individuals can be considered in terms of chances for a job and the quality of the job (van der Velden \& Wieling, 1994; Semeijn \& van der Velden, 2002). However, for physicians these labour market outcome indicators do not reveal as much information as for other graduates, such as economists. Their chances of obtaining a medical job are extremely high because only physicians can attain these jobs and labour market demand and supply are highly controlled by institutional regulations, for example by a naximum number of specialists that is allowed to be trained, and the numeri fixi for the number of students that is allowed to start the medical academic program in the first place. The salaries in specialisation positions are highly regulated as well, and therefore not very informative either. Moreover, wages are lowest for graduates that have attained a training position for further specialisation and higher for those who are not in training. As obtaining a training position is considered an indicator of professional success, wages shortly after graduation are not a good indicator of labour market success.

The chances for attaining a specialisation position seem relevant, because it seems more successful to obtain a specialisation position faster. However, it can be a well-considered choice to gain medical experience in a non-specialisation position first, and wait for a better or more preferred specialisation position a little later in the career. This leads to the situation that both physicians in specialisation and nonspecialisation positions, a year and a half after graduation, constitute heterogeneous groups. This heterogeneity may be a reason why earlier research did not find any further explaining factors for the chances to obtain a specialisation position than the medical degree as such. This means that the group who did not yet obtain a specialisation position rather shortly after graduation, consists both of graduates who are not able to get or want such a position and of graduates who are well qualified and are still waiting in the queue. S̈milarly, the group of specialists in training is heterogeneous as well, consisting of positions that require extensive training in highly specialized medical area's (hospital specialisations) and positions that require much less further training within a broader field of practice (social medicine).

Since both specialisation and non-specialisation positions are heterogeneous, we will distinguish the most important types of specialisation and non-specialisation positions as a relevant labour market outcome in terms of the type of job physicians obtain. And, of course, we will first test our assumption with respect to the attainment of a specialisation position as such.

In addition, specialisation positions themselves can be ranked according to the duration of the training period. Hospital specialisations take usually 5 to 7 years of 
training, while general practitioners' training takes 3 years, and the social medicine specialisations 2-2.5 years. In economic terms, the highest specialisation type in ranking requires the largest investment in human capital and leads to the largest returns in terms of lifetime income. It is common knowledge that hospital specialists will earn the most, during their entire career, whereas general practitioners earn much less, and social physicians will earn the least, after they have completed training. The duration of the training periods therefore reflects the individuals' opportunity to obtain a higher lifetime income.

Although the stability of obtained specialisation positions shortly after graduation may be fairly low, considering the further careers of physicians (see for example Gjerberg, 2002; Goldacre \& Lambert, 2000), the analysis of (human capital) factors affecting the attainment of a higher ranked position shortly after graduation is of interesting value on its own. Starting positions after graduation are influential for later labour market outcomes (see e.g., van den Berg et al., 2002), and although physicians do not choose their specialisation solely based on the expected income, economic incentives are found to play a significant role in their choice processes (Thornton, 2000; Quinn \& Price, 1998). 


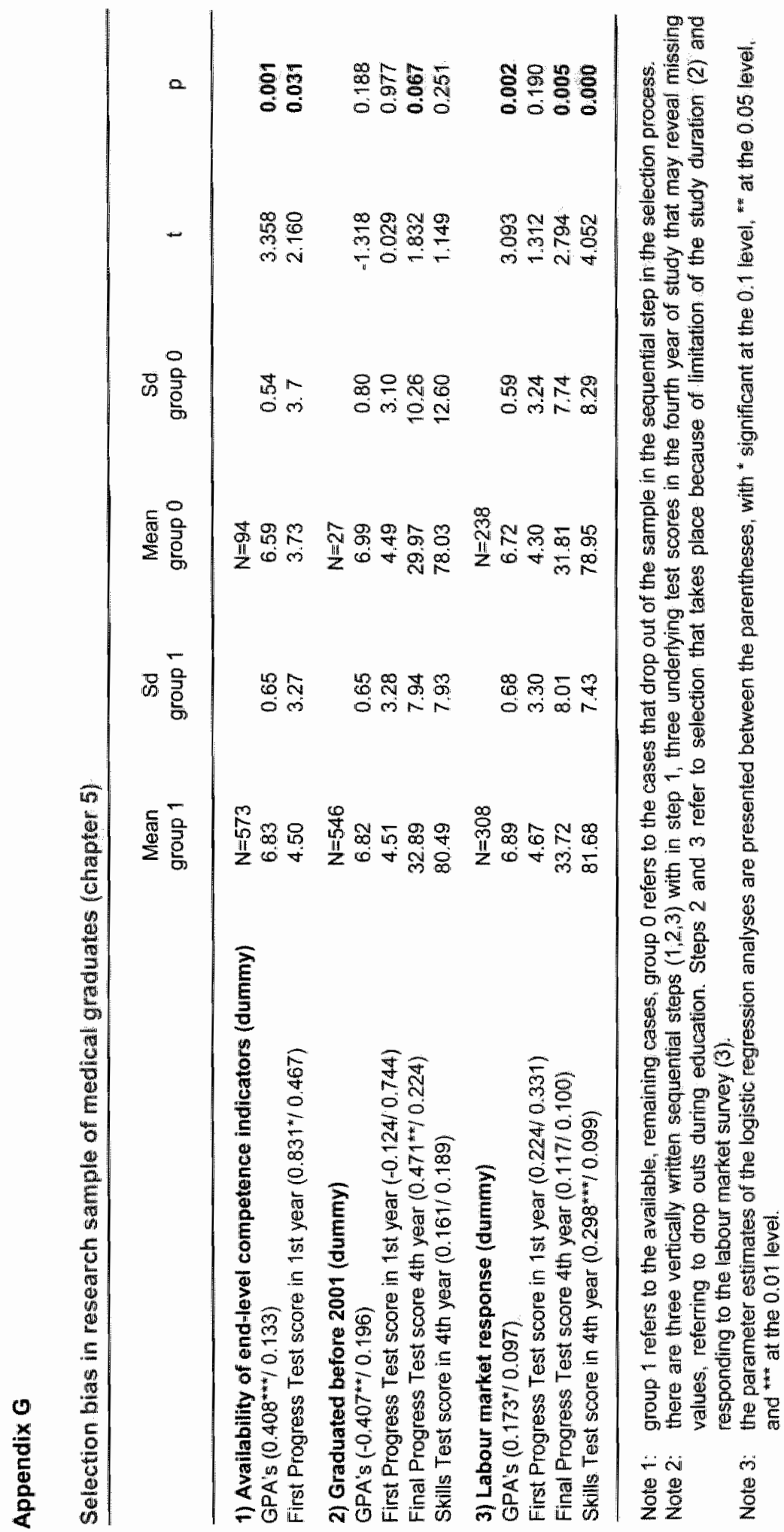





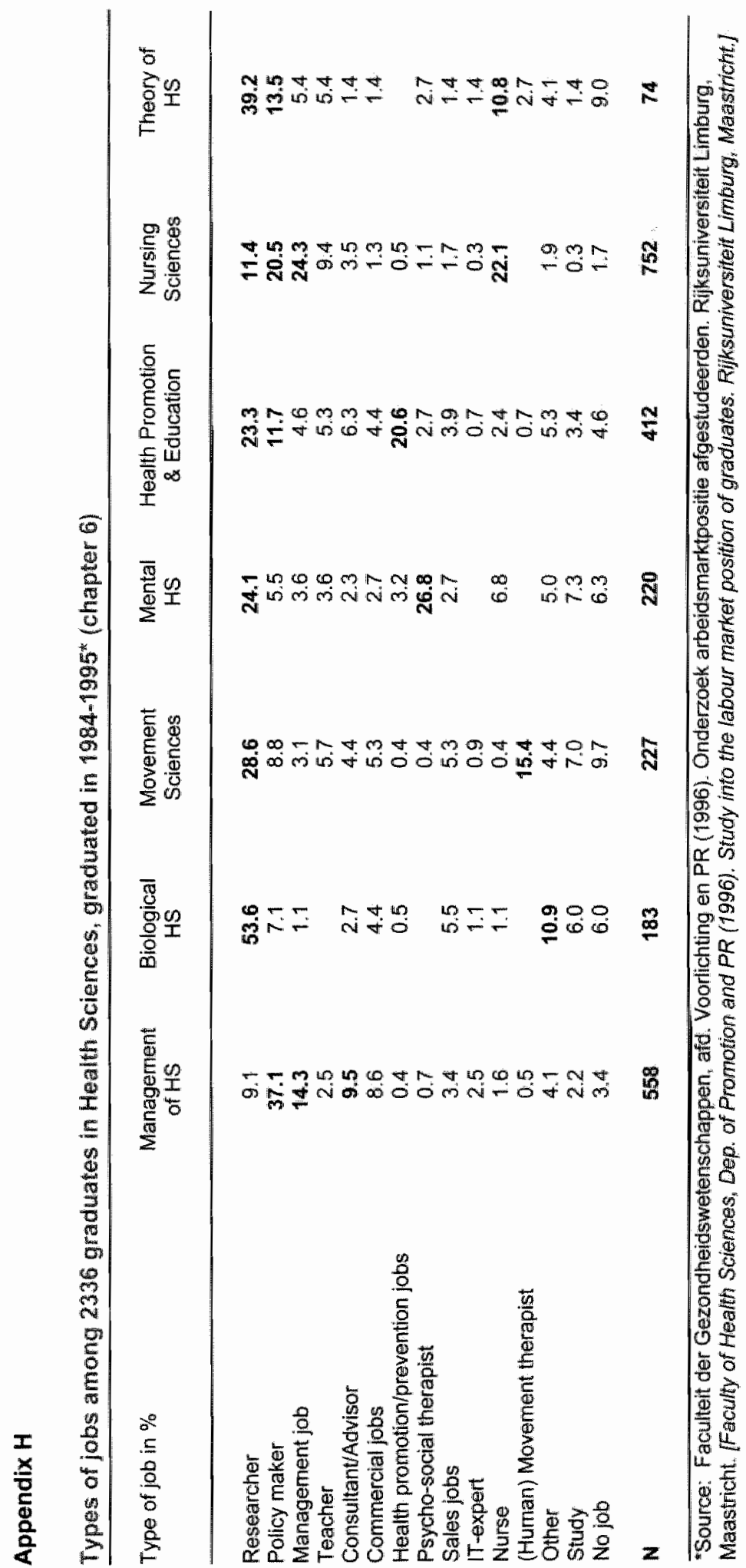





\section{Appendix I}

Selection bias in research sample of health sciences graduates (chapter 6)

We started the analysis with graduates for whom we have Progress Test scores and Masters'thesis results available $(n=502)$. There is also a significant group of graduates ( $n=432$ ) for whom we have a Masters'thesis result, but no Progress Test scores. The mean score for Masters' theses is the same in both groups ( 3.47 and 3.42 respectively). We therefore concluded that there is no selection bias on this variable. As a next step, we consider the differences in scores on the educational competence indicators between the respondents to the labour market survey versus the nonrespondents (see Table 1.1).

Table 1.1

Selection bias in educational data of the sample $(n=502)$ due to non-response on the labour market survey

\begin{tabular}{|c|c|c|c|c|c|c|}
\hline \multirow{2}{*}{$\begin{array}{l}\text { Response on the } \\
\text { labour market }\end{array}$} & \multicolumn{2}{|c|}{ Yes = Group1 } & \multicolumn{2}{|c|}{ No $=$ Group 0} & \multicolumn{2}{|c|}{ t-test } \\
\hline & Mean & $\mathrm{Sd}$ & Mean & Sid & $F$ & $\mathrm{p}$ \\
\hline $\begin{array}{l}\text { Master' Thesis result } \\
\text { Progress Test scores } \\
\text { Group Functioning } \\
\text { scores }\end{array}$ & $\begin{array}{c}n=282 \\
3.485 \\
n=282 \\
14.160 \\
n=176 \\
6.085\end{array}$ & $\begin{array}{l}0.333 \\
5.903 \\
4.047\end{array}$ & $\begin{array}{r}n=220 \\
3.451 \\
n=220 \\
13.423 \\
n=132 \\
4.341\end{array}$ & $\begin{array}{l}0.348 \\
5.926 \\
3.768\end{array}$ & $\begin{array}{l}0.902 \\
0.059 \\
3.782\end{array}$ & $\begin{array}{l}0.343 \\
0.808 \\
0.053\end{array}$ \\
\hline
\end{tabular}

Table I.1 reveals only higher scores on group functioning at the 0.10 level for the respondents to the labour market survey compared to the non-respondents. Therefore bias in the scores as caused by non-response seems minimal. The response rate of $54 \%$ is consistent with the separate annual response rates on the national level with the labour market survey (see also Allen et al. 2000). However, this type of selection bias (non-response) may affect our study outcomes in a way we can not easily predict. $\llbracket t$ is possible that the lower scoring non-responding individuals are less motivated to respond because their labour market outcomes are poorer. But on the other hand, the non-responding may also be related to different factors, not in relation to educational achievement scores, nor to labour market outcomes (see e.g. Huijgen \& Wolbers, 1999; Huijgen, 2002). 



\section{Curriculum Vitae}

Judith Semeijn was bom in Amsterdam, The Netherlands, on October $1^{\mathrm{st}}, 1970$. She attended pré-university education at Dr. Mollercollege, Waalwijk, from 1983-1889. In 1990 she finished the propaedeutic year in Health Sciences at Maastricht University. She obtained a Masters' degree in Mental Health Sciences at Maastricht University in summer 1995. Afterwards she worked at RJ.AGG Maastricht as a research assistant at the department of Psychotherapy, for one and a half year. In 1997 she turned to the Economic Faculty of Maastricht University as a researcher for the Organisation and Strategy department. Here she started the educational oriented studies that were also the basis for her $\mathrm{PhD}$ research at the Research Centre for Education and the Labour Market (ROA) two years later. She worked at ROA from 1999-2005. The PhD research was part of a larger project "The production of Human Capital and the position on the labour market", subsidized by the Dutch Council for Scientific Research (NWO). From April $\rrbracket^{\text {st }} 2005$ she works at the Centre for Innovation of Education (CINOP) in 's Hertogenbosch, The Netherlands.

Judith Semeijn is geboren op 1 oktober 1970 in Amsterdam. Van 1983 tot 1989 volgde zij haar gymnasium B opleiding aan het Dr. Mollercollege te Waalwijk. In 1990 behaalde zij het propaedeutisch examen van Gezondheidswetenschappen aan de Universiteit van Maastricht, destijds Rijksuniversiteit Limburg. In zomer 1995 studeerde ze af als Geestelijk Gezondheidkundige. Vervolgens werkte ze anderhalf jaar als onderzoeksassistent bij de RIAGG Maastricht, op de afdeling Psychotherapie. In 1997 maakte ze een overstap naar de Economische Faculteit van de Universiteit van Maastricht om als onderzoeker bij de vakgroep Organisatie te gaan werken. Hier begon ze aan de onderwijskundig georienteerde studies die ook de basis vormden voor de dissertatie bij het Research Centrum voor Onderwijs en Arbeidsmarkt (ROA) twee jaar later. Ze werkte bij het ROA van 1999-2005. Het proefschrift onderzoek maakte deel uit van een meeromvattend project, getiteld "The production of Human Capital and the position on the labour market", gesubsidieerd door de Nederlandse Organisatie voor Wetenschappelijk Onderzoek (NWO). Vanaf april 2005 werkt ze bij het Centrum voor Innovatie van Opleidingen (CINOP) in "s Hertogenbosch. 


\section{ROA Dissertation Series}

1. Lex Borghans (1993), Educational Choice and Labour Market Information, Maastricht: Research Centre for Education and the Labour Market (ROA).

2. Frank Cörvers (1999), The Impact of Human Capital on International Competitiveness and Trade Performance of Manufacturing Secrors, Maastricht: Research Centre for Education and the Labour Market (ROA).

3. Ben Kriechel (2003), Heterogeneity among Displaced Workers, Maastricht: Research Centre for Education and the Labour Market (ROA).

4. Arnaud Dupuy (2004), Assignment and Substitution in the Labour Market, Maastricht: Research Centre for Education and the Labour Market (ROA).

5. Wendy Smits (2005), The Quality of Apprenticeship Training. Conflicting Interests of Firms and Apprentices, Maastricht: Research Centre for Education and the Labour Market (ROA).

6. Judith Semeijn (2005), Academic Competences and Labour Market Entry; studies among Dutch graduates, Maastricht: Research Centre for Education and the Labour Market (ROA). 